\title{
Evaluation of Terrestrial LIDAR for Monitoring Geomorphic Change at Archeological Sites in Grand Canyon National Park, Arizona
}

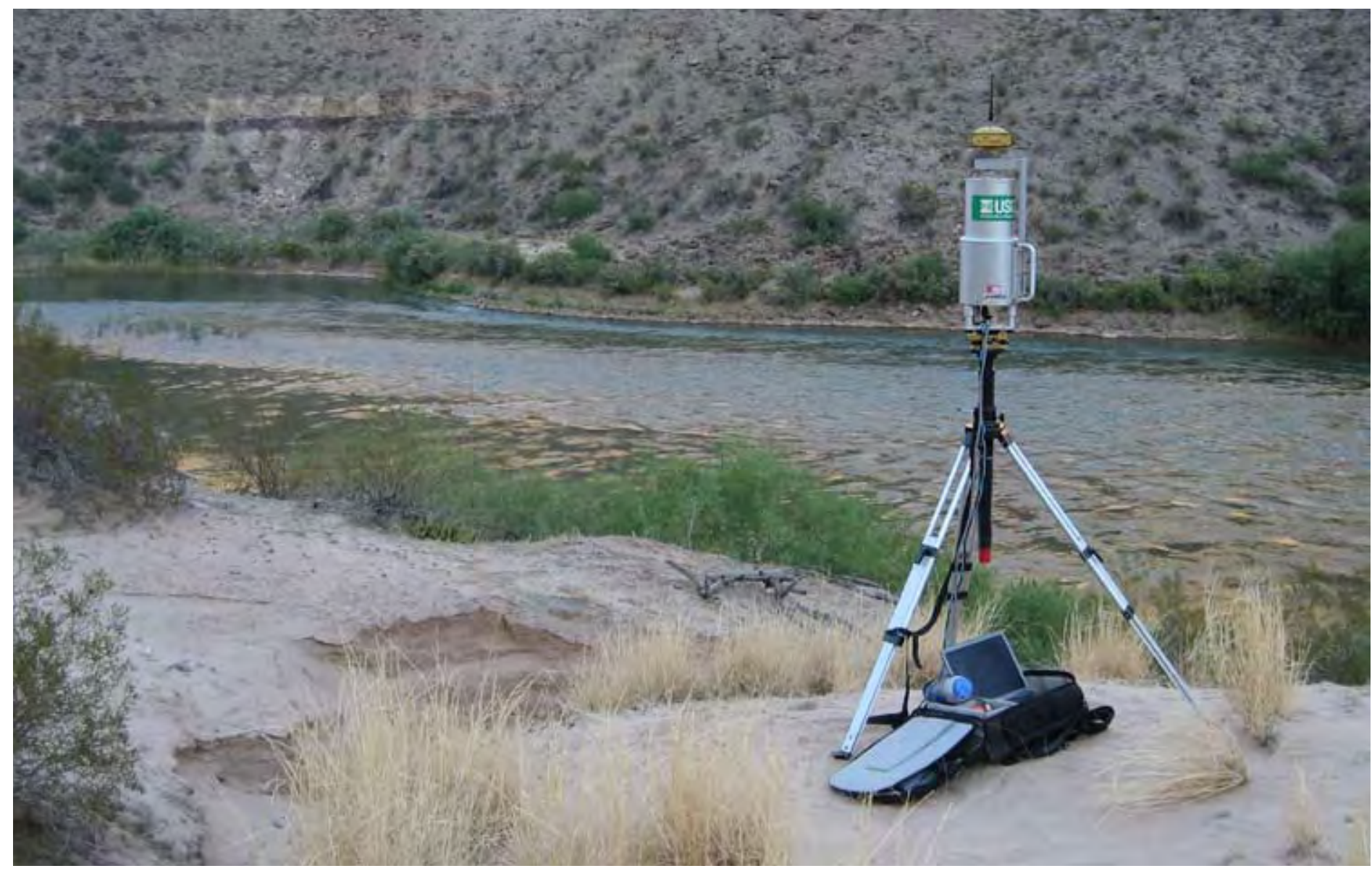

Open-File Report 2008-1384 
This page intentionally left blank 


\section{Evaluation of Terrestrial LIDAR for Monitoring Geomorphic Change at Archeological Sites in Grand Canyon National Park, Arizona}

By Brian D. Collins, Kristin M. Brown, and Helen C. Fairley

Open-File Report 2008-1384

U.S. Department of the Interior

U.S. Geological Survey 


\section{U.S. Department of the Interior Dirk Kempthorne, Secretary}

\section{U.S. Geological Survey \\ Mark D. Myers, Director}

\section{U.S. Geological Survey, Reston, Virginia 2008}

For product and ordering information:

World Wide Web: http://www.usgs.gov/pubprod

Telephone: 1-888-ASK-USGS

For more information on the USGS - the Federal source for science about the Earth, its natural and living resources, natural hazards, and the environment:

World Wide Web: http://www.usgs.gov

Telephone: 1-888-ASK-USGS

\section{Suggested citation:}

Collins, B.D., Brown, K.M., and Fairley, H.C., 2008, Evaluation of terrestrial LIDAR for monitoring geomorphic change at archeological sites in Grand Canyon

National Park, Arizona: U.S. Geological Survey, Open-File Report 2008-1384, 60 p.

World Wide Web: http://pubs.usgs.gov/of/2008/1384/

Any use of trade, product, or firm names is for descriptive purposes only and does not imply endorsement by the U.S. Government.

Although this report is in the public domain, permission must be secured from the individual copyright owners to reproduce any copyrighted material contained within this report. 


\section{Contents}

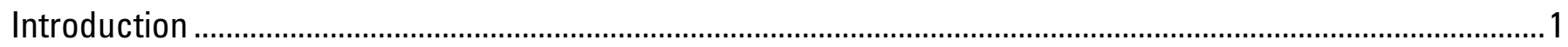

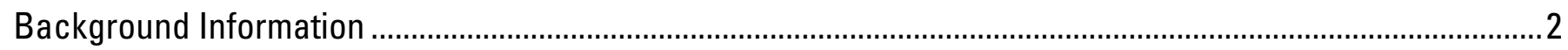

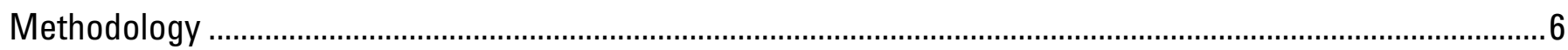

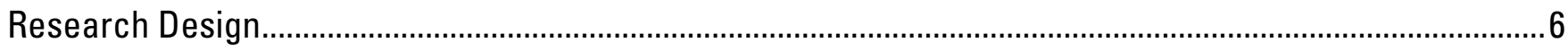

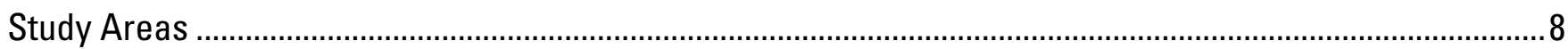

Terrestrial LIDAR Laser Scanning .......................................................................................................

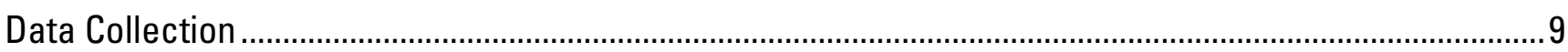

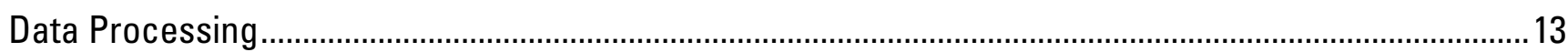

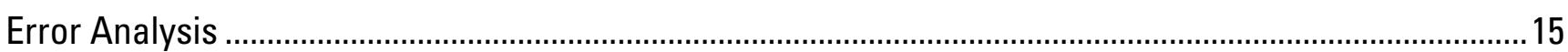

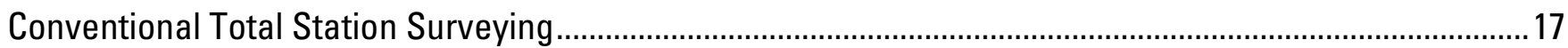

Data Collection and Processing...........................................................................................................

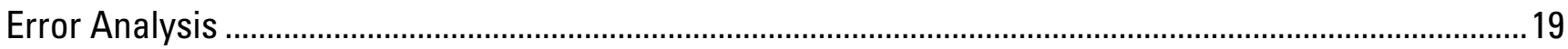

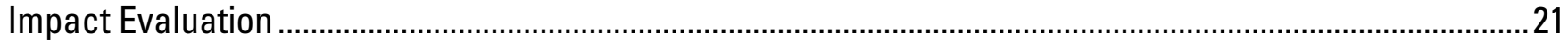

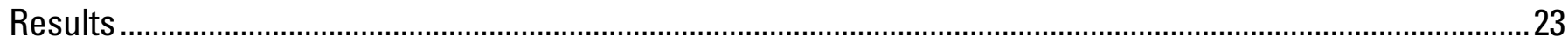

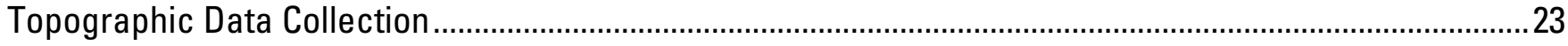

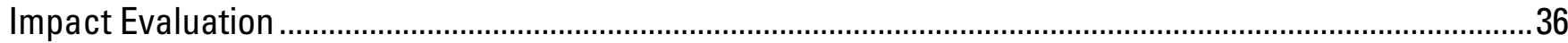

Variations within Survey Methods (Consistency Check—Parameters A1, A2, A3) ....................................40

Variations between Survey Methods (Impact Difference Check—Parameters B1, B2, B3) .................... 41

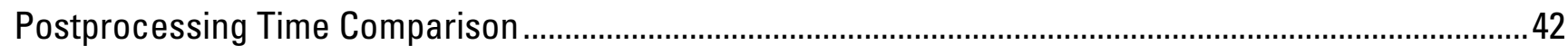

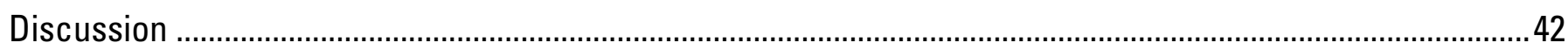

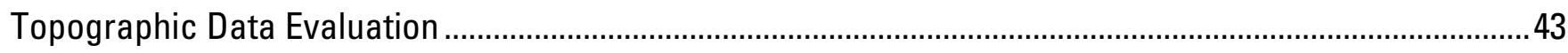

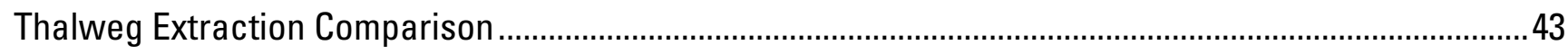

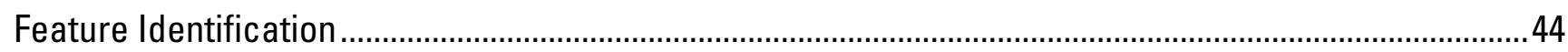

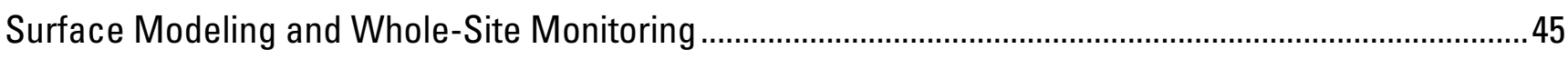

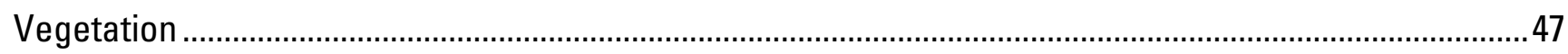

Impact Evaluation Comparison ............................................................................................................ 47

Factors Affecting the Direct Impact Evaluation—Footstep Count ............................................................ 47

Factors Affecting the Indirect Impact Evaluation—Time in Sensitive Area............................................... 48

Other Factors —Postprocessing Methods .............................................................................................. 48

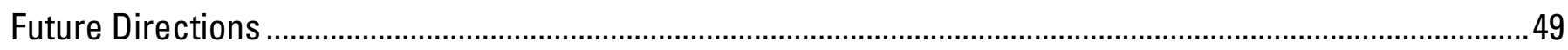

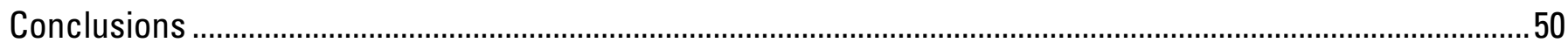




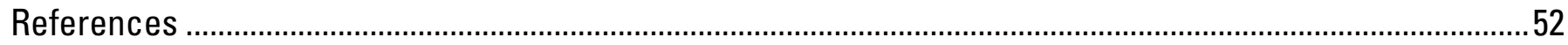

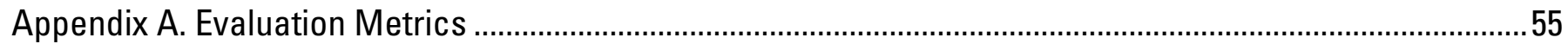

Appendix B. Impact Evaluation Results ................................................................................................. 57

Appendix C1. Variation Within Each Mapping Method for Total Time of Survey, Time in Sensitive Area, and Footstep Impact.

Appendix C2. Variation Between Total Station and LIDAR Methods for Total Time of Survey, Time in Sensitive Area, and Footstep Impact

\section{Figures}

1. Regional map showing Grand Canyon National Park, Ariz .........................................................................

2. Archeological artifacts and site excavation in Grand Canyon National Park, Ariz .....................................

3. Topography of gullied archeological sites ..........................................................................................

4. Map showing general location of eight sites included in this investigation ...............................................7

5. Terrestrial light detection and ranging data collection in Grand Canyon, Ariz., and transporting the

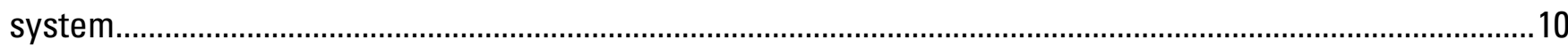

6. Typical terrestrial light detection and ranging setup locations and data coverage from a single scan .11

7. Views of terrestrial light detection and ranging points and surface model data .....................................12

8. Terrestrial light detection and ranging control points......................................................................... 14

9. Extraction of a gully thalweg using $1-\mathrm{cm}$ contours constructed from the surface model triangulated irregular network

10. Conventional total station data collection showing back site location and total station instrument.....18

11. Conventional total station data collection showing use of survey rod and prism in a gully system .......19

12. Footstep imprints impact archeological sites during surveying ..............................................................21

13. Typical gully plan view showing thalweg and relative difference in point density between terrestrial

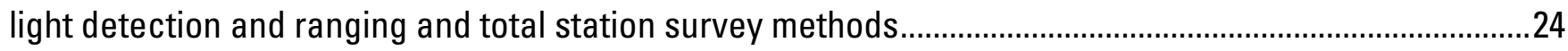

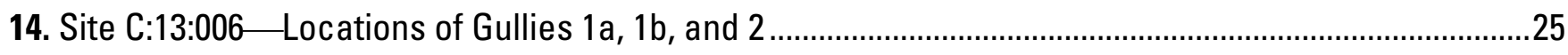

15. Site C:13:006 - Gullies 1a and 1b: Plan view of light detection and ranging-derived and total station-

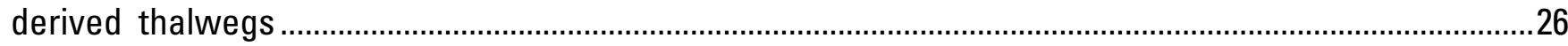

16. Site C:13:006 - Long-profile comparison of light detection and ranging and total station data for Gully $1 \mathrm{a}$ and Gully $1 \mathrm{~b}$.

17. Site C:13:006 - Gully 2: Plan view of light detection and ranging-derived and total station-derived thalwegs

18. Site C:13:006 - Gully 2: Long-profile comparison of light detection and ranging and total station data 29

19. Site G:03:041—Locations of gullies. 
20. Site G:03:041 — Gullies 1 and 2: Plan view of light detection and ranging-derived and total stationderived thalwegs

21. Site G:03:041 — Gully 1: Long-profile comparison of light detection and ranging and total station data32

22. Site G:03:041 — Gully 2: Long-profile comparison of light detection and ranging and total station data32

23. Site G:03:072 — Locations of Gullies 1 and 2

24. Site G:03:072 - Gullies 1 and 2: Plan view of light detection and ranging-derived and total stationderived thalwegs

25. Site G:03:072 - Gully 1: Long-profile comparison of light detection and ranging and total station data34

26. Site G:03:072 - Gully 2: Long-profile comparison of light detection and ranging and total station data35

27. Comparison of total survey time and time in sensitive area for terrestrial light detection and ranging and total station methods

28. Comparison of footstep count for terrestrail light detection and ranging and total station methods ....38

29. Comparison of cumulative total survey time for terrestrial light detection and ranging and total station methods plotted for each site and for each data collection effort and averaged for both surveys.

30. Section of long-profile comparison of terrestrial light detection and ranging and total station data showing knickpoint locations determined by total station surveying

31. Detail of terrestrail light detection and ranging point data from a single scan showing key features .. 46

\section{Tables}

1. Site name and dates of terrestrial light detection and ranging and total station data collection at archeological sites in Grand Canyon National Park, Ariz.

2. Errors associated with terrestrial light detection and ranging measurements.

3. Survey data summary

4. Statistical comparison of gully thalweg profiles between light detection and ranging and total station data

5. Summary of variation of impact evaluation results between terrestrial light detection and ranging and total station surveying

6. Processing time for terrestrial light detection and ranging-derived and total station surveying-derived topographic data

\section{Datum Information}

Coordinate information is not provided in order to protect the sensitive archeological sites discussed in this report. 
This page intentionally left blank 


\title{
Evaluation of Terrestrial LIDAR for Monitoring Geomorphic Change at Archeological Sites in Grand Canyon National Park, Arizona
}

\author{
By Brian D. Collins, ${ }^{1}$ Kristin M. Brown, ${ }^{2,3}$ and Helen C. Fairley ${ }^{2}$
}

\section{Introduction}

This report presents the results of an evaluation of terrestrial light detection and ranging (LIDAR) for monitoring geomorphic change at archeological sites located within Grand Canyon National Park, Ariz. Traditionally, topographic change-detection studies have used total station methods for the collection of data related to key measurable features of site erosion such as the location of thalwegs and knickpoints of gullies that traverse archeological sites (for example, Pederson and others, 2003). Total station methods require survey teams to walk within and on the features of interest within the archeological sites to take accurate measurements. As a result, site impacts may develop such as trailing, damage to cryptogamic crusts, and surface compaction that can exacerbate future erosion of the sites. National Park Service (NPS) resource managers have become increasingly concerned that repeated surveys for research and monitoring purposes may have a detrimental impact on the resources that researchers are trying to study and protect.

Beginning in 2006, the Sociocultural Program of the U.S. Geological Survey's (USGS) Grand Canyon Monitoring and Research Center (GCMRC) initiated an evaluation of terrestrial LIDAR as a new monitoring tool that might enhance data quality and reduce site impacts. This evaluation was conducted as one part of an ongoing study to develop objective, replicable, quantifiable monitoring protocols for tracking the status and trend of variables affecting archeological site condition along the Colorado River corridor. The overall study consists of two elements: (1) an evaluation of the methodology through direct comparison to geomorphologic metrics already being collected by total station methods (this report) and (2) an evaluation of terrestrial LIDAR's ability to detect topographic change through the collection of temporally different datasets (a report on this portion of the study is anticipated early in 2009). The main goals of the first element of study were to

1. test the methodology and survey protocols of terrestrial LIDAR surveying under actual archeological site field conditions,

2. examine the ability to collect topographic data of entire archeological sites given such constraints as vegetation and rough topography, and

3. evaluate the ability of terrestrial LIDAR to accurately map the locations of key geomorphic features already being collected by total station methods such as gully thalweg and knickpoint locations.

\footnotetext{
${ }^{1}$ U.S. Geological Survey, Western Earth Surface Processes Team, Menlo Park, Calif.

${ }^{2}$ U.S. Geological Survey, Southwest Biological Science Center, Grand Canyon Monitoring and Research Center, Flagstaff, Ariz.

${ }^{3}$ Present Affiliation: University of Northern Arizona, Flagstaff, Ariz.
} 
This report focuses on the ability of terrestrial LIDAR to duplicate total station methods, including typical erosion-related change features such as the plan view gully thalweg location and the gully thalweg long profile. The report also presents information concerning the use of terrestrial LIDAR for archeological site monitoring in a general sense. In addition, a detailed comparison of the site impacts caused by both total station and terrestrial LIDAR survey methods is presented using a suite of indicators, including total field survey time, field footstep count, and data-processing time. A thorough discussion of the relative benefits and limitations of using terrestrial LIDAR for monitoring erosioninduced changes at archeological sites in Grand Canyon National Park concludes this report.

\section{Background Information}

The Colorado River bisects Grand Canyon National Park, which is located just downstream from Glen Canyon Dam near the Arizona-Utah border (fig. 1). The Grand Canyon Protection Act of 1992 required the Secretary of the Interior to establish and implement a program of research and longterm monitoring to document and mitigate downstream effects of Glen Canyon Dam operations on cultural resources, natural resources, and visitor use in Glen Canyon National Recreation Area and Grand Canyon National Park. The USGS GCMRC is responsible for research and monitoring, including projects to evaluate potential impacts to archeological sites along the entire length of the Colorado River through Grand Canyon National Park.

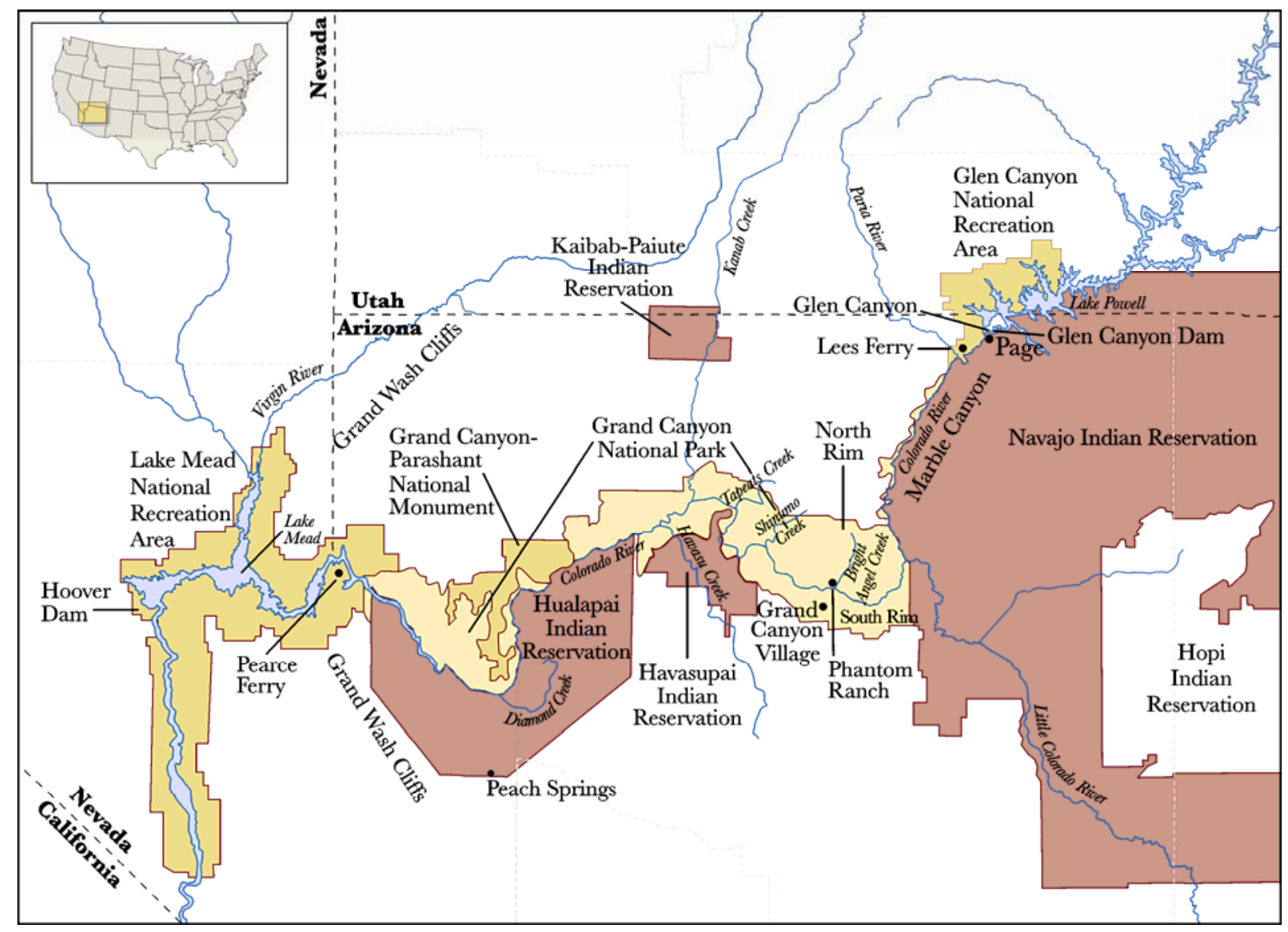

Figure 1. Regional map showing Grand Canyon National Park, Ariz. 
Archeological sites in Grand Canyon National Park are an irreplaceable cultural and scientific resource. Studies of these sites have shown that human activity in Grand Canyon dates back to 11,000 years before the present (Fairley, 2005). The sites contain materials that reflect not only the range and scope of past human activities in Grand Canyon but also information about past environmental conditions. Consequently, archeological sites provide important source evidence for understanding the cultures that inhabited this area in the past as well as the environmental conditions that influenced human use before modern times (fig. 2).
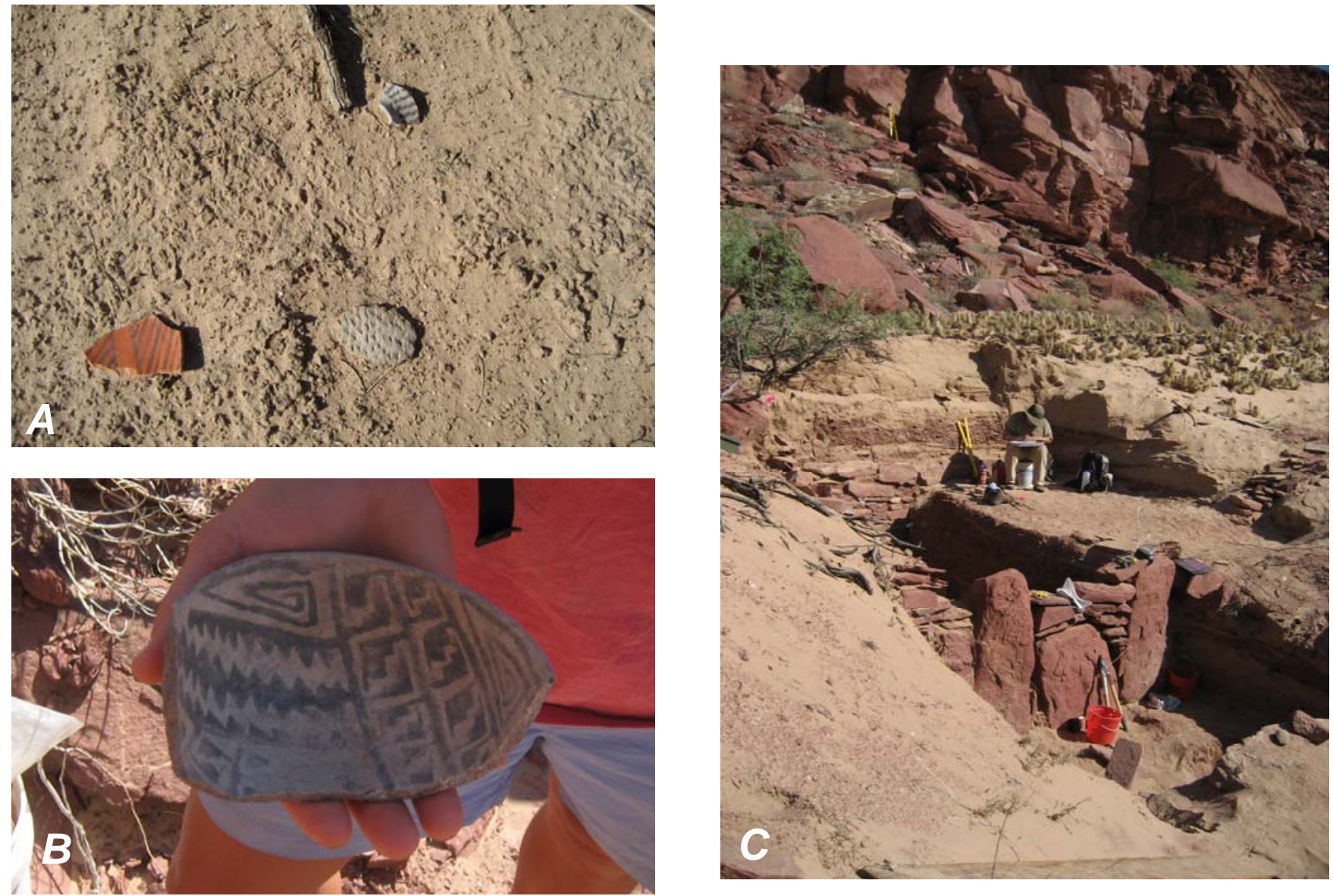

Figure 2. $A$ and $B$, Archeological artifacts, and $C$, site excavation, in Grand Canyon National Park, Ariz. The area in $C$ was previously buried by aeolian deposits and became exposed as gullying and sedimentdepletion revealed features of the habitation site. 
A thorough inventory of archeological resources along the 255-mile Colorado River corridor downstream of Glen Canyon Dam was performed between 1990 and 1991; the inventory located 475 individual sites, including 336 sites that were determined to be potentially impacted by dam operations (Fairley and others, 1994). Many of the archeological sites along the river corridor were found to be located in sediment deposits forming alluvial terraces (for example, Hereford, 1993; Hereford and others, 1993, 1996). Fairley and others (1994) identified a variety of erosion-related impacts occurring at these sites, including surface deflation, gullying (fig. 3), bank slumpage, and animal- and human-caused erosion such as trailing. Subsequent research has indicated a linkage between dam-controlled river hydrology, sediment-depleted sandbars at the river level, and erosion of archeological sites located in close proximity to the river owing to a lack of sediment replenishment at higher elevations within the river corridor and a reduction in aeolian sand transport to the sites. This theory was first suggested by Hereford and others (1991, 1993), and more recent studies by Draut and Rubin (2008) have begun to quantify these linkages.

Since 1992, NPS archaeologists have conducted repetitive site monitoring along the river corridor to document erosion and other impacts (Leap and others, 1996). In addition, NPS archaeologists have undertaken a variety of remedial activities to mitigate the effects of erosion, including mapping, maintenance and construction of erosion control features (fig. 3), and data recovery (excavation) efforts (for example, Leap and Kunde, 2000). As a part of the monitoring effort, detailed mapping using conventional survey techniques was conducted over portions of 70 sites to document potential erosioninduced changes to site topography over time. For a variety of reasons, this effort was halted before a change-detection study could be completed (Leap and others, 2000). Subsequently, researchers from Utah State University carried out a project from 2001 to 2003 to evaluate the effectiveness of check dams at slowing gully erosion at archeological sites (Pedersen and others, 2003). All of these efforts included the use of total station survey techniques, which required direct researcher access to the archeological sites being studied. Visible trampling of cryptogamic soil crusts and the development of incipient trails resulting from this work increased NPS resource managers' concerns about detrimental site impacts caused by researchers' footsteps on archeological sites (J. Dierker, personal comm., 2006).
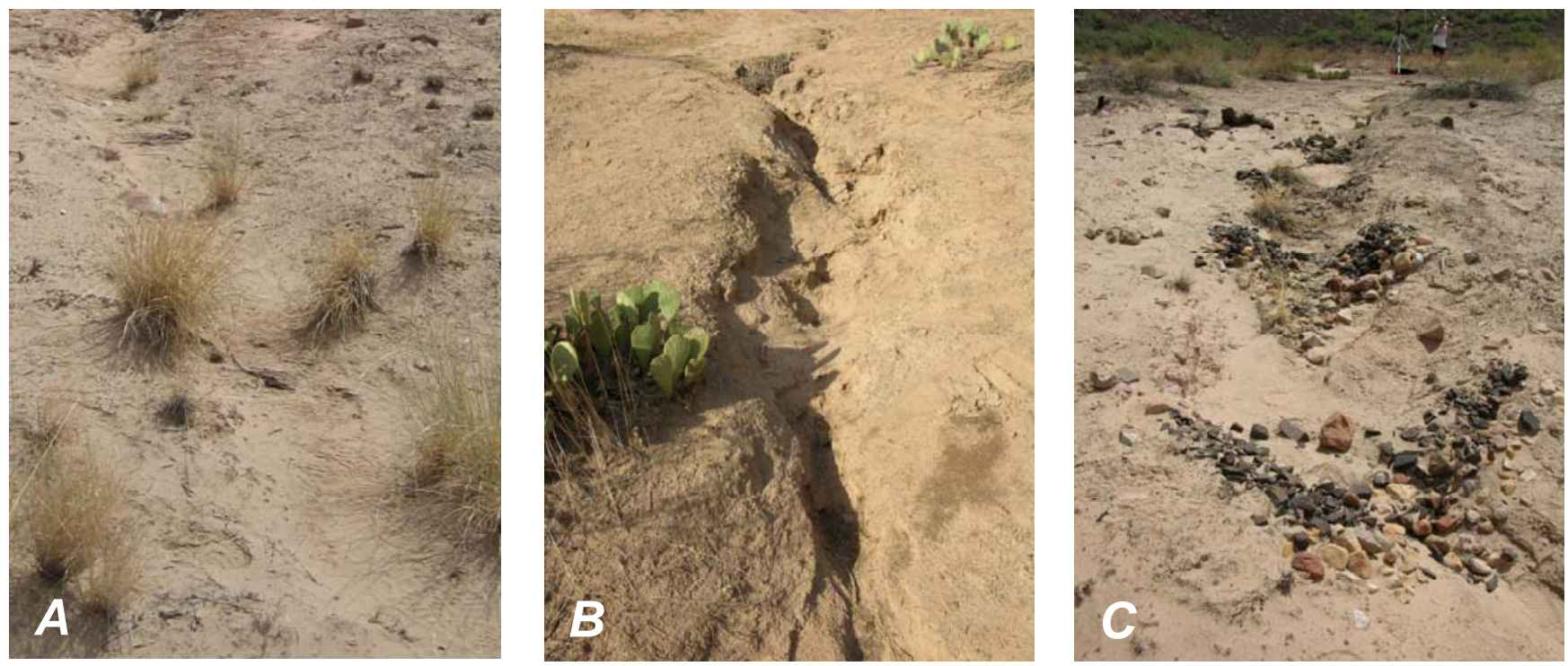

Figure 3. Topography of gullied archeological sites. Precipitation runoff causes terrace erosion and may lead to archeological resource degradation. $A$, Gully in early stage of formation. $B$, Fully incised gully. $C$, Gully with check dam to mitigate erosion. 
To eliminate human-caused erosion produced by conventional survey methods, Pederson and others (2003) explored airborne mapping techniques to monitor archeological site erosion and check dam effectiveness. Low-altitude photogrammetry (1:1,600 scale) with mean vertical accuracy of 6 to 10 $\mathrm{cm}$ was conducted in 2002 and compared to simultaneously collected total station survey data.

Unfortunately, even this high-scale airborne mapping failed to consistently detect change at the required $10-$ to $20-\mathrm{cm}$ scale - the minimum scale deemed necessary to detect significant erosion related changes to gully thalweg and knickpoint evolution. Although Pederson and others (2003) suggested that technological improvements could potentially reduce errors, the researchers also acknowledged that flights performed any lower (to further increase photo scale) were not likely to be performed because of the noise and visual impacts of low-flying aircraft in Grand Canyon National Park.

In a separate study, airborne LIDAR was also explored as an alternative means of collecting topographic data remotely from archeological sites (Davis, 2004). Like photogrammetry, the accuracy and resolution of airborne LIDAR is dependent on flight altitude and vegetation cover. Error analysis of airborne LIDAR data collected during this study along the Colorado River corridor in spring and fall 2000 and fall 2002 showed that a single pass of low-altitude LIDAR produced a point density of 10 points $/ \mathrm{m}^{2}$ and vertical accuracy of $8 \mathrm{~cm}$ on bare ground but produced relatively low accuracy in dense vegetation (1-2 m). Since change detection monitoring is dependent on roughly twice the vertical error (one each from each dataset collected over time), this method also produced change detection capabilities near to the limit of the features being investigated (centimeter to decimeter scale). The study also determined that the point density, and hence resolution, of airborne LIDAR maps could be increased by conducting multiple passes over the same area, which has concomitant increases in costs and impacts to visitors. As a result of these findings, this method has not been pursued any further as a viable means for archeological site monitoring in the river corridor.

In response to these studies, USGS researchers, in collaboration with the NPS, initiated a project to explore other remote-sensing technologies that would be more efficient, more accurate, and less intrusive for monitoring site geomorphic change. One of these, terrestrial LIDAR, was selected for testing because of its proven track record during the past 5 years for documenting site conditions with high resolution (hundreds of points per $\mathrm{m}^{2}$ ) and accuracy (centimeter level) in a variety of applications (for example, Collins and Sitar, 2004; Nagihara and others, 2004; Doneus and Neubauer, 2005; Kayen and Collins, 2005; and Collins and Sitar, 2008). Terrestrial LIDAR has also been used in previous studies in Grand Canyon National Park since 2001 as part of the Vanishing Treasures Program to document the existing conditions of archeological structures and resources (for example, Hough and Brennan, 2008); however, data collection has been limited to single temporal datasets of archeological structures rather than focused on fine-scale change detection of geomorphic features. Thus, terrestrial LIDAR's use as a change-detection tool had not been tested in Grand Canyon National Park or within the logistically challenging confines found at the bottom of Grand Canyon.

In 2004, ground-based LIDAR was tested along the Colorado River corridor in Grand Canyon National Park during an experimental high-flow release from Glen Canyon Dam; this initial application focused on a variety of scientific uses, including mapping sandbar geomorphology, archeological sites, and biological habitat (Collins and Kayen, 2006). This pilot study suggested that although the use of terrestrial LIDAR for archeological site monitoring in Grand Canyon was promising, its full use required additional evaluation. Following on these findings, the GCMRC Sociocultural Resources Program proposed an evaluation study comparing the effectiveness, portability, impacts, and accuracy of terrestrial LIDAR to the existing monitoring technology (total station surveying) currently used by GCMRC supported projects. The results of this study are presented in this report. 


\section{Methodology}

\section{Research Design}

LIDAR and total station data were collected at eight archeological sites (table 1) from May 4 to May 19, 2006, and from April 25 to May 11, 2007. Topographic results from the May 2006 surveys at three of the sites (C:13:006, G:03:041, and G:03:072) served as the basis for comparing the effectiveness and accuracy of the two methods for quantifying topographic measurements. To protect the cultural sites studied, the archeological site identification numbers are used for reference when describing site locations (fig. 4). Note that an "AZ:" precedes site identification numbers for officially cross-referenced archeological sites (for example, AZ:C:13:006). Topographic data comparisons of the other sites and collection date will be evaluated in a separate report to be completed in 2009. Impact evaluation data, consisting of the time and number of personnel footsteps taken within each site area during data collection were collected from all eight sites in both 2006 and 2007. These data are used as an indication of possible degradation caused by each survey method to sensitive archeological sites.

Table 1. Site name and dates of terrestrial light detection and ranging (LIDAR) and total station data collection at archeological sites in Grand Canyon National Park, Ariz. (bold indicates sites where topographic data is presented in this report).

\begin{tabular}{l|l|l}
\hline \multicolumn{1}{c|}{ Site name } & \multicolumn{1}{c}{ Date 1 } & \multicolumn{1}{c}{ Date 2 } \\
\hline C:13:006 & May 6, 2006 & April 28, 2007 \\
C:13:336 & May 7, 2006 & April 29, 2007 \\
C:13:099 & May 8, 2006 & April 29, 2007 \\
C:13:348 & May 8, 2006 & April 30, 2007 \\
G:03:041 & May 14, 2006 & May 7, 2007 \\
G:03:002 & May 15, 2006 & May 8, 2007 \\
G:03:072 DS (downstream gullies) & May 16, 2006 & May 10, 2007 \\
G:03:072 US (upstream gullies) & May 17, 2006 & May 9, 2007 \\
\hline
\end{tabular}




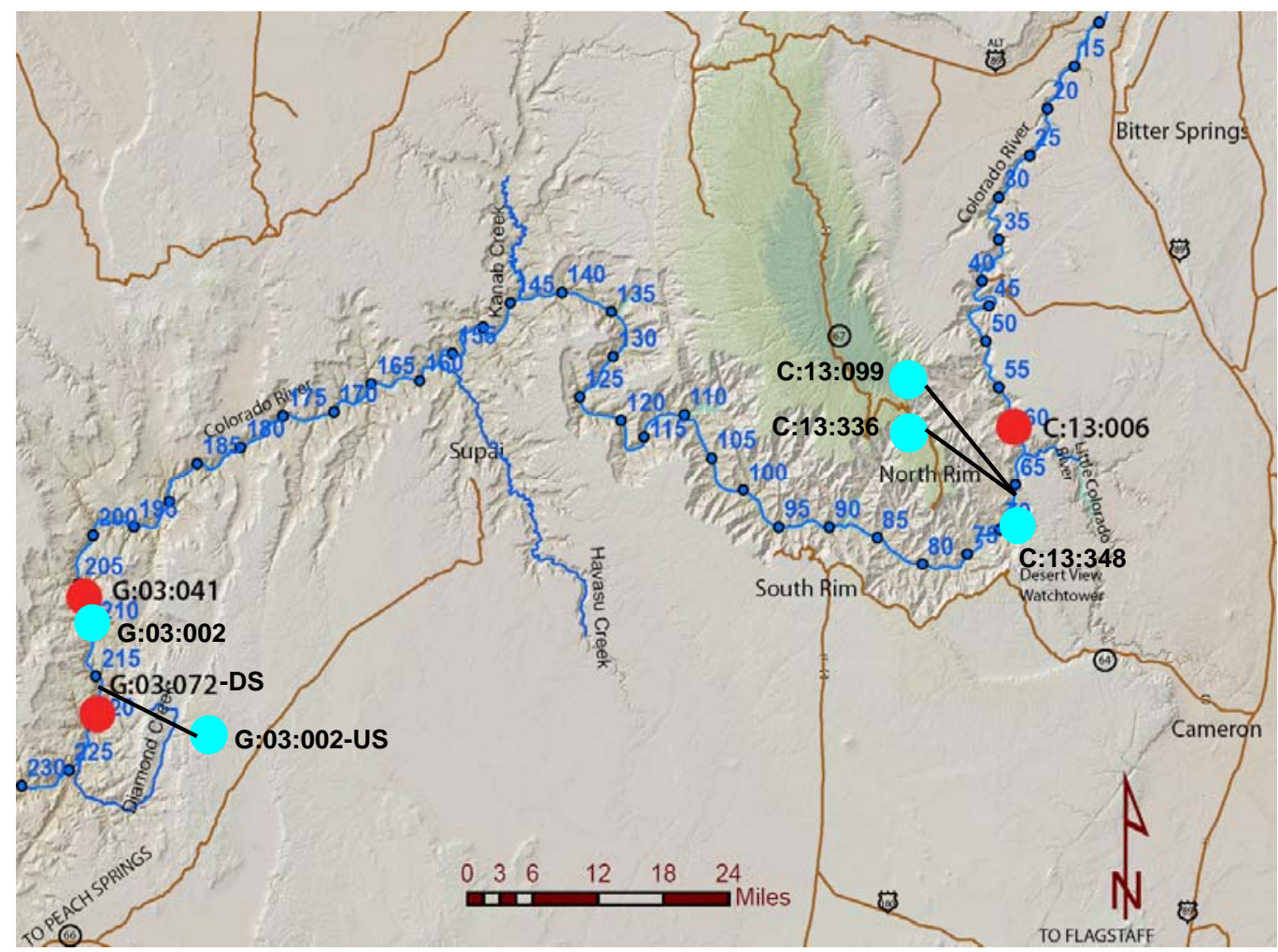

Figure 4. Map showing general location of eight sites included in this investigation. Terrestrial light detection and ranging (LIDAR) and total station data were collected at these eight archeological sites. Topographic results from three of the sites (red) served as the basis for comparing the effectiveness and accuracy of the two methods for quantifying topographic measurements. Five sites (blue) were evaluated only for site impacts in this report.

Data collection efforts were focused on one or more gully systems, referred to in this report as Gully 1, Gully 2, etc., and numbered sequentially at each site, moving from upstream to downstream along the river corridor or contributing side drainage. The total station (conventional) survey collected data along the gully systems, whereas the LIDAR survey focused on both the gully systems and the surrounding topography. Although this report concentrates on evaluation of data collected from the gully systems, it should be recognized that the LIDAR data collection and processing methodologies were selected to achieve an efficient collection of data over the entire site and to compare extracted gully features from this data. Thus, extended data coverage and survey efficiency were important in the selection of surveying protocols.

Support for survey activities was provided by two GCMRC motor rafts, which carried all personnel and equipment for each 16-day trip. Equipment included the terrestrial LIDAR unit (courtesy of the USGS Coastal and Marine Geology Program), GCMRC's total station unit, battery charging units for all electronics, and camping gear and food supplies. The terrestrial LIDAR team consisted of personnel from the USGS Earth Surface Processes Team and Coastal and Marine Geology Team in Menlo Park, Calif. The total station team was from the USGS GCMRC in Flagstaff, Ariz., assisted by a team from Utah State University performing geomorphologic assessments. Additional trip personnel included archeologists from NPS, USGS GCMRC scientists, Zuni Tribe members, and raft pilots (boatmen). 


\section{Study Areas}

Archeological sites that were previously monitored by the GCMRC and studied for NPS projects (Pederson and others, 2003) were selected as study areas. Thus, baseline datasets on gully thalweg topography already existed for the study areas before this study, and these datasets were already being evaluated independently as part of a larger research effort (Fairley and others, 2007). All sites evaluated in this study are within the elevation limits of areas potentially subjected to influence by dam operations and, with one exception, are located 100 to $200 \mathrm{~m}$ from the Colorado River. In general, site geomorphology consists of Holocene and Pleistocene alluvial, slope wash, or debris deposits; aeolian dune sands also cover these deposits in many places. In some locations, the dune sands have been stabilized by cryptogamic crust or small cacti vegetation. Sites are typically low gradient in the upper catchment but increase dramatically as they descend to river level. Thus, knickpoint formation has been most often monitored in these locations. The gullies studied are on the order of 10 to $30 \mathrm{~m}$ in length, up to $1 \mathrm{~m}$ in width, and generally several centimeters to tens of centimeters in depth. Additional details of the three sites evaluated for topographic comparison are provided here for reference. Pederson and others (2003) also provide additional site and geomorphology related information.

Site C:13:006 (fig. 4) is a prehistoric habitation area in close proximity to the Colorado River. The site is composed of overwash cliff deposits from Bright Angel Shale bedrock covered by aeolian dune sands and is of increasingly convex gradient moving down in elevation towards the Colorado River. Total catchment site for the area is 0.12 ha (Pederson and others, 2003). Four small drainages (G1a, G1b, G2, and G3) traverse the site, three of which appear to be nearing a state of incipient gully incision. The other drainage (G3) is a deeply incised gully that formed as a result of monsoonal summer rain in 2002 (Pederson and others, 2003). Vegetation cover is a mix of small cacti, chiefly prickly pear, generally averaging less than $20 \mathrm{~cm}$ in height with a few larger mesquite trees near the boundaries of the site. This report evaluates the topography of the first three gullies.

Site G:03:041 (fig. 4) is a prehistoric habitation area upstream of a large arroyo that forms the main geomorphic feature of the area. In general, the site is flatter at its upper end and increases in gradient toward the Colorado River. Four small gullies traverse the site, parallel in flow direction to the larger arroyo, and drain directly to the Colorado River. Individual catchment size of the gullies ranges from 0.02 to $0.18 \mathrm{ha}$, with gullies generally steep (12-28 percent) in gradient (Pederson and others, 2003). This report evaluated only two of the gullies, both of which are located almost entirely within aeolian sediments. Vegetation cover consists of a mix of both (1) small grasses, prickly pear cacti, and shrubs and (2) larger ocotillo and cholla cactus and creosote and mesquite trees. Overall, very few open, unvegetated areas are present, and, in some cases, the gullies traverse the site below dense shrubs and trees.

Archeological site G:03:072 (fig. 4) consists of multiple roasting pits spread over a debris fan. To facilitate mapping, the site was divided into upstream and downstream areas, designated G:03:072US and G:03:072DS. Site G:03:072DS (the only site evaluated for topographic comparison) forms a triangular-shaped area bounded by large (several meters in width) boulder-chocked drainages on two sides and a significant change in slope on the third side. The area is generally of increasingly convex gradient; three gullies (G1, G2, G3) of various development traverse the site. Because the third gully is already incised to bedrock, only the first two gullies are evaluated in this report. The gullies begin in an area of generally flat topography but dramatically increase in gradient as they reach the edge of the site. Catchment size is small (about 0.002 to 0.06 ha), but, again, the gullies have steep (24-27 percent) gradients (Pederson and others, 2003). The gullies lead into the two larger bordering drainages that then converge and drain to the Colorado River some $40 \mathrm{~m}$ downstream. Site vegetation includes 
several larger mesquite trees and a broad mix of cacti, including prickly pear, ocotillo, and yucca. In the gullies, vegetation is generally absent. Vegetation and cryptogamic crust appear to have generally stabilized the soils at this site.

\section{Terrestrial LIDAR Laser Scanning}

\section{Data Collection}

Terrestrial LIDAR, or three-dimensional (3-D) laser scanning, involves sending and receiving laser pulses to build a point file of 3-D coordinates of virtually any surface. A laser-scanning device is set up at a fixed location with an open field of view and aimed at the ground surface. The time of travel for a single laser pulse reflection is measured along a known trajectory such that the distance from the laser scanner, and consequently the exact location of a point of interest, is computed. Precise stepper motors within the scanner are typically used to aim the laser at defined areas or in a $360^{\circ}$ path around the scanner location. These devices, which were in many cases specifically developed for rapid topographic surveys, allow data to be collected at rates up to many thousands of points per second, generating a "point cloud" of 3-D coordinates. Acquisition of sufficiently dense point clouds can fully describe site topography. The point files generated from data collection are typically transformed into 3D surfaces for cross-section and volumetric analyses.

In the present study, a Riegl Z210 laser scanner (Riegl, 2008) was used as a tripod-mounted survey instrument (fig. 5A) and transported from the raft to each site by backpack (fig. 5B). An elevated tripod was used to position the laser above each site to capture a wide range and more direct line of sight to the area topography. Multiple scans were collected during each survey to fill in "shadow zones" of locations not directly in the line of sight of the laser and to expand the range and density of the point data (fig. 6). In some cases, additional scan locations are required to provide sufficient overlap of point clouds from one gully area to the next. This is often necessary for accurate registration of the point clouds (discussed in more detail in the following section). In general, to minimize impacts, scan locations were positioned outside archeological site boundaries; locating scans outside of site boundaries was not possible in all cases because of the complex geometry of some of the gullies. Data were collected at a rate of 8,000 points/second, scanning a range of $336^{\circ}$ in the horizontal direction and plus and minus $40^{\circ}$ from the horizontal in the vertical direction. This provided approximately 2.3 million points for each scan, although, only a portion of those points actually defined the gully topography of interest. With LIDAR, the area immediately adjacent to the gully and throughout the range of the scanner is captured in the same high-resolution detail (fig. $7 A$ ). On nearly flat ground, an area within a radius of about $20 \mathrm{~m}$ from the scanner location is captured in this detail; although, the data range is dependent entirely on the incident angle of the laser, as determined by the height of the scanner above the ground and the obliqueness of the scanner to the site topography. Combining many scans results in a topographic surface image of an entire site, such that entire site monitoring is possible (fig. $7 B$ ). Many other features can therefore be monitored in addition to the gully topography. 

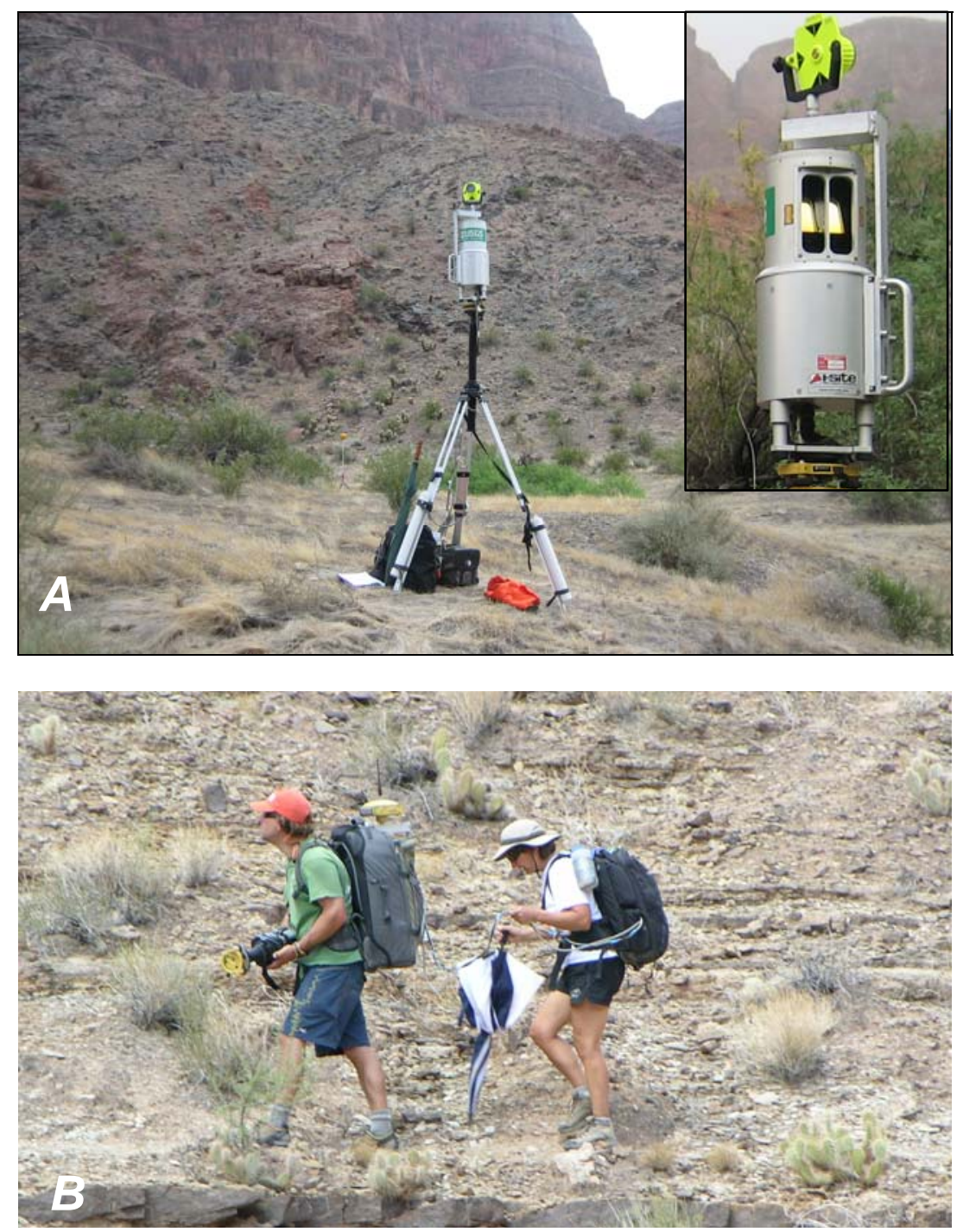

Figure 5. A, Terrestrial light detection and ranging (LIDAR) data collection in Grand Canyon, Ariz. Extendable tripod allows a larger area of data collection and less oblique laser returns from flat ground. Inset shows laser pulse and return windows and survey prism used to georeference the instrument location. $B$, Transporting the system requires two people in most cases, the first to carry the laser and tripod and the second to carry the data acquisition unit (laptop computer) and laser batteries. 


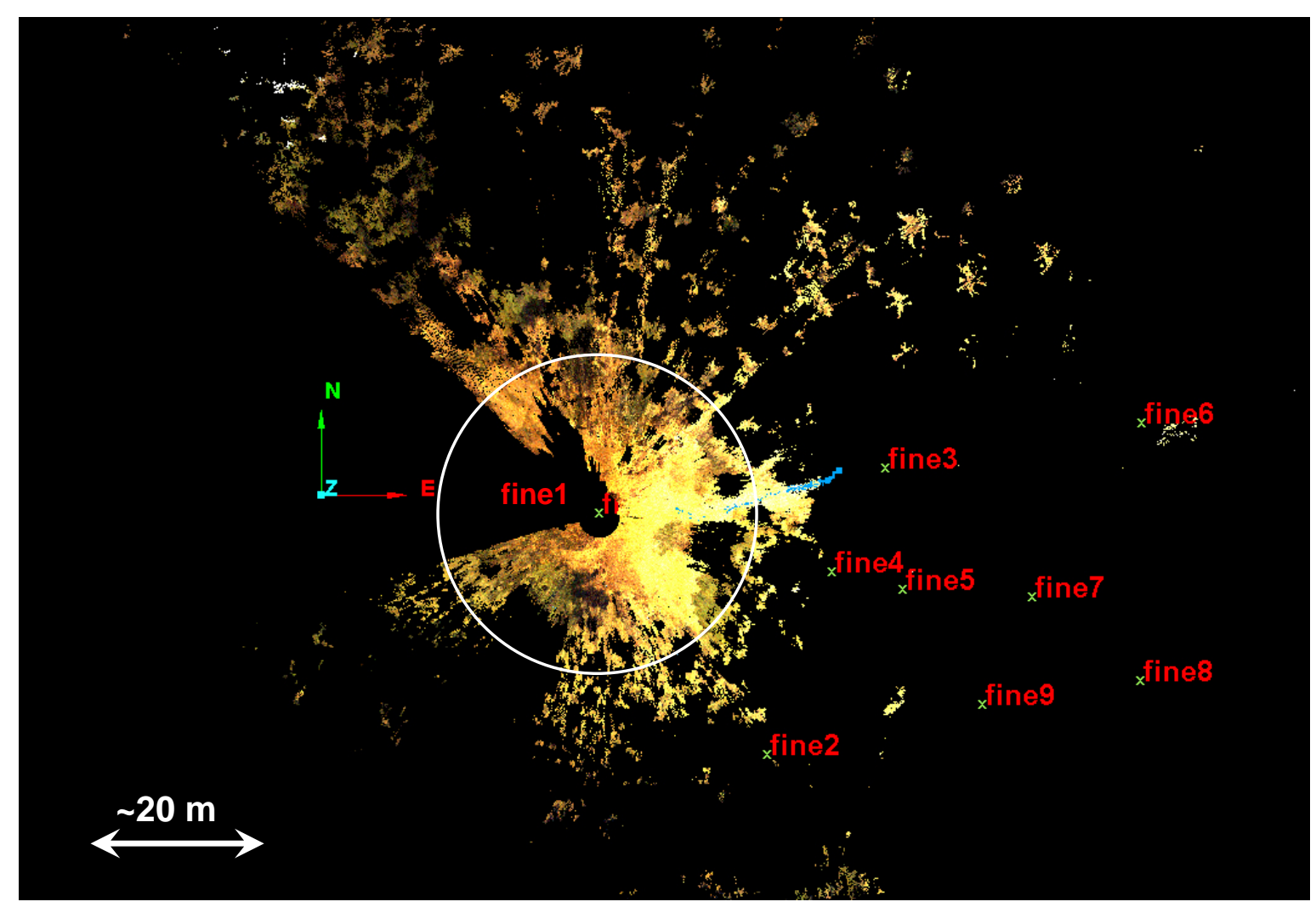

Figure 6. Typical terrestrial light detection and ranging (LIDAR) setup locations (fine2, fine3, etc.) and data coverage from a single scan (fine1) for site G:03:041. "Fine" refers to the point density setting of the laser (approximately 2.3 million points per scan). Each scan provides a different view of the gully system, sometimes overlapping with neighboring scans but expanding the data coverage and point density. Black areas indicate shadow zones or areas where no data were collected beyond the range of the laser. The circle has approximately a $20-\mathrm{m}$ radius and delineates the area of highest point density. 

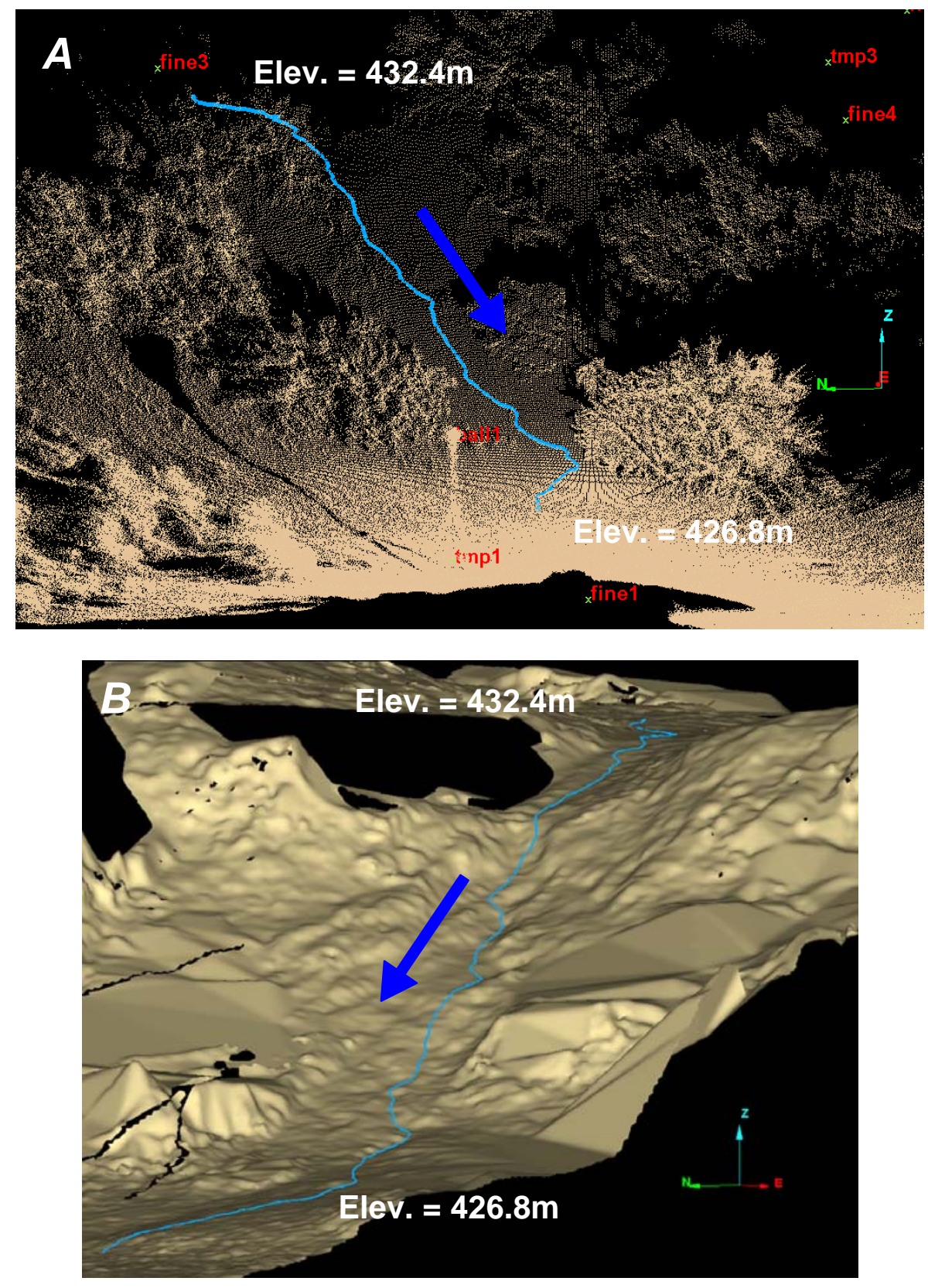

Figure 7. Views of $A$, terrestrial light detection and ranging (LIDAR) points and $B$, surface model data. (Site G:03:041 — Gully 1. Blue line is $22 \mathrm{~m}$ in length, arrow shows direction of flow.) Point data in $A$ are from a single scan (fine 1 ) and show extremely high point density from terrestrial LIDAR data. Other scan locations (fine3, fine4) and control points (tmp1, ball1, etc.) are labeled. The surface model in $B$ is constructed of $5-\mathrm{cm}$ triangular facets developed from multiple scans and shows the extensive definition of the site topography, including gully bottom, side walls, and neighboring ground. Vegetation has been removed through filtering algorithms; black areas define zones with no ground points due to filtering or limited data collection. 
Georeferenced coordinates of the scan locations were determined by either locating the instrument over known survey benchmarks or by collecting total station positioning via a survey prism mounted directly to the laser (fig. 5A). Additional registration fit was provided by scanned survey control points (LIDAR balls) located in and adjacent to each site (fig. 8). Metadata for the data collection effort are available at http://walrus.wr.usgs.gov/infobank/1/lg106gc/html/1-g1-06gc.meta.html.

\section{Data Processing}

The processing methodology was selected to result in high-resolution topographic models of the entire site area, such that advanced hydrologic modeling could be performed on the final surface model to extract gully features. This methodology best met the duality of the project goals by both investigating the applicability of terrestrial LIDAR to model site morphology and extracting meaningful geomorphic features at the same level of detail as total station data.

The data were processed using I-SiTE software (I-SiTE, 2008), which was specifically designed to handle laser scan data. Scans for each location were first registered to each other and georeferenced through a surface registration algorithm that finds best-fit solutions to overlapping areas of the point clouds. Increased overlapping point density typically results in more accurate data registration. The origin of each scan was held fixed according to its known survey position, and the scans were allowed to rotate in three dimensions. The final 3-D georeferencing of the dataset was achieved by registering at least three scans to form an approximately equilateral triangle, thus forming a plane with a single solution. Additional scans were then registered to this georeferenced plane.

Data filtering to define the bare ground surface (without vegetation) was performed through a lowest point filter on a $0.5-\mathrm{m}$ grid, followed by a $0.10-\mathrm{m}$ surface proximity filter. The surface proximity filter reintroduced all points within $0.10 \mathrm{~m}$ of the lowest point surface. Then a $0.05-\mathrm{m}$ minimum separation filter provided a homogenously dense final dataset for surface processing. Surfaces were created from the bare-ground point data in triangulated irregular network (TIN) format and analyzed using an automated water-drop pathway algorithm to define the lowest points (that is, the thalweg) for each gully. The algorithm is based on an evaluation of the centroid elevation of each TIN triangle; choosing smaller triangles results in a more exact solution but possibly more sinuous thalweg. In some cases, the TIN was prohibitively complex for determining the thalweg using automated techniques. For these gullies, the thalweg was extracted manually by linking the lowest drainage path of 1-cm contour intervals constructed from the site TIN (fig. 9). Long profiles and cross sections were then developed from the surface and thalweg data.

Note that since the selected methodology did not use the entire set of data points collected, the methodology design could be considered biased towards the goal of whole site modeling. Although other processing and modeling techniques are available and could have been used to investigate increased accuracy of the results, they come at a commensurate and greatly increased price in terms of data-processing efficiency and were therefore not selected for this investigation. 

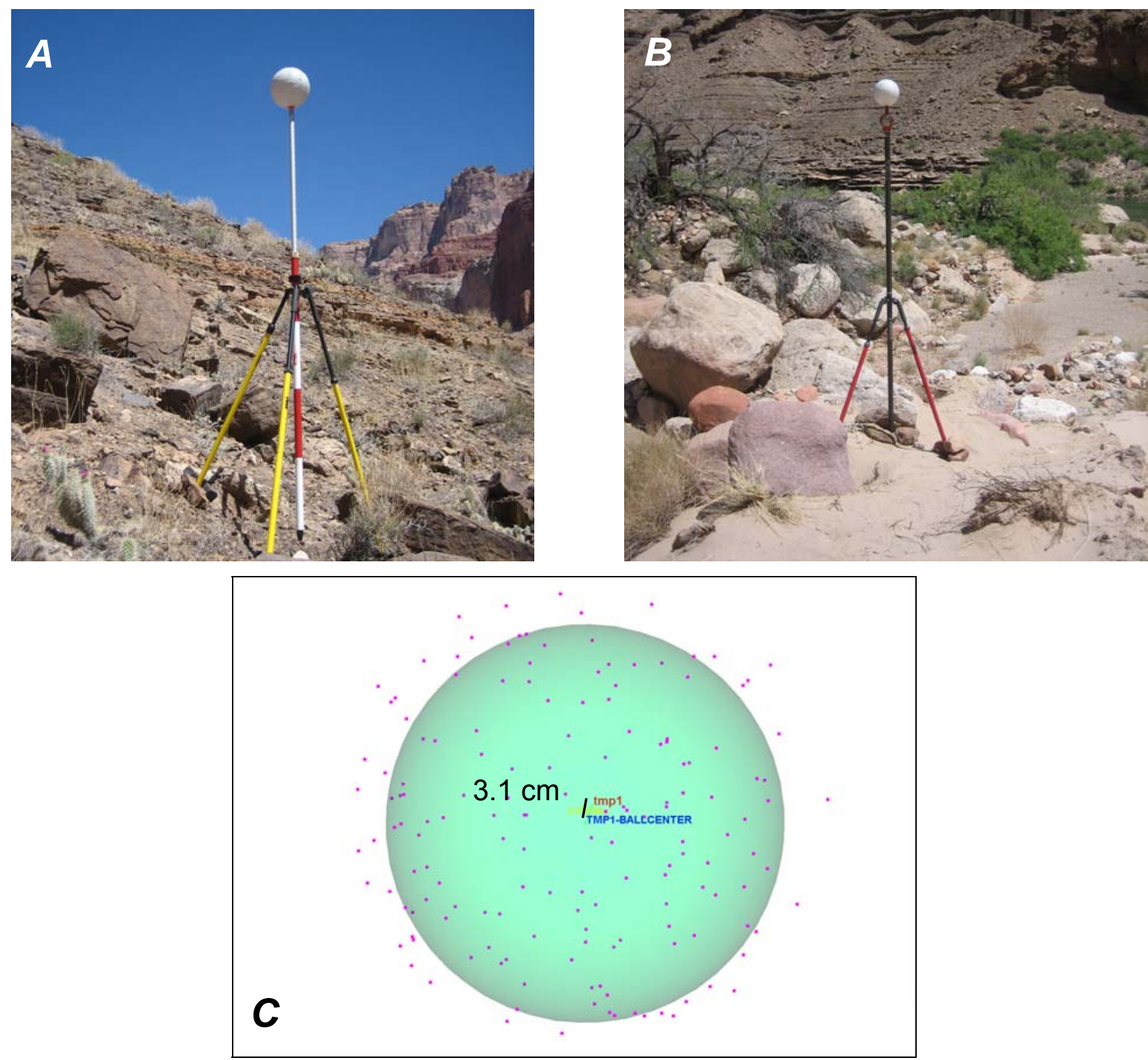

Figure 8. Terrestrial light detection and ranging (LIDAR) control points (LIDAR balls). Each ball is covered with strips of reflective tape, highly visible in the point-cloud data. $A$, The ball is either switched out with a survey prism and its position determined by total station survey or $B$, a survey prism is located beneath the LIDAR ball and surveyed directly. C, Error analysis is performed by matching a spherical model of the balls (green) to the points reflected from the balls (purple points). The distance $(3.1 \mathrm{~cm})$ between the surveyed coordinate (tmp1) and the center of the sphere (TMP1-BALLCENTER) is a measure of the accuracy of the data. 


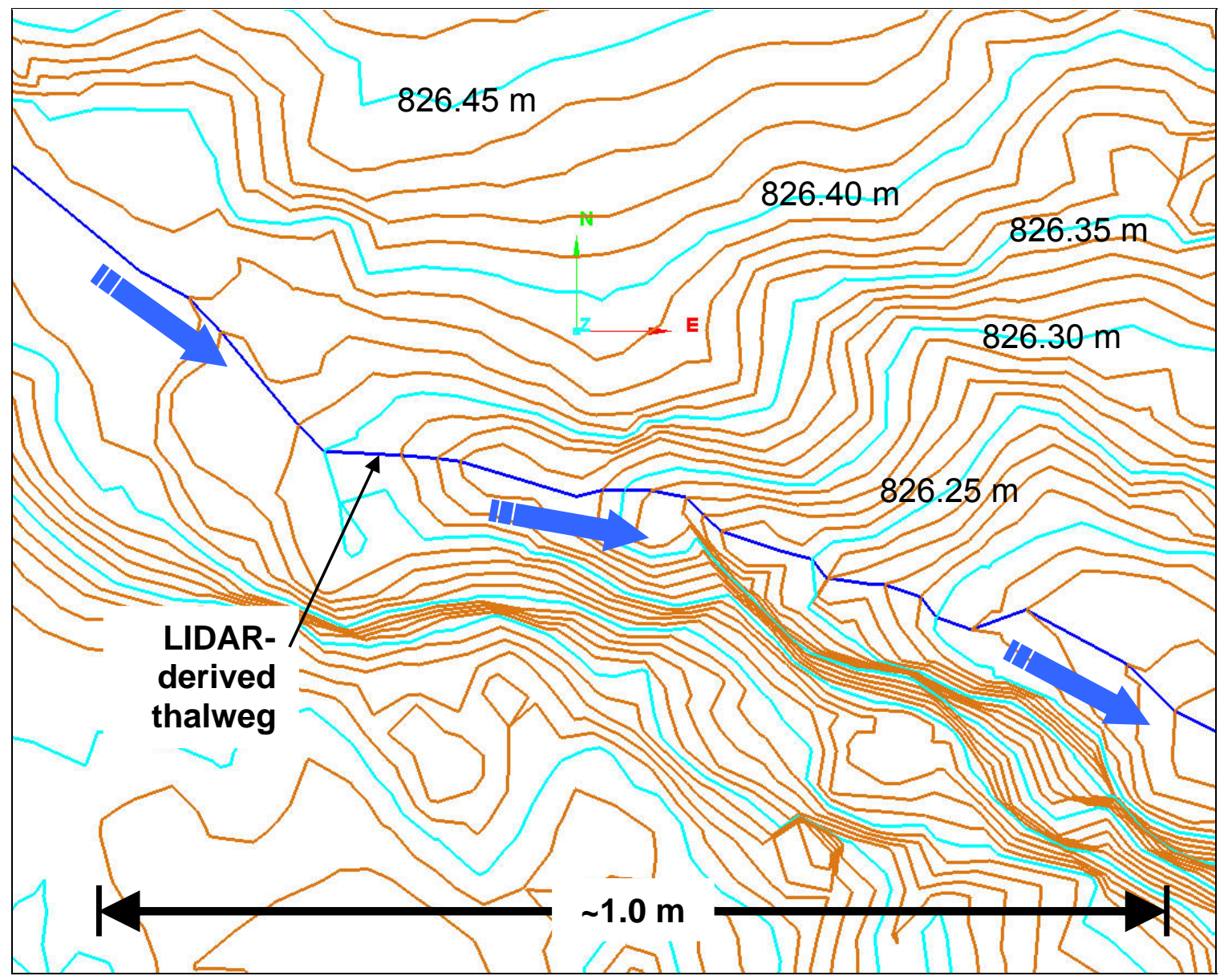

Figure 9. Extraction of a gully thalweg (thin dark-blue line) using 1-cm contours constructed from the surface model triangulated irregular network (TIN). Blue arrows indicate downward direction of surface water flow in the gully.

\section{Error Analysis}

Several sources of error are present in the LIDAR data that should be considered when using either the points or their associated surfaces for sources of linear and volumetric measurements. These errors include those from the laser instrument, those from total station survey control, and those from the registration process.

The total error varies depending on the type of measurement or specific use of the data (table 2). For example, measurements made within a LIDAR point cloud from a single scan are accurate to within the instrument error $\left(E_{\text {laser }}=1.5 \mathrm{~cm}\right)$. Thus, a measurement made between two points may contain twice this error $(2 \times 1.5 \mathrm{~cm}=3.0 \mathrm{~cm})$, since these errors are considered dependent (the error is from one source - the laser). The accuracy of a single point in a registered (but not georeferenced) scan depends on the laser error and the registration error. The registration error is not easily calculated since the alignment of two scans depends on the proximity of overlap of the specified point clouds. It is estimated here by calculating the best fit of the point clouds from a set of three scans registered to one another in a triangle layout with the three degrees of translational freedom removed (that is, the laser origins are 
Table 2. Errors associated with terrestrial light detection and ranging (LIDAR) measurements.

\begin{tabular}{l|c}
\hline \multicolumn{1}{c|}{ Type of measurement } & $\begin{array}{c}\text { Total three- } \\
\text { dimensional } \\
\text { error }\end{array}$ \\
\hline Single-point accuracy (local coordinates) & $1.5 \mathrm{~cm}$ \\
Distance between two points in a single scan & $3.0 \mathrm{~cm}$ \\
Single-point accuracy (registered coordinates) & $5.1 \mathrm{~cm}$ \\
Distance between two points in two registered scans & $5.8 \mathrm{~cm}$ \\
Single-point accuracy (relative georeferenced coordinates) & $7.3 \mathrm{~cm}$ \\
\hline
\end{tabular}

fixed in space). Using this technique, the registration error obtained in this study was approximately 5 $\mathrm{cm}$. The laser and registration errors are considered to be independent and the total error is calculated as the root of the sums of the squares of each $\left(E=\sqrt{E_{\text {laser }}^{2}+E_{\text {reg }}^{2}}=5.1 \mathrm{~cm}\right)$. Measurements made between two points in two different scans in a single dataset are accurate to the (doubled) instrument error (one each for each point in the measurement) and the registration process error for the two scans $\left(E_{\text {reg }}\right)$, which is not doubled $\left(E=\sqrt{\left(2 E_{\text {laser }}\right)^{2}+E_{\text {reg }}{ }^{2}}=5.8 \mathrm{~cm}\right)$.

Measurements made between any LIDAR point and geographic coordinates include these previous errors plus the total station error $\left(E_{\text {control }}=1.0 \mathrm{~cm}\right)$ for the scanner locations (used to georeference the data). This error was calculated through dual-repeat measurements of a single LIDAR scanner position and the total station back sight. They are therefore more accurate than any single total station measurement used in that part of the survey. Because identical benchmarks were used for surveying both the total station data and the laser setup locations, any additional georeferenced error introduced through the original survey of the control points is zero and can be ignored, assuming minimal tectonic drift and maximum control point stability. However, if these datasets are used in comparisons to studies that do not use these benchmarks, the error associated with the initial benchmark survey and stability must be included. For the control points used in this evaluation, mean 3-D error is approximately 5 to $8 \mathrm{~cm}$ (U.S. Geological Survey, 2008) but, as noted, is not included in the error estimate. Here, we refer to the total error as the 3-D relative georeferenced error (table 2).

Each of these errors is independent and calculated by the root of the sum of the squares of each error, but here $E_{\text {laser }}$ is not doubled because only one laser measurement is being quantified. Further, because the registration technique is calculated based on the point-cloud matching of three triangularly positioned scans in two independent computations, the registration error is included twice (for one scan to the next, $E_{r e g l}[5 \mathrm{~cm}]$, followed by this pair of scans to the third scan, $E_{r e g 2}[5 \mathrm{~cm}]$, to define a plane that is "locked" in the three rotational degrees of freedom of the point clouds). The total error for a

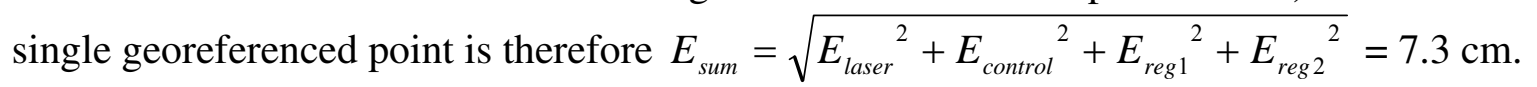

An independent check of these errors was performed by comparing the locations of the LIDAR survey control balls in the point clouds to the surveyed locations from the total station data (fig. $8 \mathrm{C}$ ). The average 3-D positional error was $7.8 \mathrm{~cm}$ for the three datasets presented in this report, verifying the expected order of magnitude of the calculated errors. 
For evaluation of the vertical accuracy of the data $(\otimes z)$, the 3-D error $\left(E_{\text {sum }}\right)$ calculated previously (about $7.5 \mathrm{~cm}$ ) can be decomposed into only an error for a single dimension by way of the following

formulation: $E_{\text {sum }}=\sqrt{3} \Delta z$, which assumes that the errors are distributed evenly between the three coordinate dimensions. Thus, the expected vertical accuracy of the data is $4.3 \mathrm{~cm}$. This value is therefore less than that obtained by previous efforts using both airborne LIDAR ( $8 \mathrm{~cm}$; Davis, 2004) and photogrammetry (6-10 cm; Pederson and others, 2003), verifying that terrestrial LIDAR should be expected to detect topographic change at the subdecimeter scale.

All of these estimates should be noted as being conservative (maximum) errors, representative of worst-case scenarios, because they depend on the registration of data from the entire site. In areas close in to the scanner locations, and with better registration fit (that is, near the gully thalwegs), maximum errors should be expected to be less, since the laser and registration errors are systematic errors that increase in magnitude with increasing distance from the scanner origin. It is therefore likely that change-detection measurements using temporally different datasets will be somewhat less than these maximum errors.

\section{Conventional Total Station Surveying}

\section{Data Collection and Processing}

Conventional survey techniques using an electronic total station are the most common means of surveying in Grand Canyon and continue to be used to meet the GCMRC's mapping objectives, including topography, site location, and control. In total station surveying, the surveyor sights on one or more survey rod personnel (that is, rodmen) holding a survey rod mounted with a reflective prism on a point of interest. The total station instrument accurately measures horizontal angles, vertical angles, and slope distances in order to position or locate survey points of interest or define a feature. The GCMRC uses four Topcon total stations for all mapping: two GPT 2003 models and two GTS 313 models. To establish positional reference to the State Plane Coordinate System and provide verification of positional accuracy, conventional survey methods require the total station to be centered over a known control point and a prism centered over another known control point (that is, back site; fig. 10). In the case of a topographic survey, this two-point occupation establishes the State Plane coordinate grid, and all other points needing location are systematically measured as side shots by sighting on the prism that the rodman accurately centers over a required survey point. A data collector is used as an electronic field book to record the total station measurements, which are subsequently electronically downloaded to a computer for reduction and processing. A total station survey requires a minimum of a surveyor and a rodman (fig. 11) but usually involves several rodmen for increased efficiency. For the gully surveys, a lone rodman is most efficient where the gullies are narrow or the point spacing is less than $1.5 \mathrm{~m}$. When two or more rodmen are involved in the surveying process, measurements are collected from one rodman, while the other rodman moves to the next data point and prepares for measurement collection. Because this surveying method requires personnel to locate themselves directly in or near the surveyed points to define the gully, impact to the archeological site in the form of footsteps is typical and generally concentrated in the gully itself. 


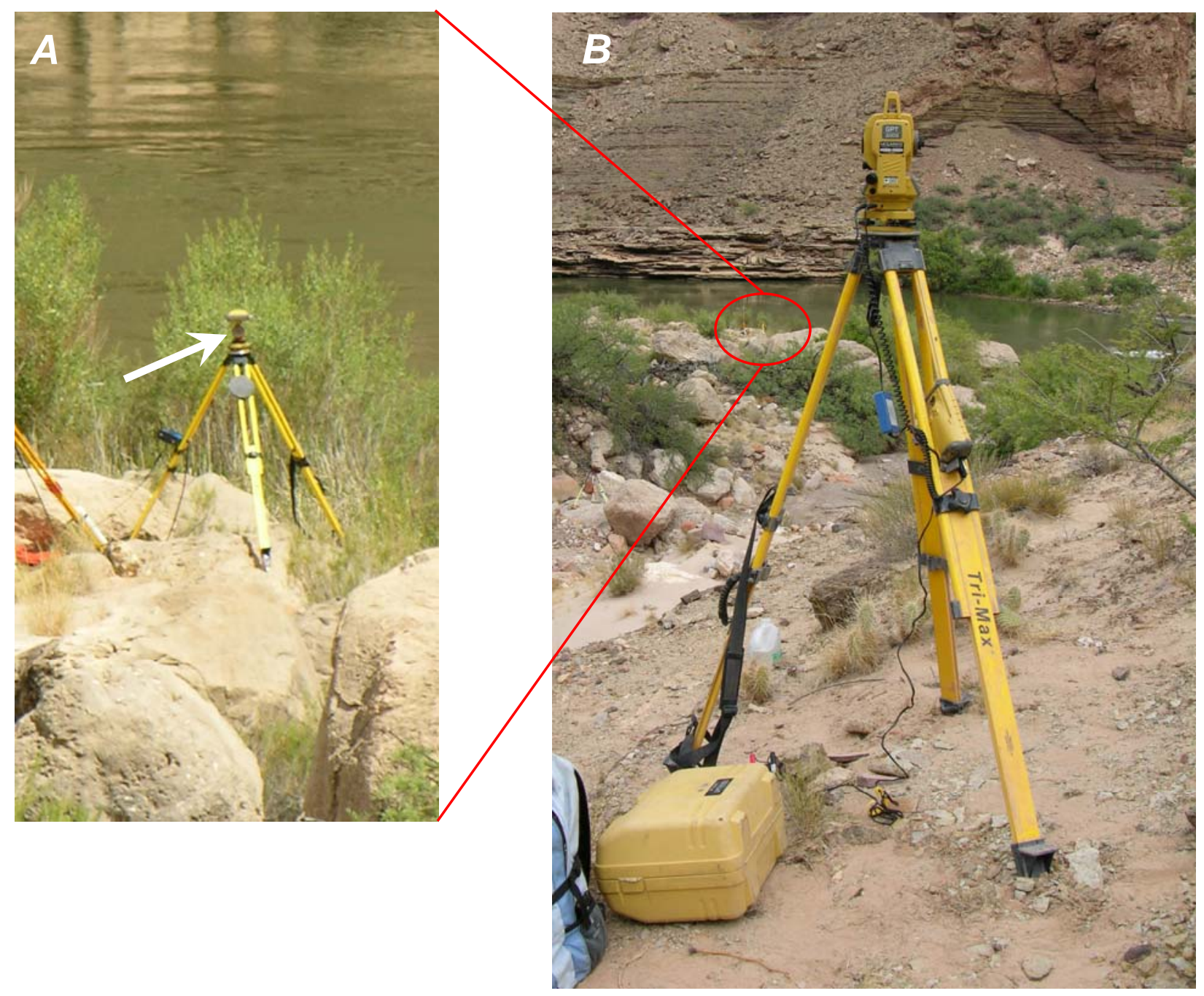

Figure 10. Conventional total station data collection showing $A$, back site location with prism assembly (arrow) for angular and distance control. In this figure, the prism is located directly beneath a global positioning system (GPS) receiver being used for a separate survey. In $B$, the total station instrument is set up at a fixed, known location (that is, benchmark or control point) for positional control.

Specific geomorphic features in the gully (the thalweg, the gully bottom, and the knickpoints) are coded into the data collector before taking a measurement. For monitoring check dams, the process requires surveying the area covered by the check dam as well as noting check dam type in the data collector. The angle and distance data are reviewed and corrections are edited and then converted to State Plane coordinates using specialized software (for example, Survey Link 7.5.5 software by Tripod Data Systems). After this process, coordinates for points are available as a text file for modeling in a variety of geographic information system (GIS) or surveying-based software packages. 


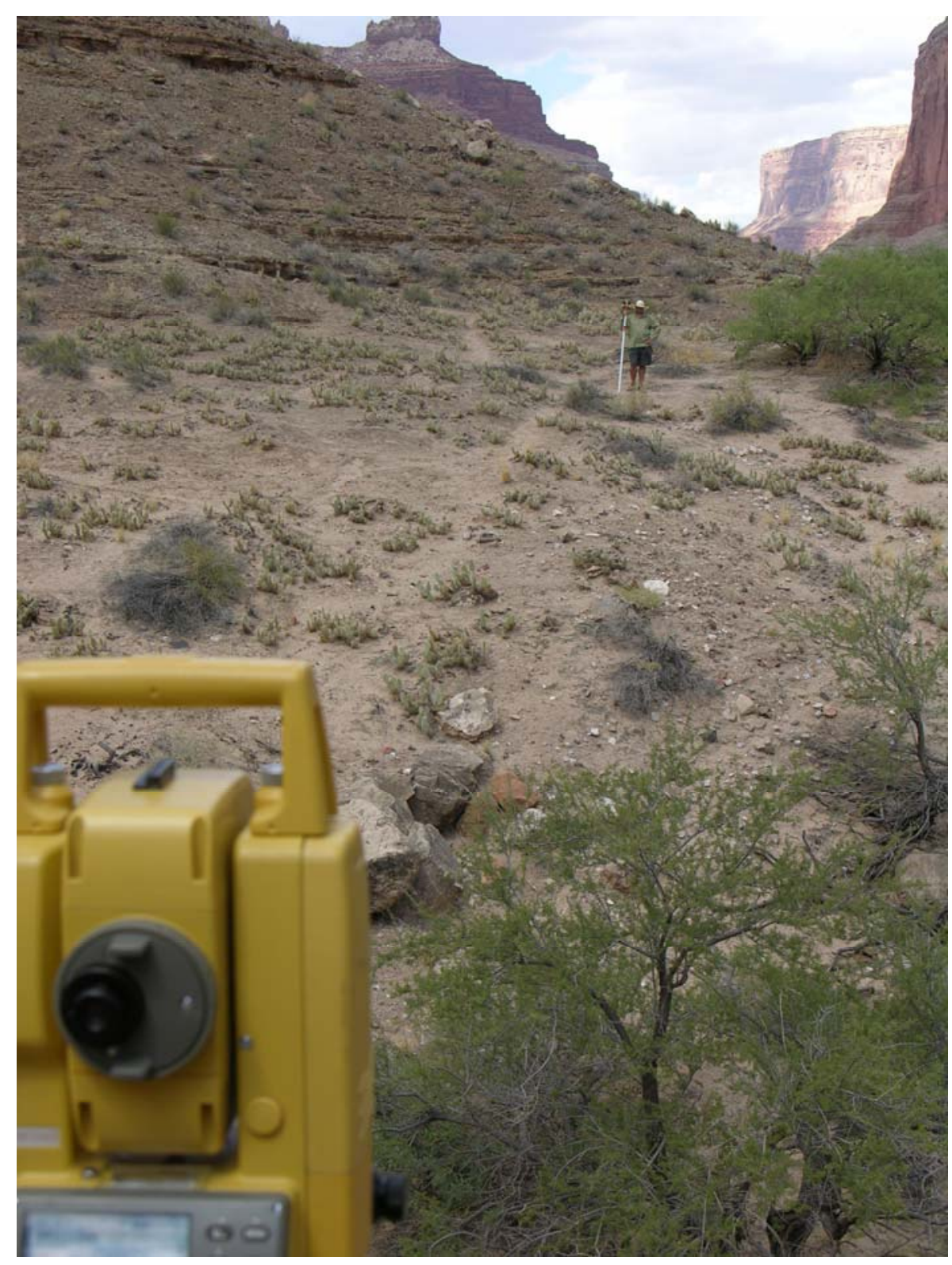

Figure 11. Conventional total station data collection showing use of survey rod and prism in a gully system. Communication between the surveyor at the total station and the personnel in the gullies is achieved through a combination of voice, arm signals, or handheld two-way radios.

\section{Error Analysis}

Total station measurements are subject to error from three sources: the instrument error, prism location error, and georeferencing error. The instrument error is calculated by a root mean sum of the error induced by both range $\left(E_{\text {range }}\right)$ and angular measurements $\left(E_{\text {horiz, }}\right.$ and $\left.E_{\text {vern }}\right)$ for 3-D positioning. Thus, the total instrument error is $E_{\text {instrument }}=\sqrt{E_{\text {range }}{ }^{2}+E_{\text {ang1 }}{ }^{2}+E_{\text {ang } 2}{ }^{2}}$. The instruments used in this study have a documented angular accuracy of $3 \mathrm{~s}$ or 1 milligon (mgon) and a distance accuracy of $\pm(3 \mathrm{~mm}+2 \mathrm{ppm}$ 
$\times \mathrm{D})$ mean squared error $(\mathrm{MSE})$, where $\mathrm{D}=$ measuring distance $(\mathrm{mm})$. Based on a mean average range from instrument to target of $150 \mathrm{~m}$, the range error is $3.3 \mathrm{~mm}$ and the angular errors are each $2.2 \mathrm{~mm}$. The total instrument error is therefore $4.5 \mathrm{~mm}$ or approximately $0.5 \mathrm{~cm}$.

The prism location error is based on both environmental conditions and errors introduced by the rodmen. Environmental factors affecting measurements include heat shimmers and wind. Heat shimmers interfere with precise sightings on the survey prism and affect laser distance measurements; strong wind may cause the tripod and total station to quiver while taking a measurement. The heat shimmer and wind error are dependent on the intensity of the environmental factor and were not quantified in this study. Wind may also cause the survey rod to arc when it is extended beyond $3.2 \mathrm{~m}$, which is necessary when the line of sight is obstructed by vegetation, boulders, or landforms. Humaninduced errors are mainly associated with miscoding data points, selecting the wrong point to survey, and holding the survey rod off plumb. To remedy the last problem, a bubble level is attached to the survey rod that allows the rodman to verify that the survey rod is plumb when taking a measurement. The bubble level can only verify that the two lower portions of the extendable survey rod are plumb, so when the survey rod is extended by three or more extensions (up to $4.7 \mathrm{~m}$ ), the total station operator must verify that the rod is plumb by using the eyepiece crosshair to sight the center of the rod as close to the ground as possible to capture the horizontal position of the point of interest. The point measurement is then taken by moving the eyepiece to the elevation of the survey prism while maintaining the previously established horizontal angle. While this approach generally provides usable data with a horizontal error estimate of $10 \mathrm{~cm}$ when the survey rod is visible within a meter or two of the ground, the error value increases when the lower portion of the rod is hidden and only the survey prism or upper portion of the survey rod is visible to sight on for a measurement. In this case, the horizontal error can increase to tens of centimeters. The survey data included in this evaluation were primarily collected using less than three survey rod extensions; three or more extensions were used only occasionally when data collection occurred in high vegetation, deep gullies, or behind protruding areas of the ground surface. In this study, the total prism location error is estimated to be between 3 and $10 \mathrm{~cm}$.

Georeferencing error is based on possible error in the known coordinate positions of the total station and back sight control points. However, since the control points are used throughout each survey and are occupied identically during both previous and subsequent surveys of the area, they form only a relative measure of error, do not directly effect the total error estimate, and are therefore not quantified in this study. Similarly to the LIDAR error analysis, the error estimates calculated here should be interpreted as relative georeferenced errors because the error associated with the control point benchmarks is not included. Again, since identical benchmark control points were used in both the total station and LIDAR surveys, this error can be ignored when the two datasets are compared directly.

Total station error is computed in this study by two methods: (1) summing the three components of error and (2) comparing measurements taken directly on points with known coordinates. The sum of the three components of error (instrument $=0.5 \mathrm{~cm}$, prism location $=2$ to $10 \mathrm{~cm}$, and georeferencing $=0$ $\mathrm{cm}$ ) results in a total error estimate of 2.5 to $10.5 \mathrm{~cm}$ in 3-D positioning. Measurements made on known points (that is, back sight control points) provide a secondary error check. Here, the measured average difference coordinate value for the back sight is compared to the published coordinate value known for each point. On average in this survey, the positional difference between the published coordinate value and the measured coordinate value was $2.4 \mathrm{~cm}$. Thus, the total error in any single point is likely on the lower end of the initial total error estimate range.

Because of the nature of the differences between data processing in the terrestrial LIDAR and total station survey methods, direct comparisons of the various errors summarized in table 2 for terrestrial LIDAR cannot be made. In total station surveying, the single point accuracies for local, 
registered, and georeferenced coordinates are all identical and on the order of 2 to $3 \mathrm{~cm}$. Measurements between two points based on these values can be calculated similarly to the LIDAR data, and are therefore accurate to twice the single point error (that is, 4-6 cm).

In this evaluation, the maximum 3-D errors associated with each method are used to calculate a maximum inaccuracy threshold for the data comparison. Whereas the vertical accuracy estimate technically should be used, it is assumed that some errors may not be independent between the horizontal and vertical components; therefore, this evaluation uses the more conservative 3-D errors instead. Thus, the terrestrial LIDAR 3-D error of approximately $7.8 \mathrm{~cm}$ combined with the total station 3 -D error of $2.4 \mathrm{~cm}$ results in an expected maximum accuracy threshold of $10.2 \mathrm{~cm}$ between the datasets. A threshold of $10 \mathrm{~cm}$ is used in the topographic evaluation, with vertical or horizontal differences more than $10 \mathrm{~cm}$ being unacceptable.

\section{Impact Evaluation}

Site impacts were evaluated using two chief metrics: the number of footsteps taken and the time spent within each archeological site boundary (sensitive area). These metrics were selected based on the premise that the more footsteps taken and the longer time spent within the boundary, the higher the likelihood for site degradation resulting from the researchers' presence (that is, surface erosion and soil compaction; fig. 12). More footsteps are likely to occur when researchers are moving around within the site boundary, but even when a researcher is not moving around, there is still a potential for soil compaction and site erosion simply from the shuffling of feet. Site boundaries investigated in this study had been previously established by NPS archaeologists; these archaeologists were also present in the field during each survey effort.
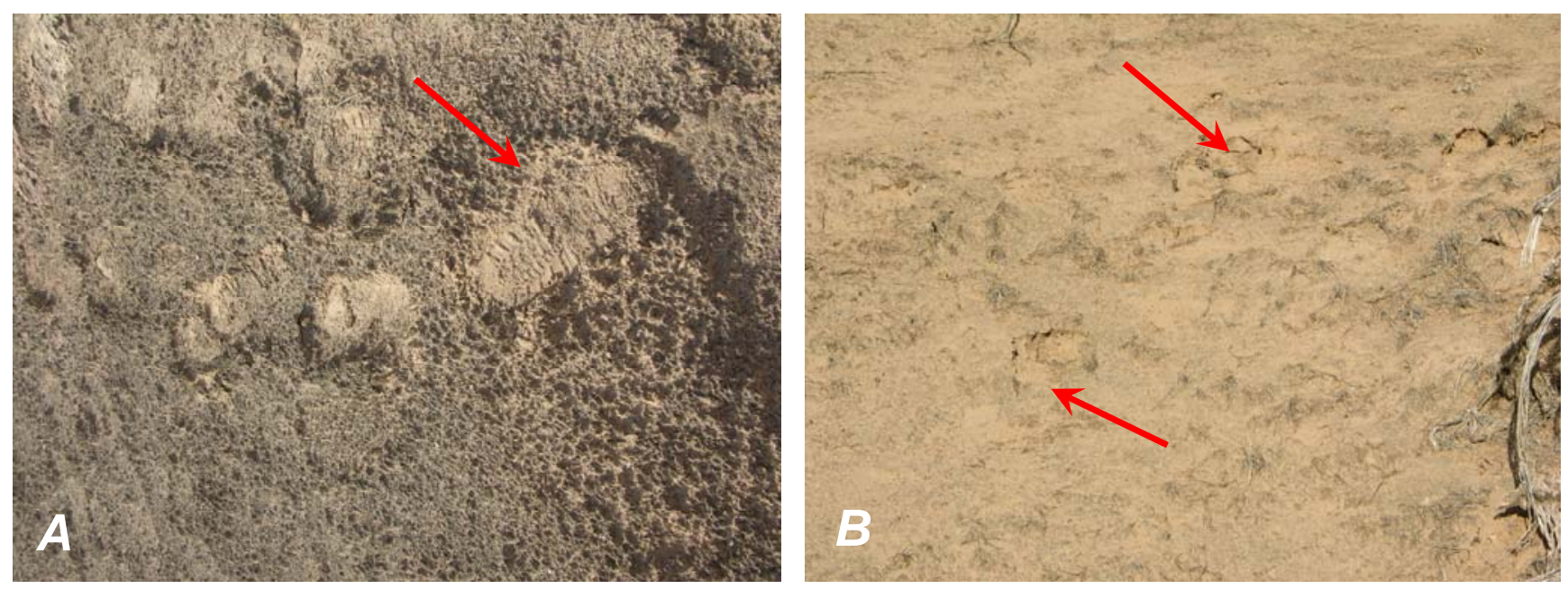

Figure 12. Footstep imprints impact archeological sites during surveying by compacting soils or damaging cryptogamic soil crusts. In $A$, fresh footprints are in a well-developed crust, whereas in $B$, the fresh footprints are set amid other footprints from previous site visits, which results in a mottled soil texture. 
To measure footsteps (footstep count), mid-quality-brand hip-unit pedometers were used on all surveyors to sense footstep-related leg movement. At the start of each survey and before entering the sensitive area, the pedometer was clipped onto the hip and the step count reset to zero. When exiting the sensitive area, the accumulated footsteps were recorded, or, alternatively, the pedometers were removed and left near the site until the person returned and reclipped the unit to the hip. If one of the pedometers malfunctioned or the procedures were not followed correctly, the erroneous data were discounted and footsteps recorded by another surveyor were doubled for that time interval. This method was considered an appropriate approximation for footstep count because the surveyors for both mapping techniques worked closely with each other. In this study, we found that the pedometer footstep count was biased toward a heavier gait or greater hip movement; a tiptoeing wearer rendered no count, while stomping counted each step as two. For example, since rodmen for the total station surveying moved more slowly and over a smaller distance with each footstep, some footsteps may not have been recorded. Given these limitations, the footstep counts must be considered approximations useful only for making gross comparisons.

Time in the sensitive area was measured by wristwatch and recorded similarly to footstep count as the surveyors entered and exited the site boundary. This provided an independent proxy measurement of site impact.

To further investigate trends in the impact data, additional analysis was performed by calculating the variation within each type of mapping method (2006 versus 2007) as well as the variation between mapping methods (total station versus LIDAR). While the difference between the survey efforts within each method provided a measure of consistency from year to year, the difference between the survey method values provided a direct indication of varying impacts caused by each method.

The variation within each type of mapping technique was determined by subtracting each method's 2007 values from their 2006 values for each site (TS = total station):

A1 $=\left[(\text { total survey time })_{2006}-(\text { total survey time })_{2007}\right]_{\text {TS }}$ or LIDAR

$\mathrm{A} 2=\left[(\text { time in sensitive area })_{2006}-(\text { time in sensitive area })_{2007}\right]_{\text {TS or LIDAR }}$

A3 $=\left[(\text { footstep count })_{2006}-(\text { footstep count })_{2007}\right]_{\text {TS or LIDAR }}$

Each parameter represents variations in either person-hours or footstep count: a negative number indicates fewer person-hours or footsteps in 2006, a positive number indicates fewer person-hours or footsteps in 2007, and an overall average near zero reflects consistency within the survey method. The variation between mapping methods was calculated similarly:

$$
\begin{aligned}
& \mathrm{B} 1=[(\text { TS total survey time })-(\text { LIDAR total survey time })]_{2006} \text { or } 2007 \\
& \mathrm{~B} 2=[(\text { TS time in sensitive area })-(\text { LIDAR time in sensitive area })]_{2006} \text { or } 2007 \\
& \mathrm{~B} 3=[(\text { TS footstep count })-(\text { LIDAR footstep count })]_{2006} \text { or } 2007
\end{aligned}
$$

Similar to the A-parameters, a negative number indicates fewer person-hours or footsteps in the total station method, a positive number indicates fewer person-hours or footsteps in the LIDAR method, and an overall average near zero reflects consistency within the survey methods.

As an additional purpose of this study was to evaluate all facets of the use of terrestrial LIDAR for gully thalweg and whole site monitoring, several other indirect impact components were also measured, including quantity and quality of data and relative cost. Protocols for these criteria were selected a priori and are detailed in appendix A. Data density and accuracy were evaluated through direct comparison of the number of points collected and the postprocessed data point accuracy from each survey method. Data accuracies from each method are reported in the previous error analysis 
section of this report. The cost component was divided into two categories: (1) equipment purchase and maintenance and (2) personnel cost. Personnel cost was evaluated by comparison of both total survey time and the time required to postprocess the data to State Plane (X, Y, Z) coordinates, both measured in person-hours. During fieldwork, the time interval was documented by recording the start and end times of each survey, and subtracting break time and down time. The total survey time includes such items as transportation of equipment to and from each site to the raft, setup time, and surveying time outside the site boundary. This is in contrast to the time in the sensitive area metric, which only measures those times when personnel were within the site boundaries. Thus, while the total time provides a measure of survey efficiency, the time in the sensitive area provides a measure of site impact.

\section{Results}

\section{Topographic Data Collection}

For the three sites investigated in this study for topographic change (C:13:006, G:03:041, and G:03:072), data from seven individual gully systems were collected (table 3). Using the terrestrial LIDAR method, a total of 21 scan locations were required to develop the appropriate surface models for these sites, generating a total of 3,343,600 ground (nonvegetation) points. Using the total station method, a total of 2,408 points were collected of the gully thalweg, gully bottom edge, gully top edge, and locations of knickpoints and check dams. Note that in some cases, a greater number of LIDAR scan locations were required to capture a smaller overall surface area of terrain. This is because of the complicated topography (that is, nonlinear or steep thalwegs) of some of the sites, which required multiple vantage points to image a comparatively small area. Overall, the point density collected is three orders of magnitude greater for LIDAR than for total station survey (table 3, fig. 13).

The LIDAR-derived thalweg for each gully is presented in both long-profile section and plan view, along with an image of each gully, in figures 14 through 26. The long-profile section and plan view of the thalweg data from the total station data are also shown in the cross sections and serve as the baseline to which the LIDAR data are compared. Whereas the entire LIDAR-derived thalwegs are shown in plan view, they have been normalized with the total station channel head location in the profile views for direct comparison. Mean $(\mu)$ and one standard deviation $(\sigma)$ statistics are included in the cross sections to delineate the vertical comparison between the total station and LIDAR data.

In general, the plan view data (figs. 15, 17, 20, and 24) indicate that the gully locations identified by the LIDAR technique were generally in close proximity $(<10 \mathrm{~cm})$ to that obtained by total station methods. The overall length of extracted gully topography is greater in all cases using the LIDAR dataset because of the inability to conclusively select the channel head or channel bottom from the LIDAR dataset, a point discussed in more detail later in this report. 
Table 3. Survey data summary.

\begin{tabular}{|c|c|c|c|c|c|}
\hline \multirow[b]{2}{*}{ Site number } & \multirow{2}{*}{$\begin{array}{l}\text { Number } \\
\text { of gullies } \\
\text { surveyed }\end{array}$} & \multicolumn{3}{|c|}{$\begin{array}{c}\text { Terrestrial light detection and } \\
\text { ranging (LIDAR) }\end{array}$} & \multirow{2}{*}{$\begin{array}{c}\text { Total station } \\
\begin{array}{c}\text { Number of } \\
\text { ground points } \\
\text { surveyed }\end{array} \\
\end{array}$} \\
\hline & & $\begin{array}{l}\text { Number } \\
\text { of scans }\end{array}$ & $\begin{array}{c}\text { Number of } \\
\text { ground points } \\
\text { surveyed }\end{array}$ & $\begin{array}{l}\text { Modeled } \\
\text { surface } \\
\text { area }\left(\mathrm{m}^{2}\right) \\
\end{array}$ & \\
\hline C:13:006 & 3 & 6 & $1,323,471$ & 7,713 & 953 \\
\hline G:03:041 & 2 & 9 & $1,564,445$ & 3,063 & 656 \\
\hline G:03:072 & 2 & 6 & 455,684 & 1,160 & 799 \\
\hline
\end{tabular}

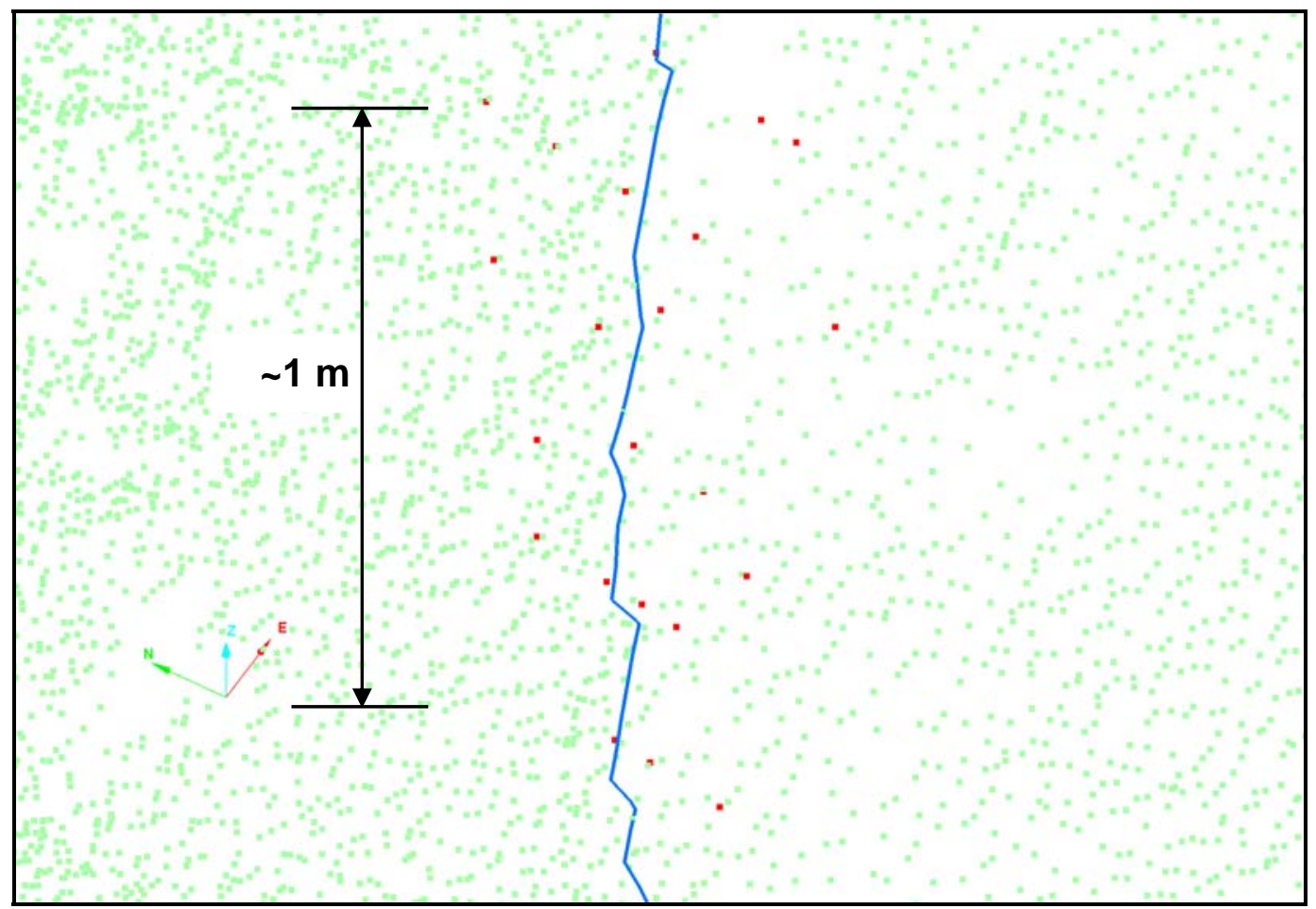

Figure 13. Typical gully plan view showing thalweg (blue line) and relative difference in point density between light detection and ranging (LIDAR) (green points) and total station (red points) survey methods. LIDAR points are spaced approximately $5 \mathrm{~cm}$ from one another and have been down filtered according to LIDAR processing methods. 

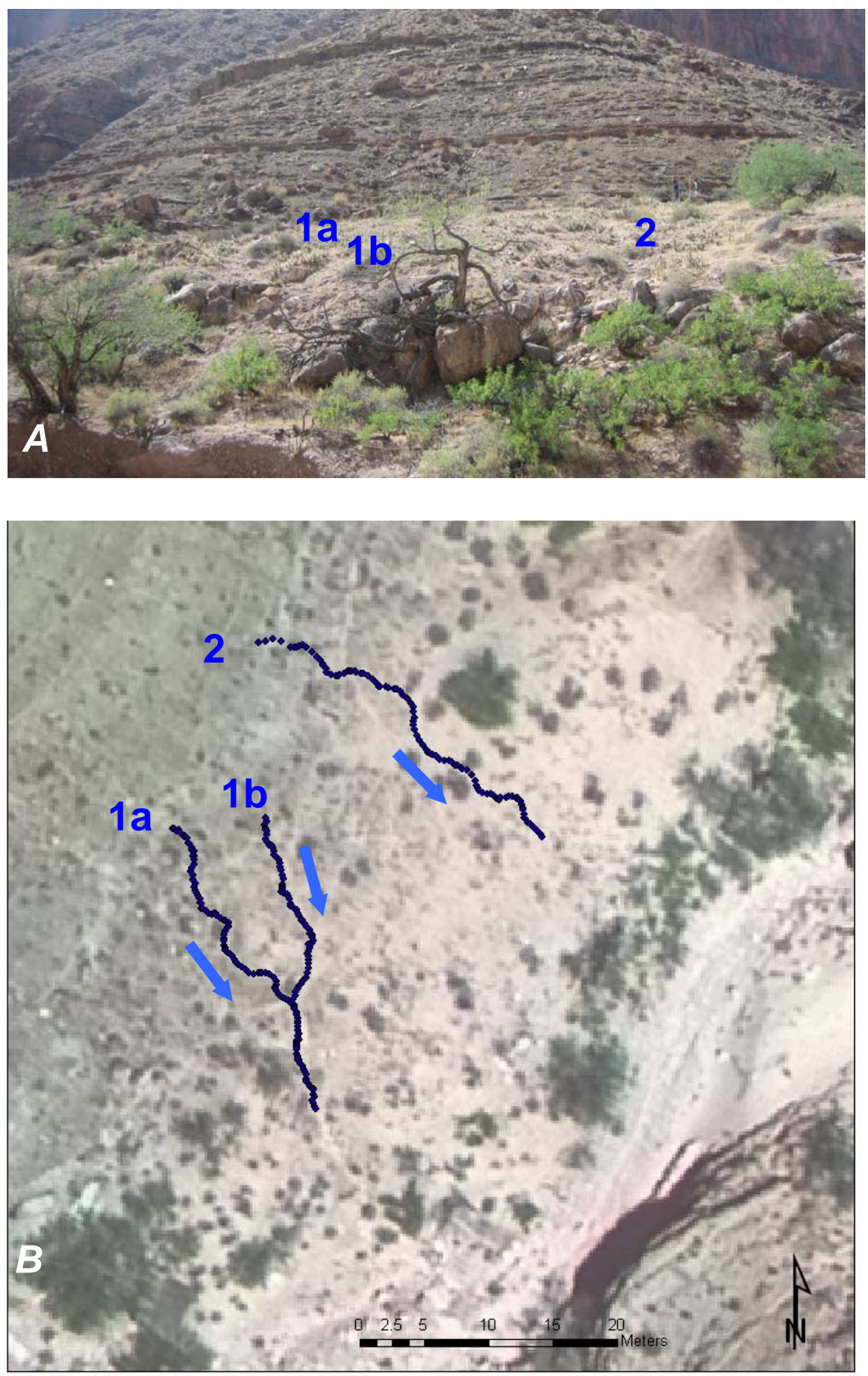

Figure 14. Site C:13:006 - Locations of Gullies $1 \mathrm{a}, 1 \mathrm{~b}$, and 2 in $A$, oblique view; and $B$, plan view. 


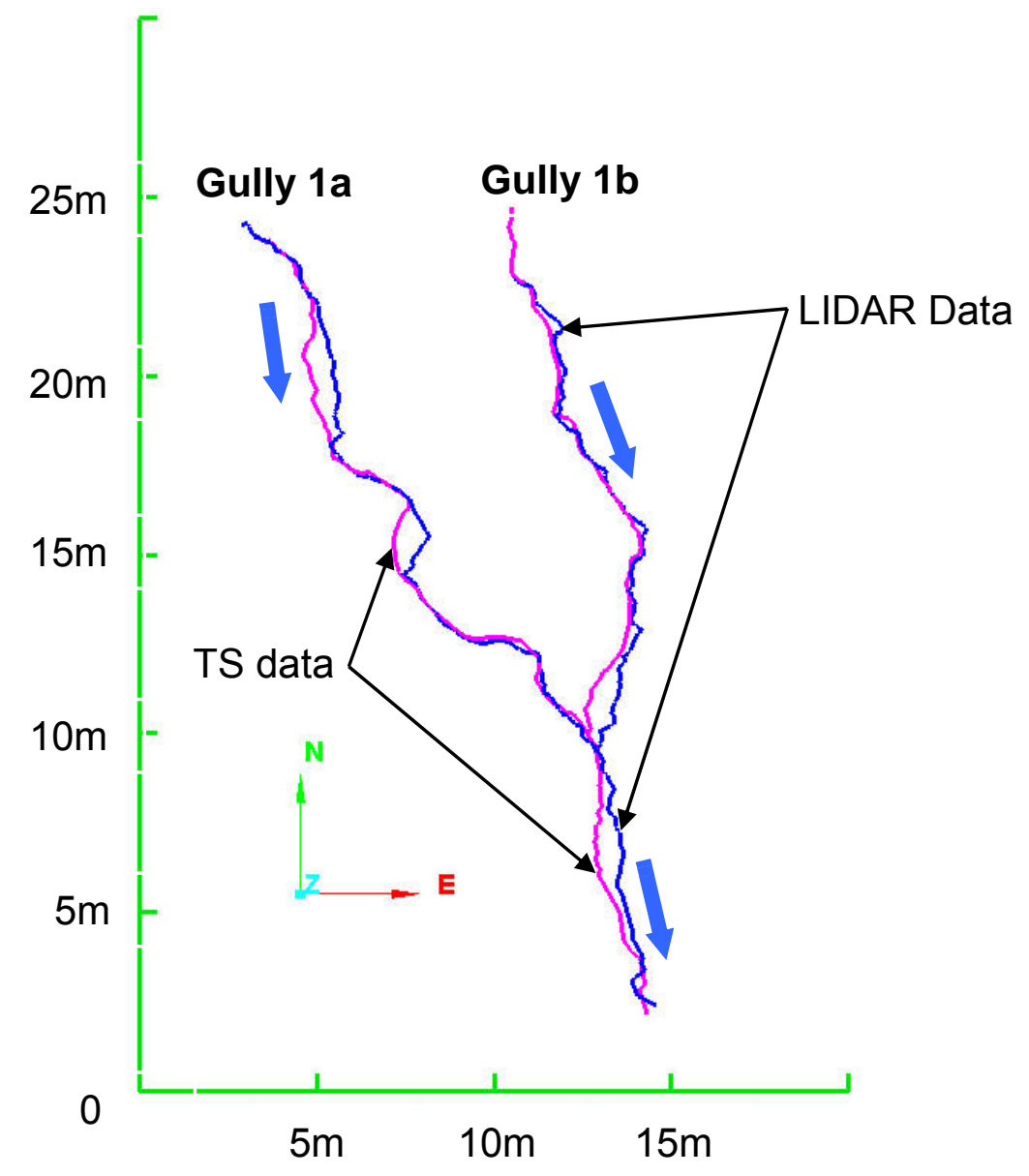

Figure 15. Site C:13:006 - Gullies 1a and 1b: Plan view of light detection and ranging-derived (LIDAR; blue) and total station-derived (TS; purple) thalwegs. 


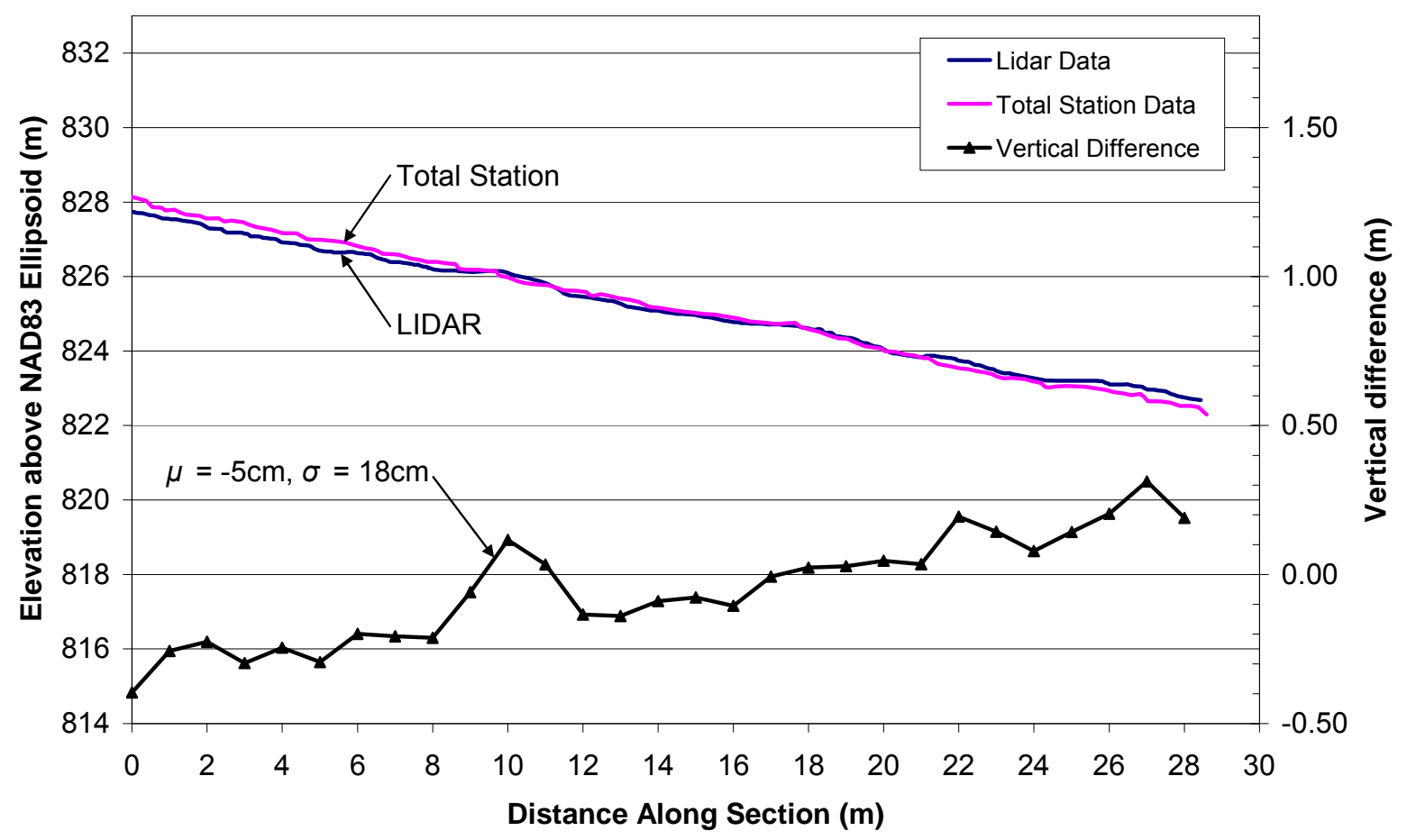

$A$

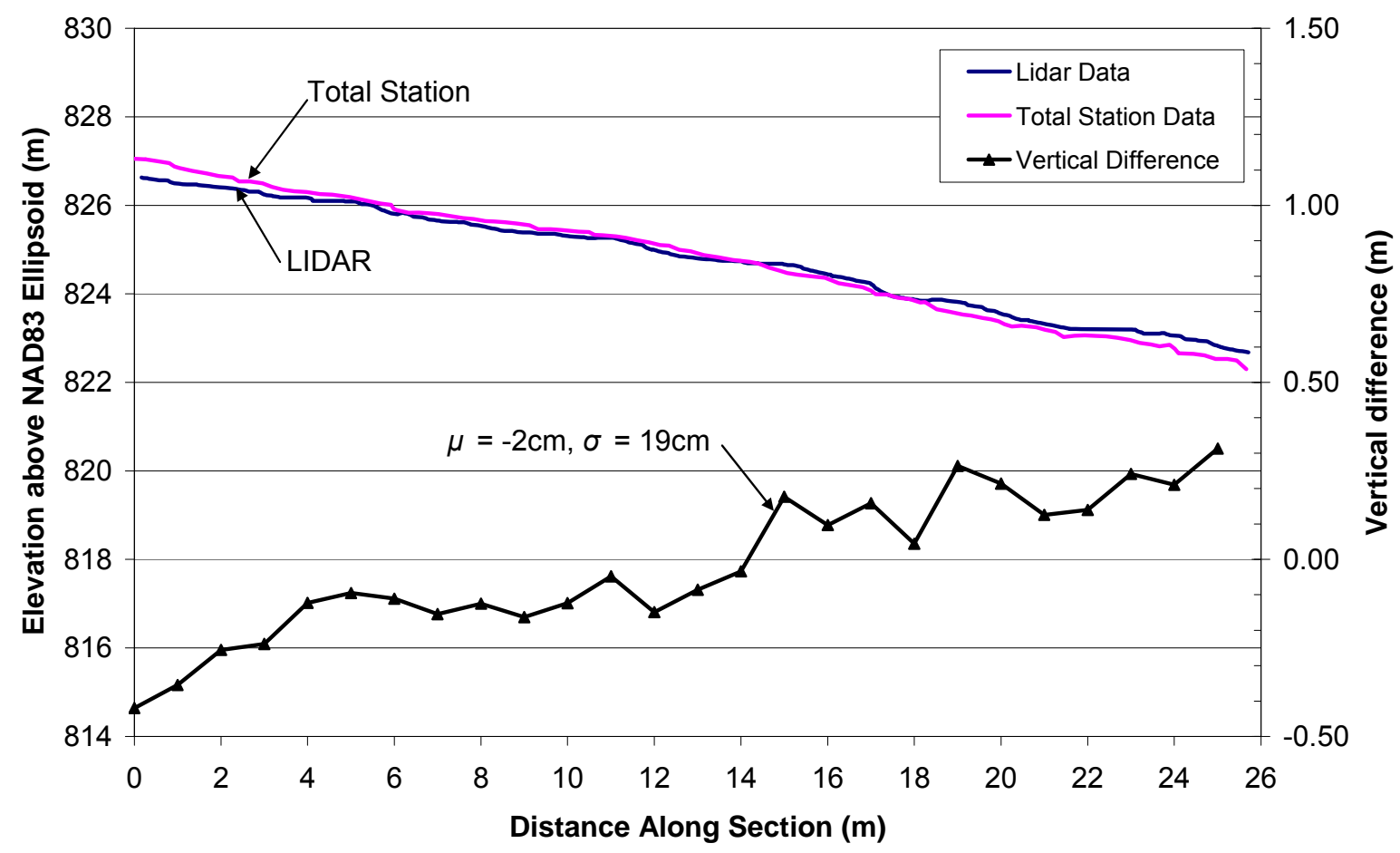

$B$

Figure 16. Site C:13:006 - Long-profile comparison of light detection and ranging (LIDAR) and total station data for $A$, Gully $1 \mathrm{a}$; and $B$, Gully $1 \mathrm{~b}$. 


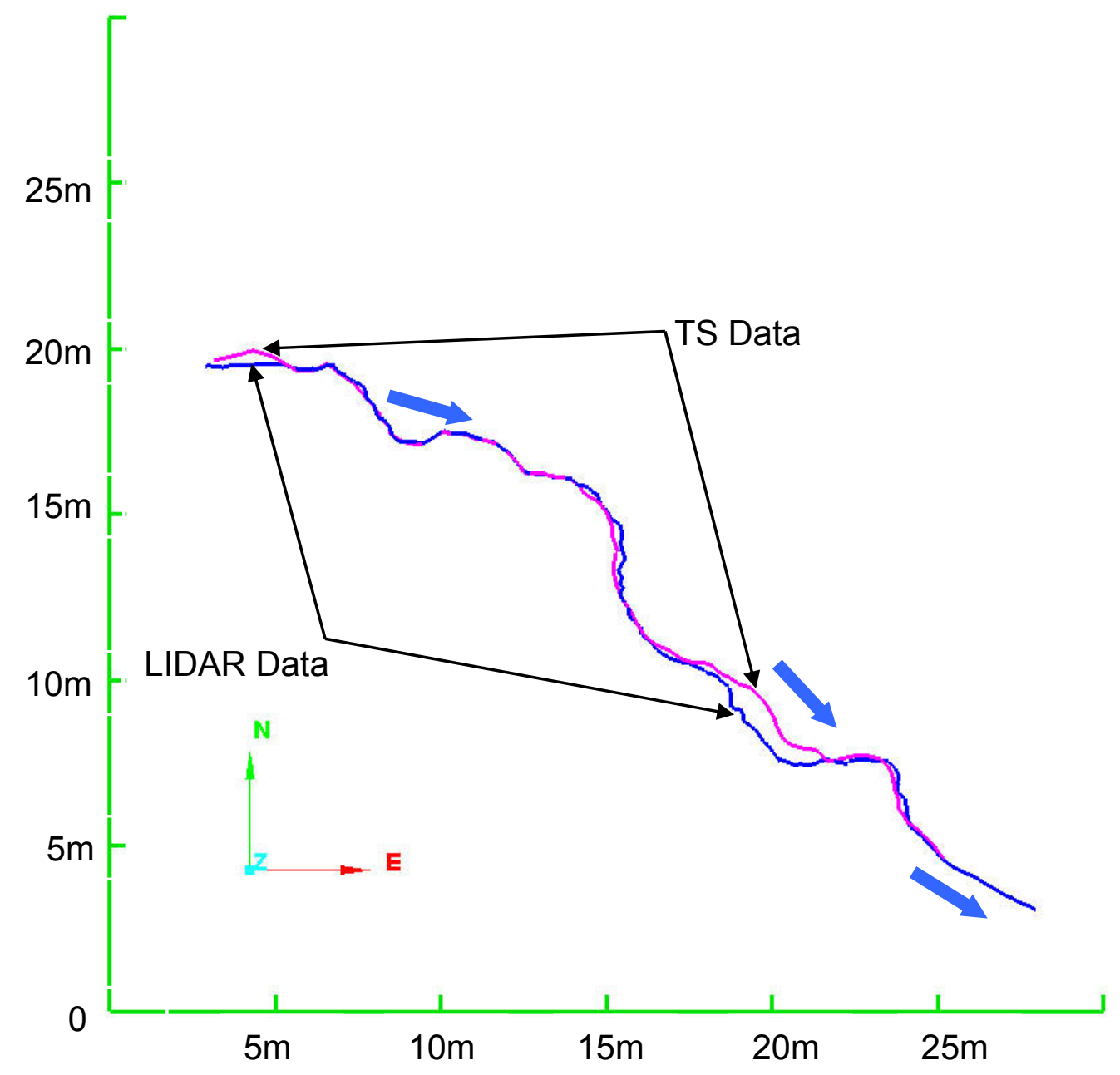

Figure 17. Site C:13:006 — Gully 2: Plan view of light detection and ranging-derived (LIDAR; blue) and total station-derived (TS; purple) thalwegs. 


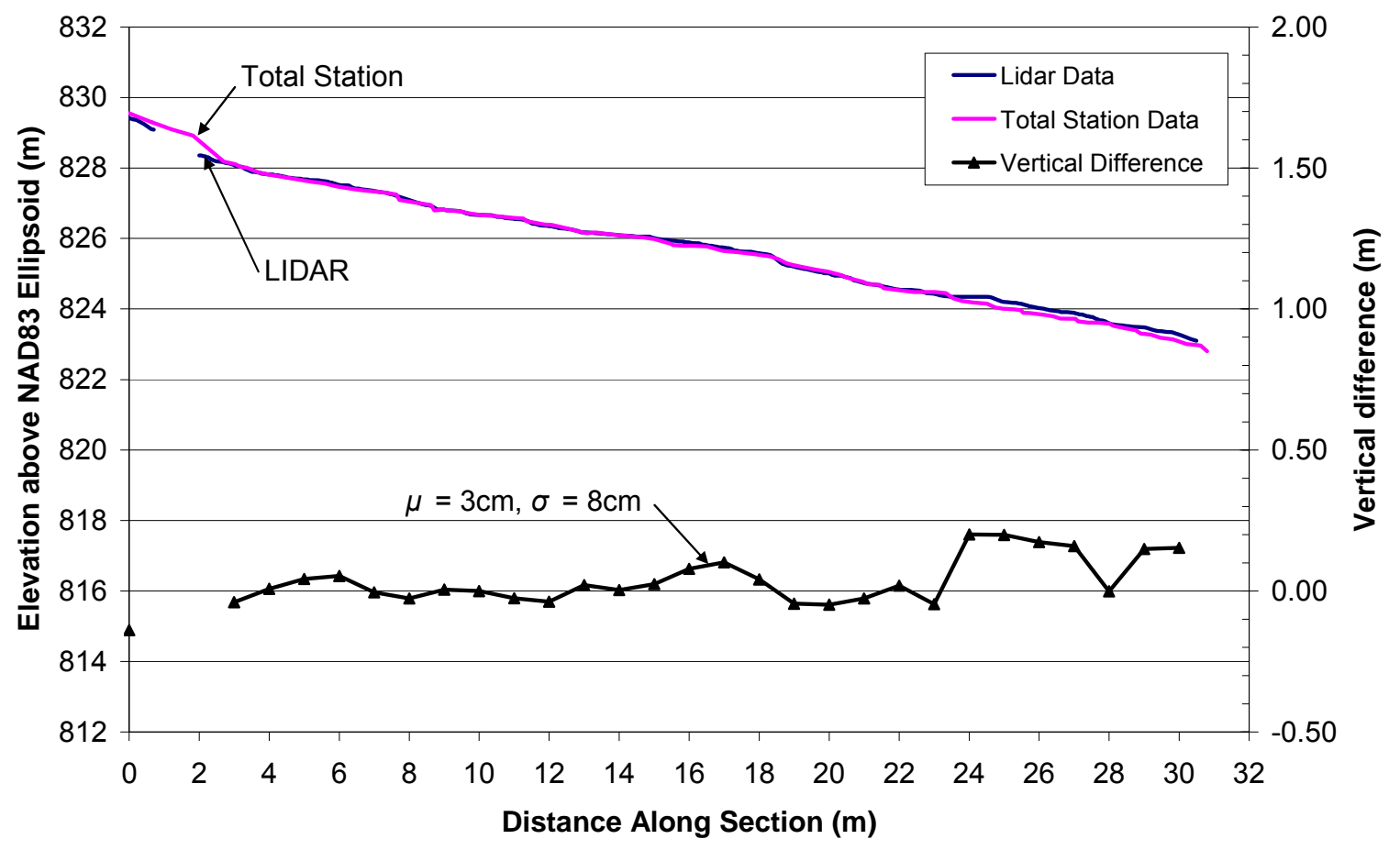

Figure 18. Site C:13:006 - Gully 2: Long-profile comparison of light detection and ranging (LIDAR) and total station data. 

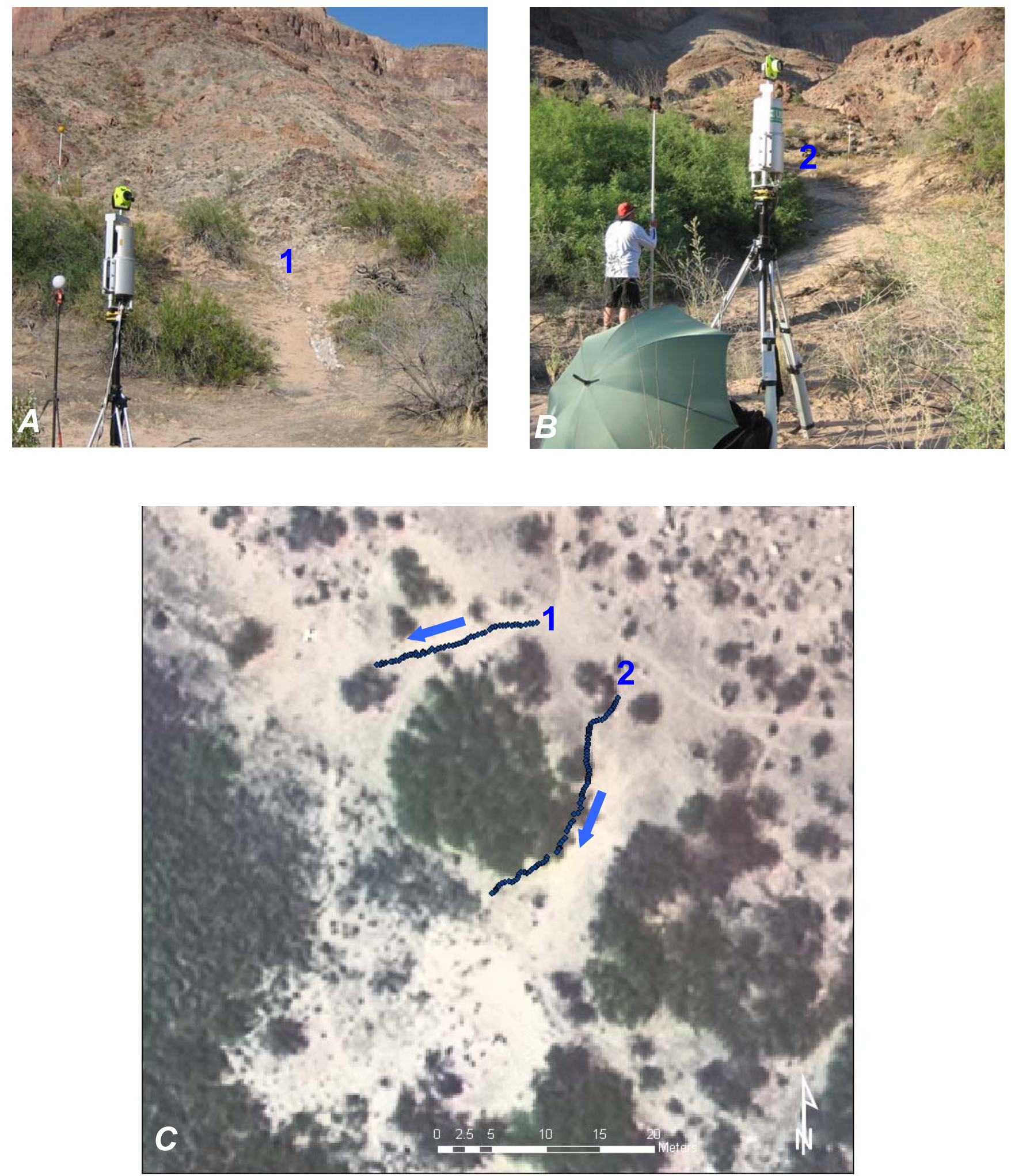

Figure 19. Site G:03:041—Locations of gullies in $A$, oblique view, Gully $1 ; B$, oblique view, Gully 2 ; and $C$, plan view. 


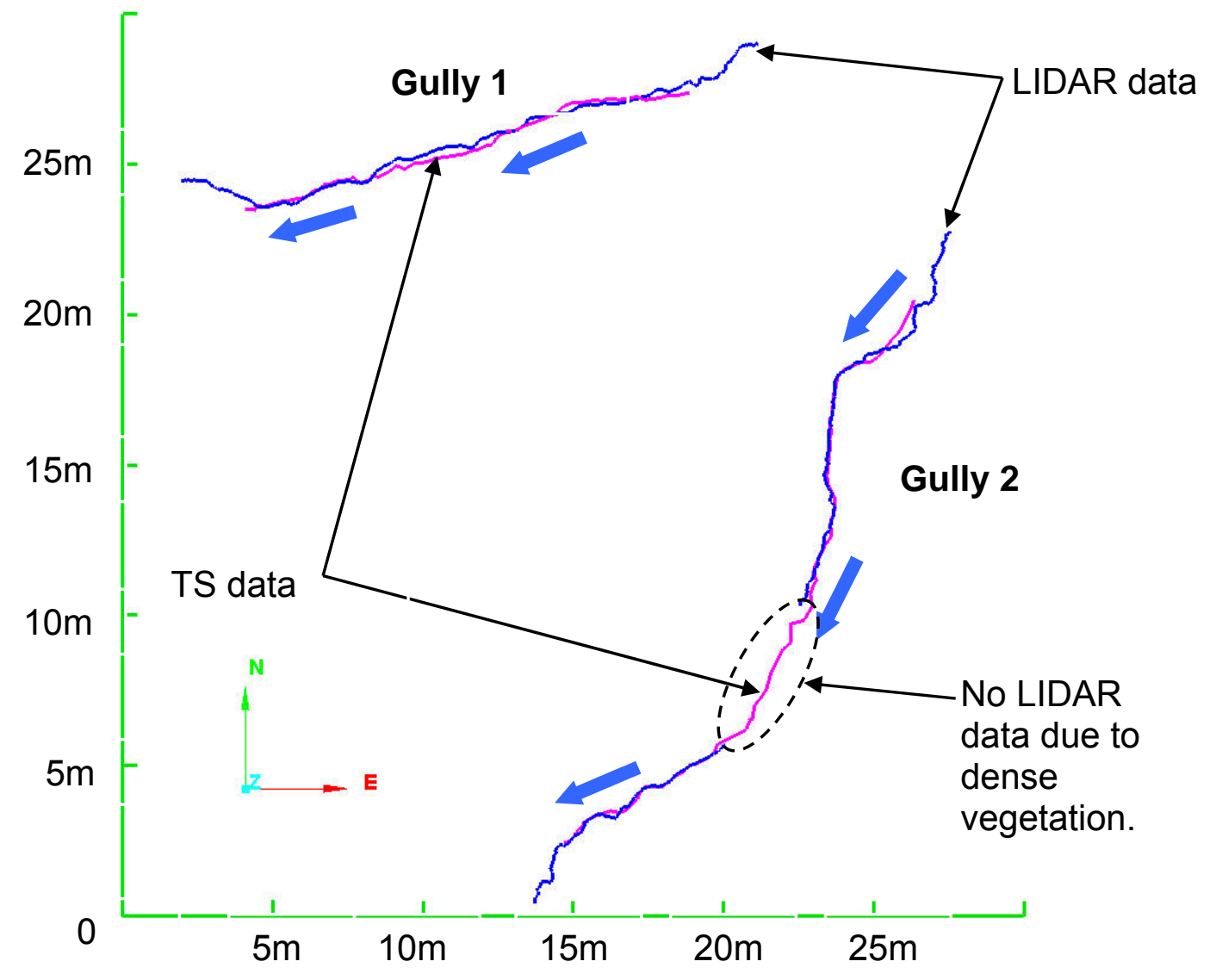

Figure 20. Site G:03:041 — Gullies 1 and 2: Plan view of light detection and ranging-derived (LIDAR; blue) and total station-derived (TS; purple) thalwegs. 


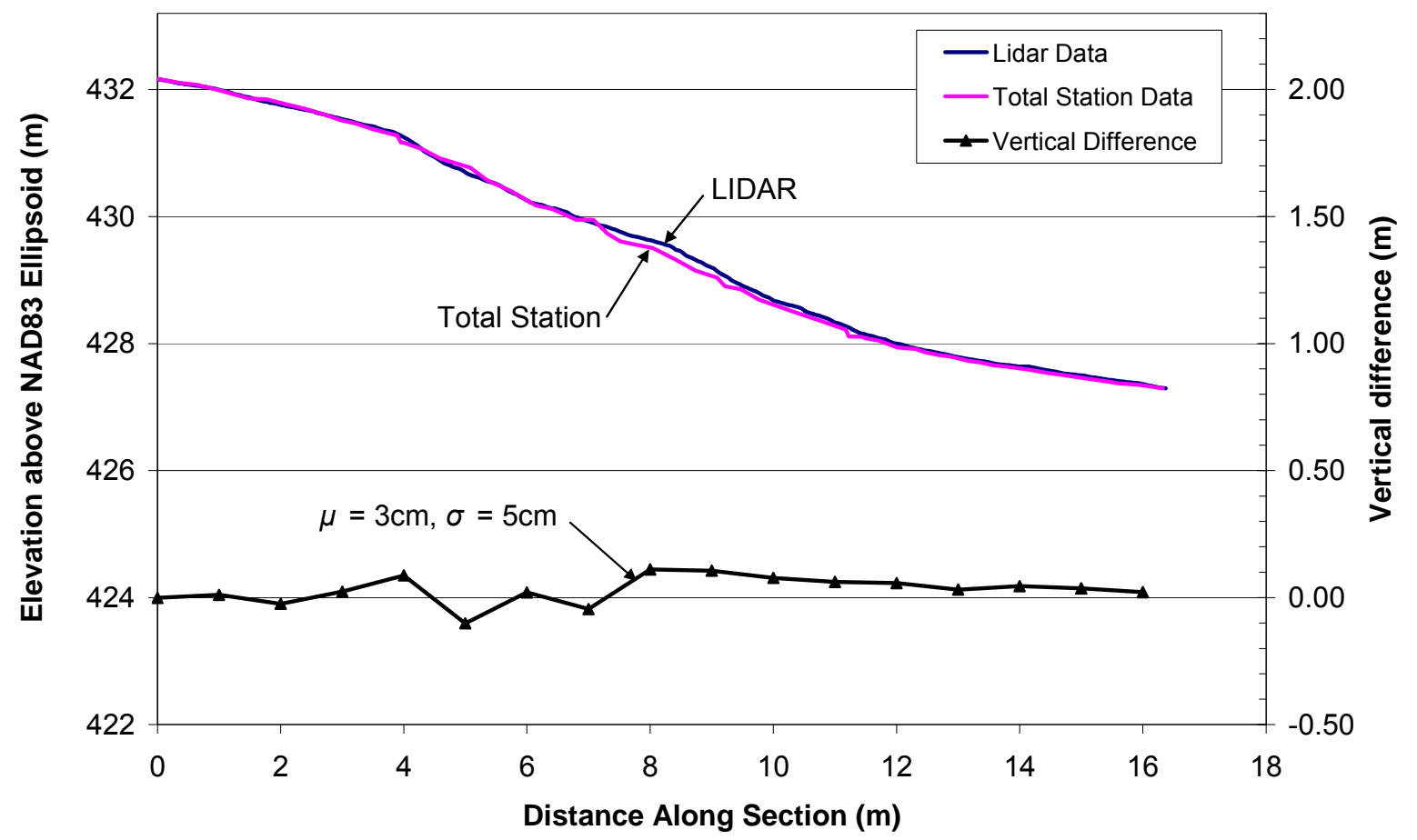

Figure 21. Site G:03:041 — Gully 1: Long-profile comparison of light detection and ranging (LIDAR) and total station data.

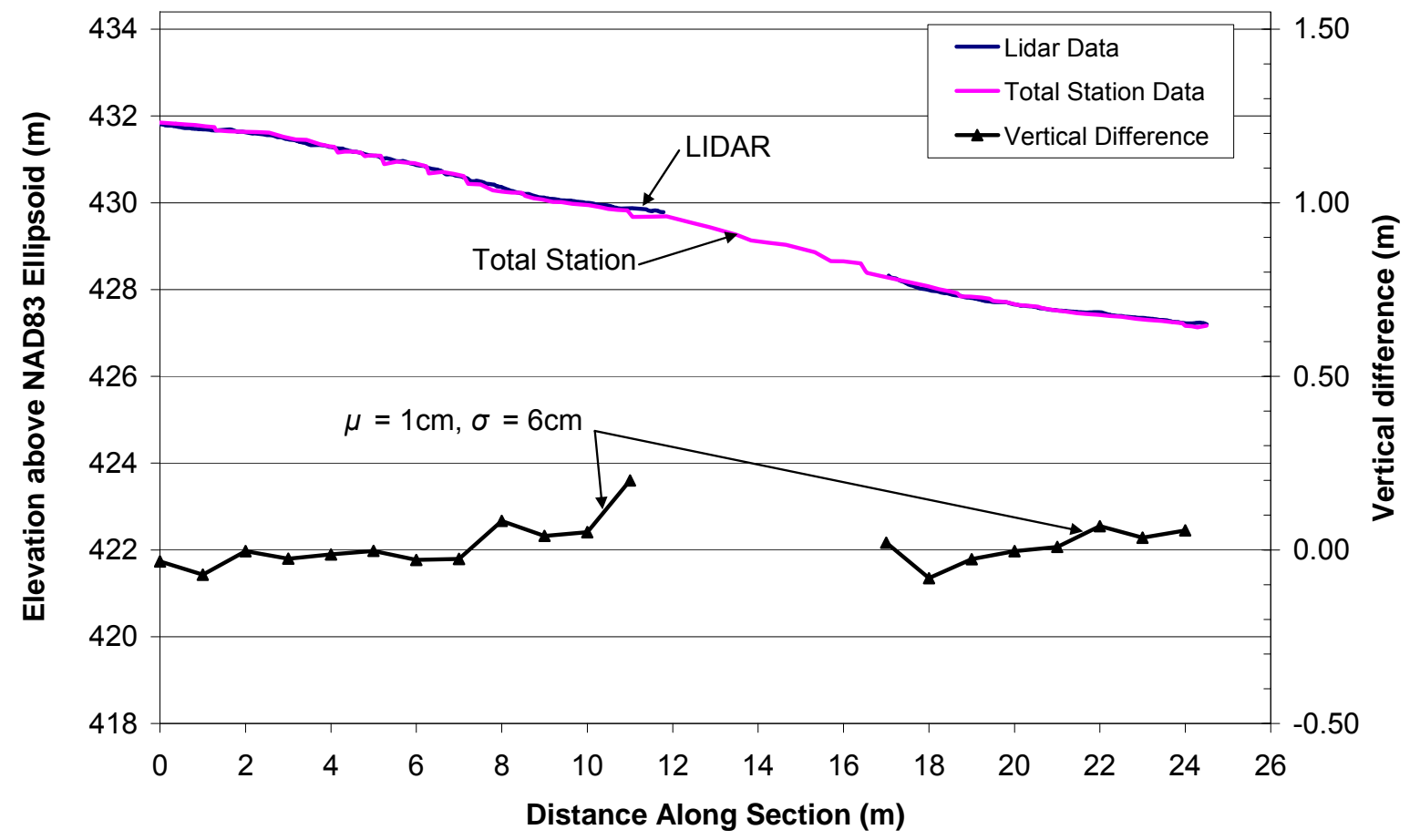

Figure 22. Site G:03:041 — Gully 2: Long-profile comparison of light detection and ranging (LIDAR) and total station data. 

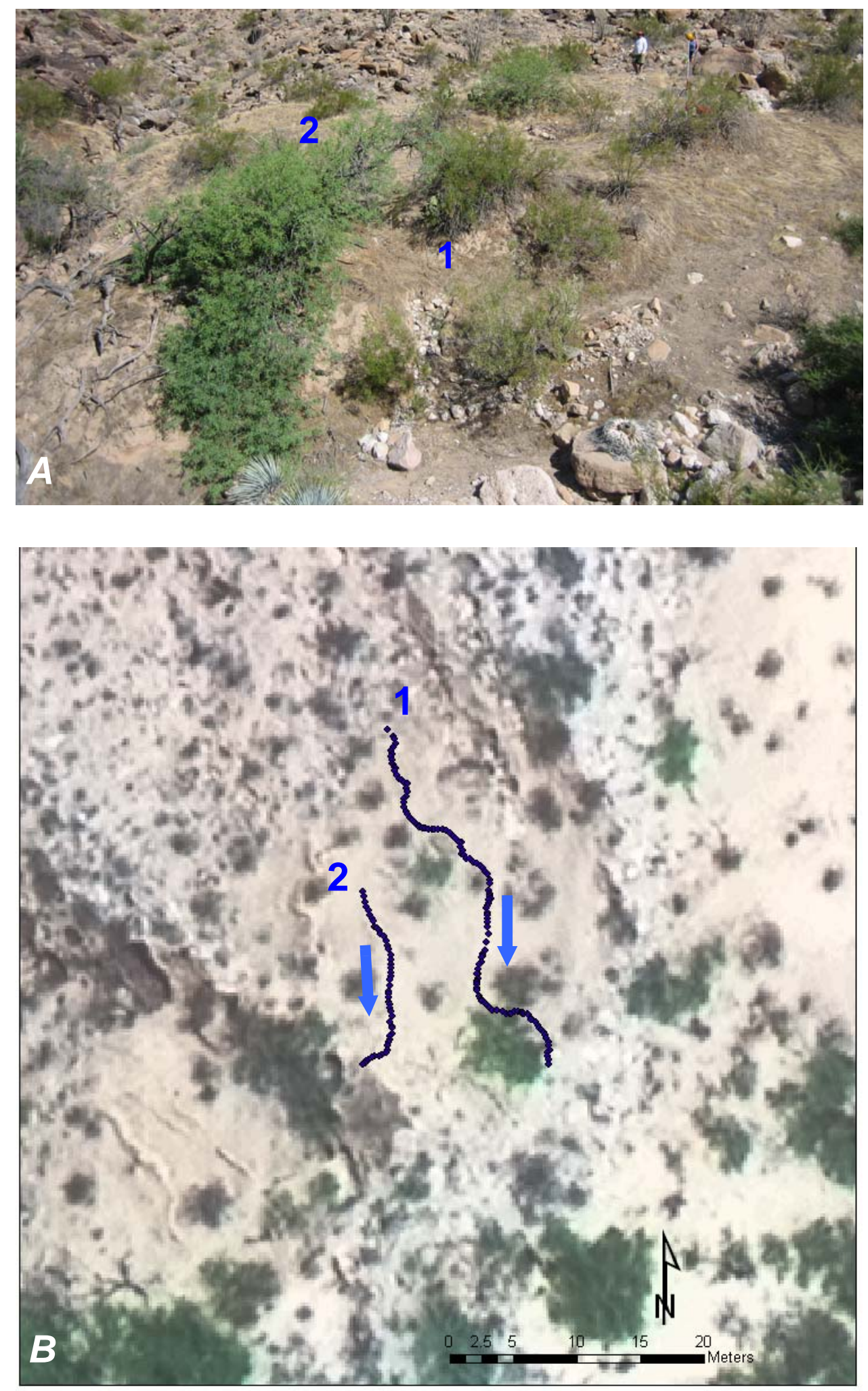

Figure 23. Site G:03:072 - Locations of Gullies 1 and 2 in $A$, oblique view; and $B$, plan view. 


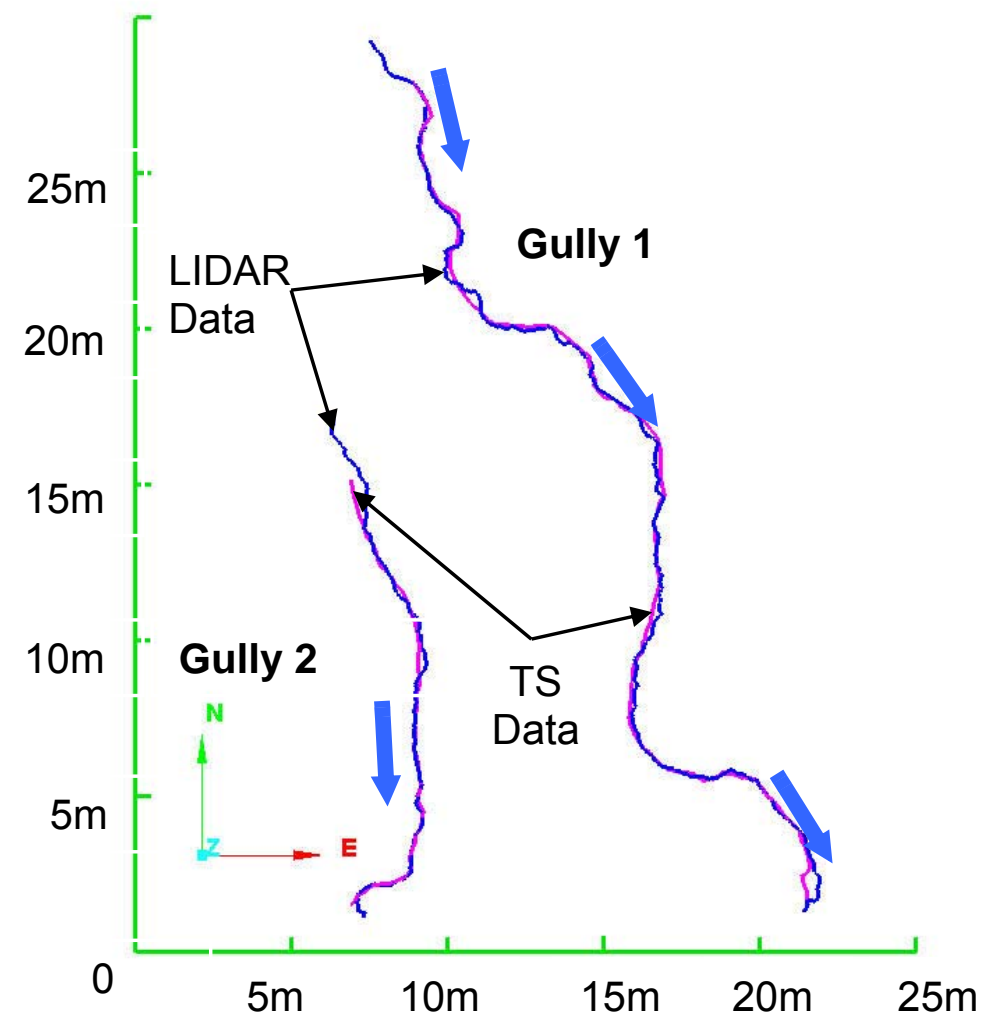

Figure 24. Site G:03:072 — Gullies 1 and 2: Plan view of light detection and ranging-derived (LIDAR; blue) and total station-derived (TS; purple) thalwegs.

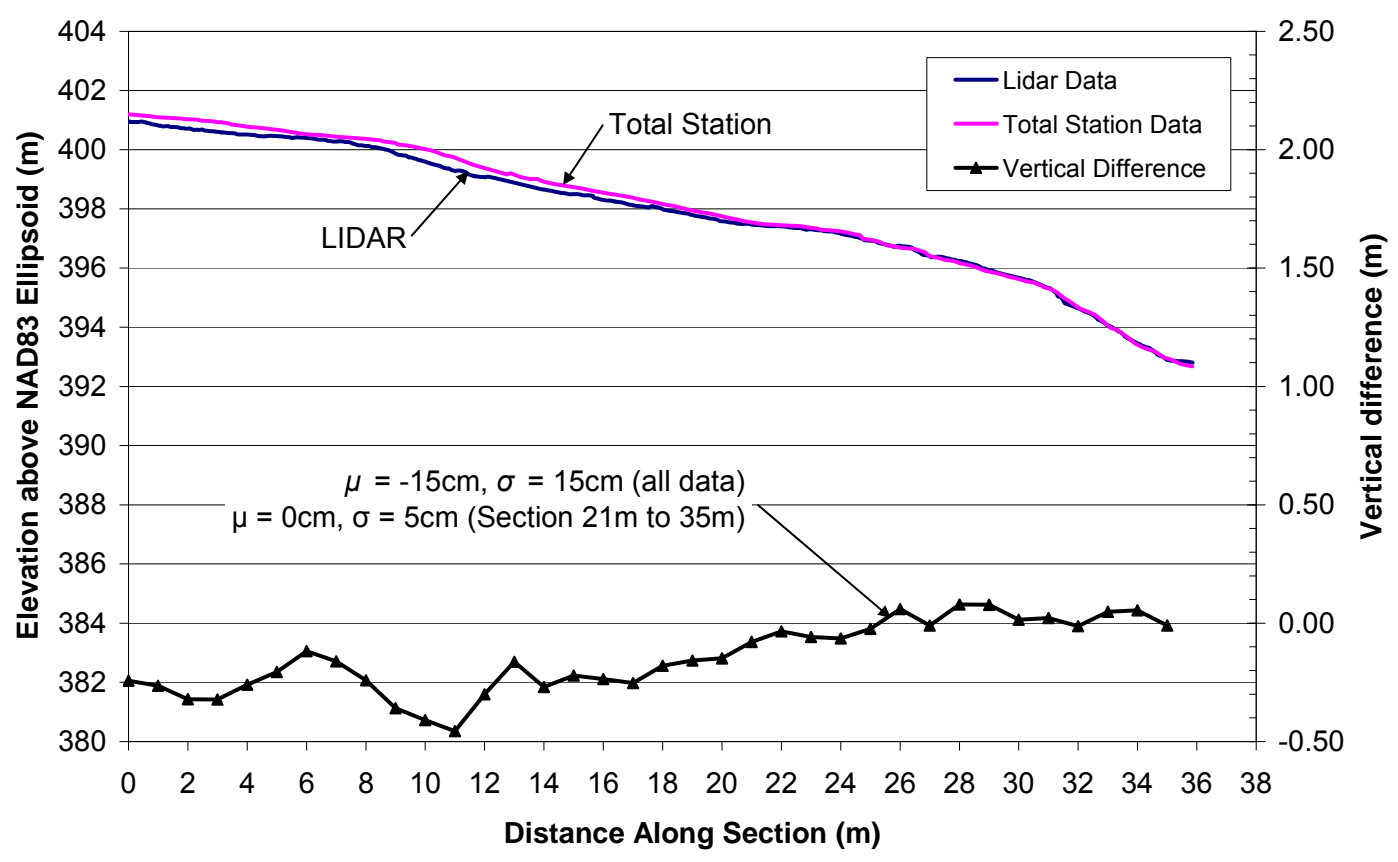

Figure 25. Site G:03:072 — Gully 1: Long-profile comparison of light detection and ranging (LIDAR) and total station data. 


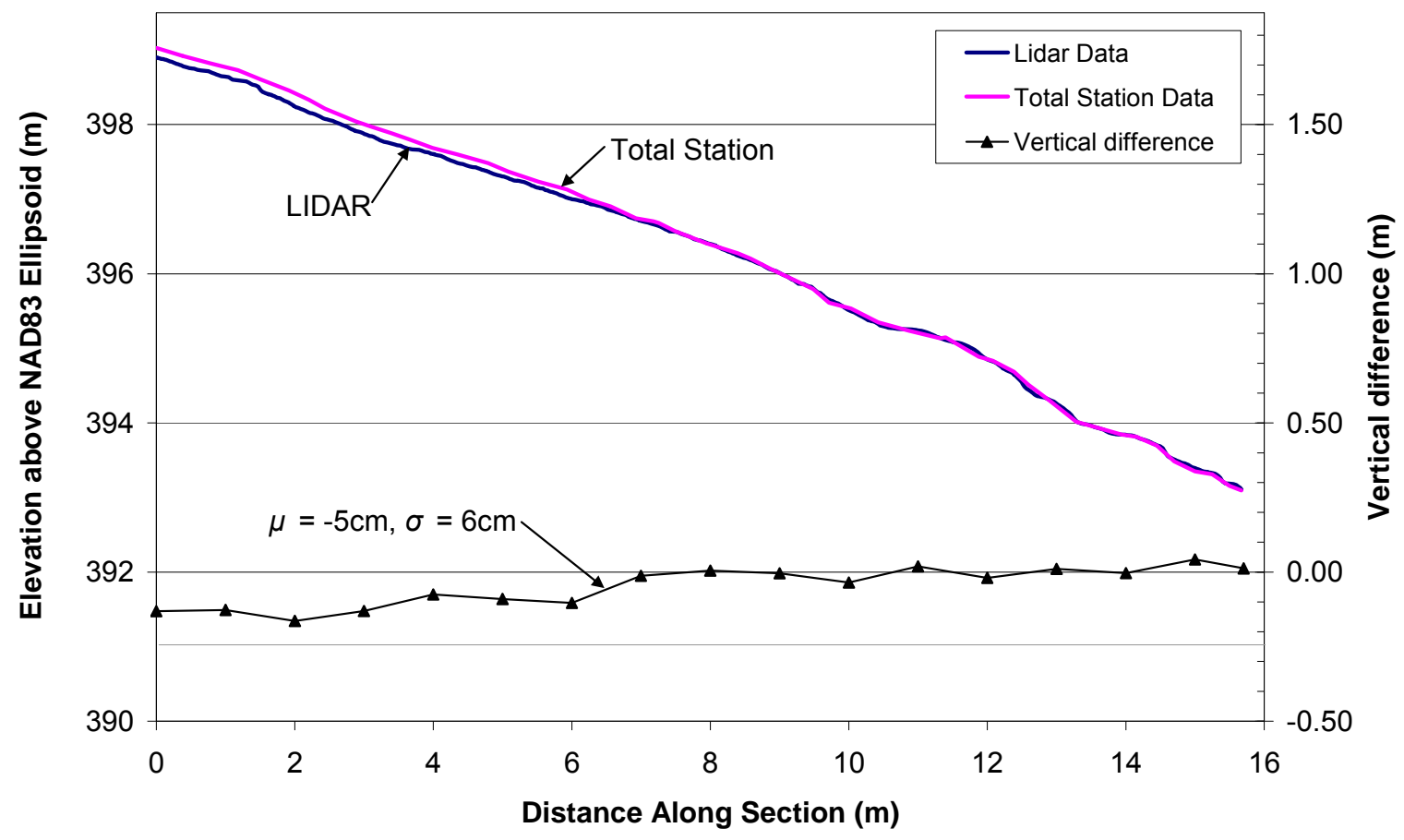

Figure 26. Site G:03:072-Gully 2: Long-profile comparison of light detection and ranging (LIDAR) and total station data.

Whereas errors were often within the methodology limits, error increased to unacceptable ranges $(>10 \mathrm{~cm})$ when the topography was either flat or the gully did not form a distinct pathway through the topography. For example, at Site C:13:006, the plan view comparison shows horizontal errors up to $1 \mathrm{~m}$ in the flatter plateau areas (figs. 15 and 17). Here, the gullies are not very deep and were difficult to distinguish in the LIDAR data. In these cases, the automated water-drop pathway algorithm was not able to distinguish a clear thalweg pathway, and manual contour linking likely introduced greater errors.

The profile view data (figs. 16, 18, 21, 22, 25, and 26) show similar and improved results but with indications of systematic errors as determined by the calculated maximum and minimum differences (table 4). The data show that with the exception of gully 1 at Site G:03:041, all sites had either isolated or integrated errors between 14 and $46 \mathrm{~cm}$ for some portion of each long-profile section. However, taken as a whole, each gully cross section extracted from the LIDAR data was within $10 \mathrm{~cm}$ of the total station data throughout most of the length of the profiles. Mean $(\zeta)$ and standard deviation $(\oint$ ) values calculated along $1-\mathrm{m}$ sections for all extracted thalweg cross sections are summarized in table 4. The total percent length of the thalweg surveyed accurately within a $\pm 10 \mathrm{~cm}$ error bound ranged from 23 percent in the worst case (C:13:006-Gully 1b) to 95 percent in the best case (G:03:041-Gully 2). However, overall, only 56 percent of the total thalweg lengths were within these error bounds. Confidence intervals cannot be calculated from the standard deviation data because of the unlikelihood that the errors are normally distributed; errors appear systematic with regard to their location within a particular gully. Errors propagated beyond acceptable ranges $(>10 \mathrm{~cm})$ in areas of flat topography (for example, Site G:03:072; compare the upstream (flat) and downstream (steep) sections of figs. 25 and 26) and where no clearly defined gully bottom could be distinguished in the LIDAR data (for example, Site C:13:006; fig. 16). Meanwhile, at Site G:03:072-Gully 2 (fig. 25), the mean error drops from -15 $\mathrm{cm}$ to zero when only the steep data (Station 21 to $36 \mathrm{~m}$ ) is compared. 
Table 4. Statistical comparison of gully thalweg profiles between light detection and ranging (LIDAR) and total station data.

\begin{tabular}{lccccc}
\hline Site name & $\begin{array}{c}\text { Mean, } \mu \\
(\mathrm{cm})\end{array}$ & $\begin{array}{c}\text { Standard } \\
\text { deviation, } \sigma \\
(\mathrm{cm})\end{array}$ & $\begin{array}{c}\text { Maximum } \\
(\mathrm{cm})\end{array}$ & $\begin{array}{c}\text { Minimum } \\
(\mathrm{cm})\end{array}$ & $\begin{array}{c}\text { Percent gully } \\
\text { length within } \\
\pm 10 \text { cm error } \\
\text { bound }\end{array}$ \\
\hline C:13:006-Gully 1a & -5 & 18 & 31 & -40 & 35 \\
C:13:006-Gully 1b & -2 & 19 & 31 & -42 & 23 \\
C:13:006-Gully 2 & 3 & 8 & 20 & -14 & 72 \\
G:03:041-Gully 1 & 3 & 5 & 11 & -10 & 82 \\
G:03:041-Gully 2 & 1 & 6 & 20 & -18 & 95 \\
G:03:072 DS-Gully 1 & -15 & 15 & 8 & -46 & 42 \\
G:03:072 DS-Gully 2 & -5 & 6 & 4 & -16 & 71 \\
\hline All gully data & -4 & 15 & 31 & -46 & 56 \\
\hline
\end{tabular}

*Mean and standard deviation for Station 21 to $36 \mathrm{~m}$ (steeper section) are 0 and $5 \mathrm{~cm}$, respectively.

A limitation of the LIDAR methodology is shown clearly in figure 20, which identifies an area of the gully where the thalweg location could not be obtained from the LIDAR data because of dense vegetation (fig. 19B). Here, the total station method has an advantage, since it is possible for survey personnel to set the survey prism rod through the vegetation to identify the gully thalweg ground point. The LIDAR technique is also limited in its ability to discern the location of knickpoints and check dam features (shown, for example, in fig. 22 between stations 4 and 8 in the total station data), which are not always obvious in the LIDAR cross sections. Because the LIDAR method does not identify or name particular features during the data collection process ("feature coding"), these must be extracted during the postprocessing stage by comparison with site photographs or a previously collected total station dataset. This limitation is also discussed in more detail later in this report.

\section{Impact Evaluation}

The data from the impact evaluation on all eight sites are shown in appendix B and plotted in figures 27 and 28, where values for total survey time, time in sensitive area, and footstep count are detailed by site name and survey method for the two field excursions in May 2006 and May 2007. The cumulative mapping times for each survey method and field effort and the average cumulative mapping time for each method were also calculated (fig. 29). Note that one site was not monitored by total station methods in 2007 (site C:13:099); the average cumulative mapping time should therefore be used for direct comparison between the two survey methods. The data are used to make gross quantitative evaluations of the direct (footstep count) and indirect (hours in sensitive area) impacts to each archeological site. In addition, the total person-hours value provides an indication of the efficiency of each method (that is, less total survey time means greater efficiency). 

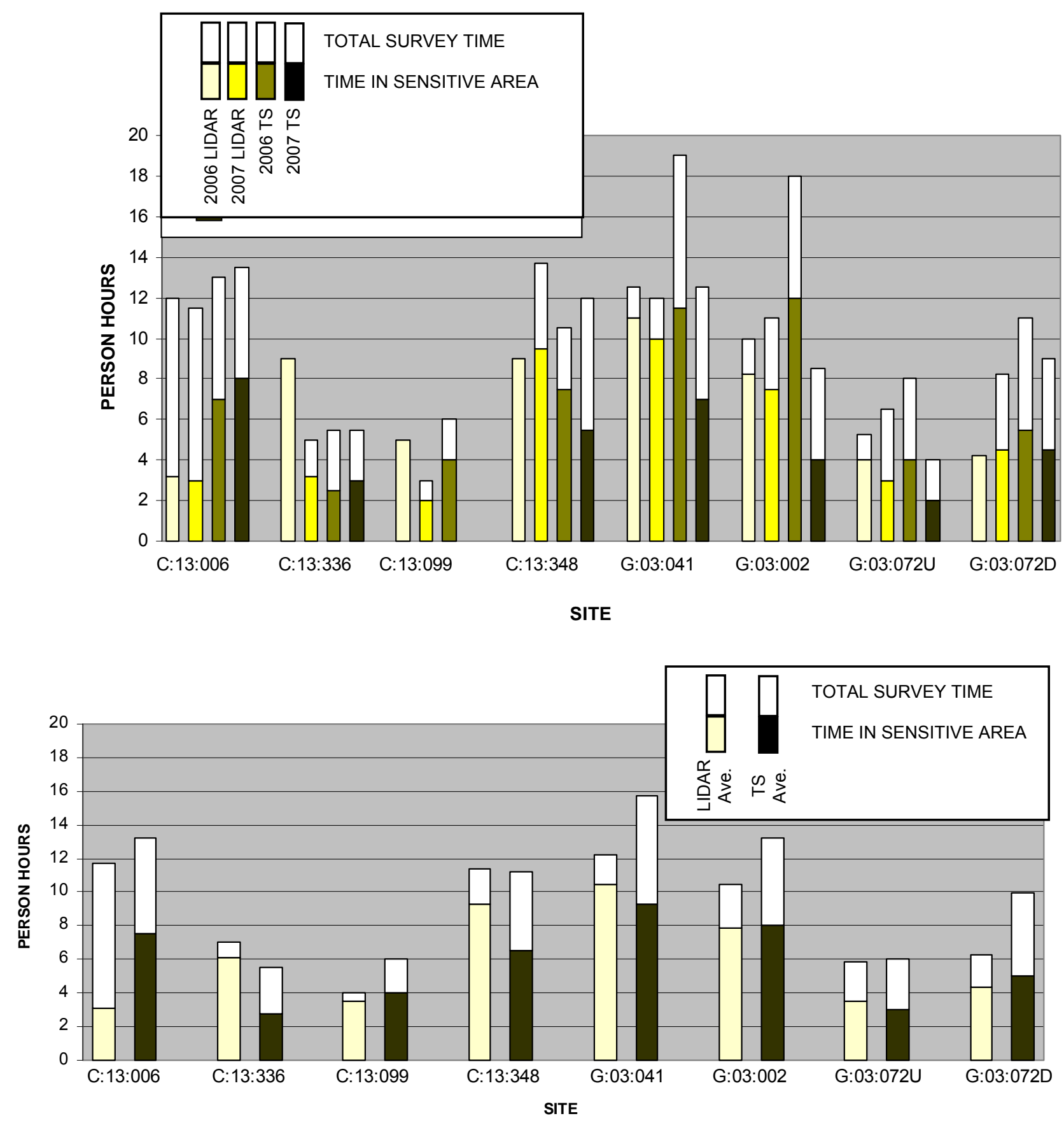

Figure 27. Comparison of total survey time and time in sensitive area for terrestrial light detection and ranging (LIDAR) and total station (TS) methods plotted for each site and data collection effort (upper graph) and averaged for both surveys (2006 and 2007) (lower graph). The shaded portion of the bar graphs represents time in the sensitive area of the site, while the open portion is the additional time required to complete the mapping effort outside the sensitive area of the site. Note: site C:13:099 was not surveyed by total station surveying in 2007. 

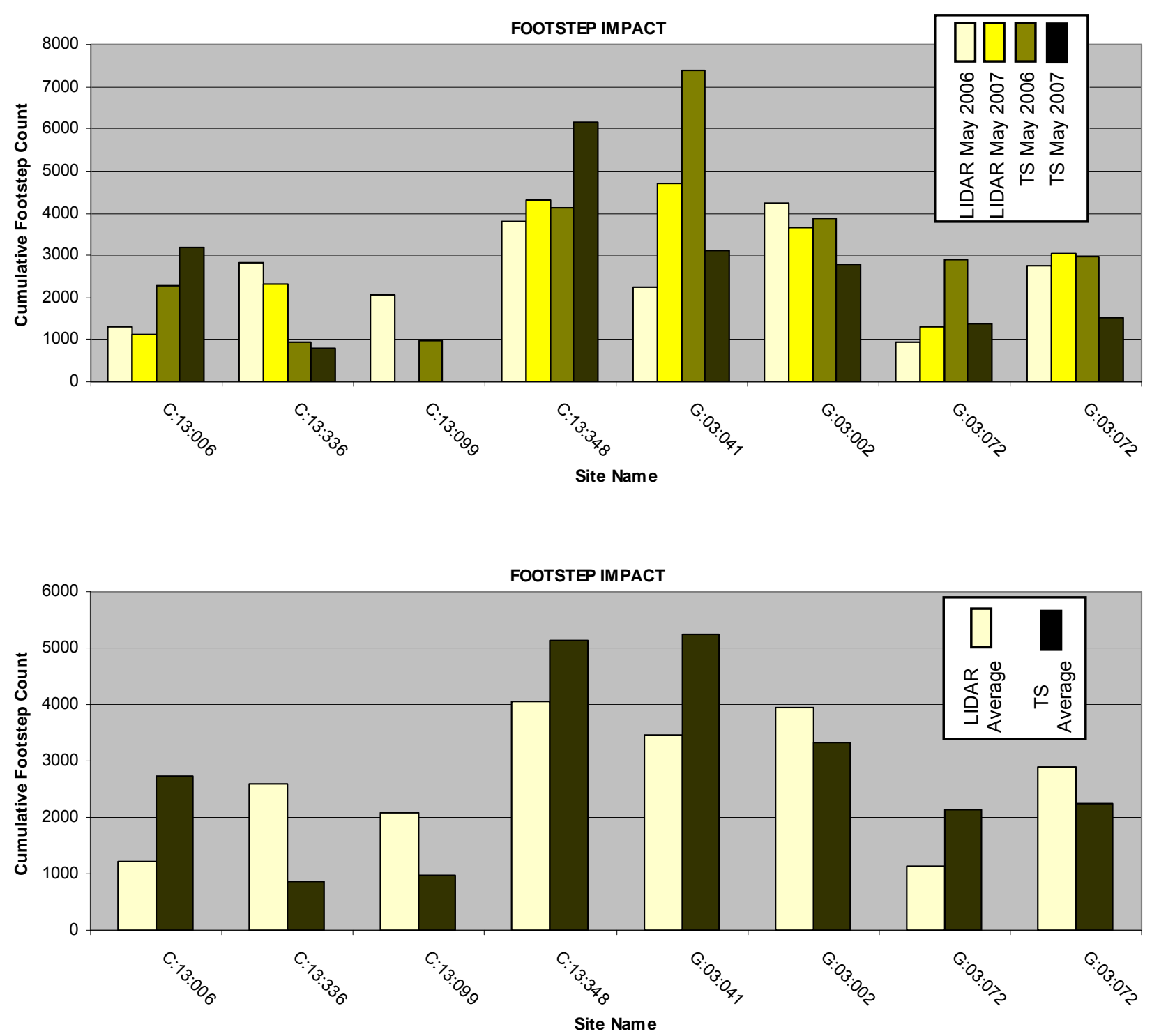

Figure 28. Comparison of footstep count for terrestrial light detection and ranging (LIDAR) and total station (TS) methods plotted for each site and data collection effort (upper graph) and averaged for both surveys (2006 and 2007) (lower graph). Note: site C:13:099 was not surveyed by total station surveying in 2007 and the LIDAR footstep count was not measured. 


\section{CUMULATIVE MAPPING TIMES}

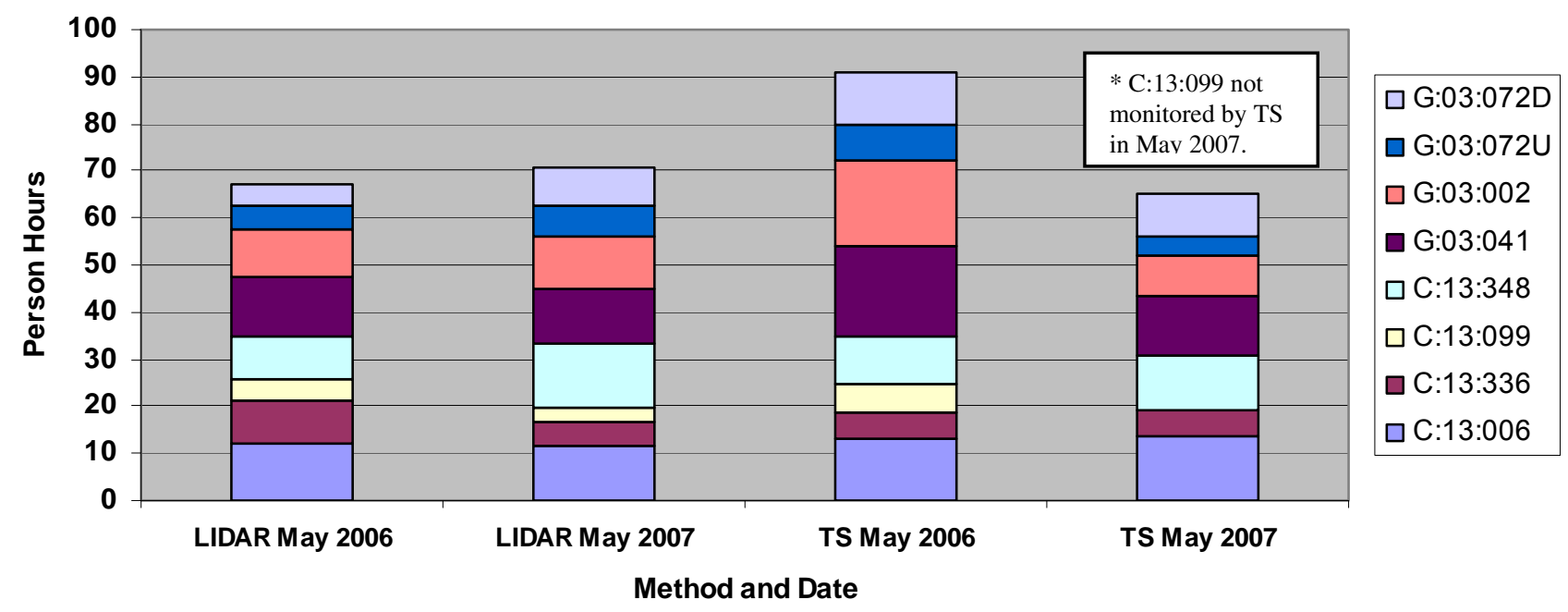

CUMULATIVE AVERAGE MAPPING TIMES

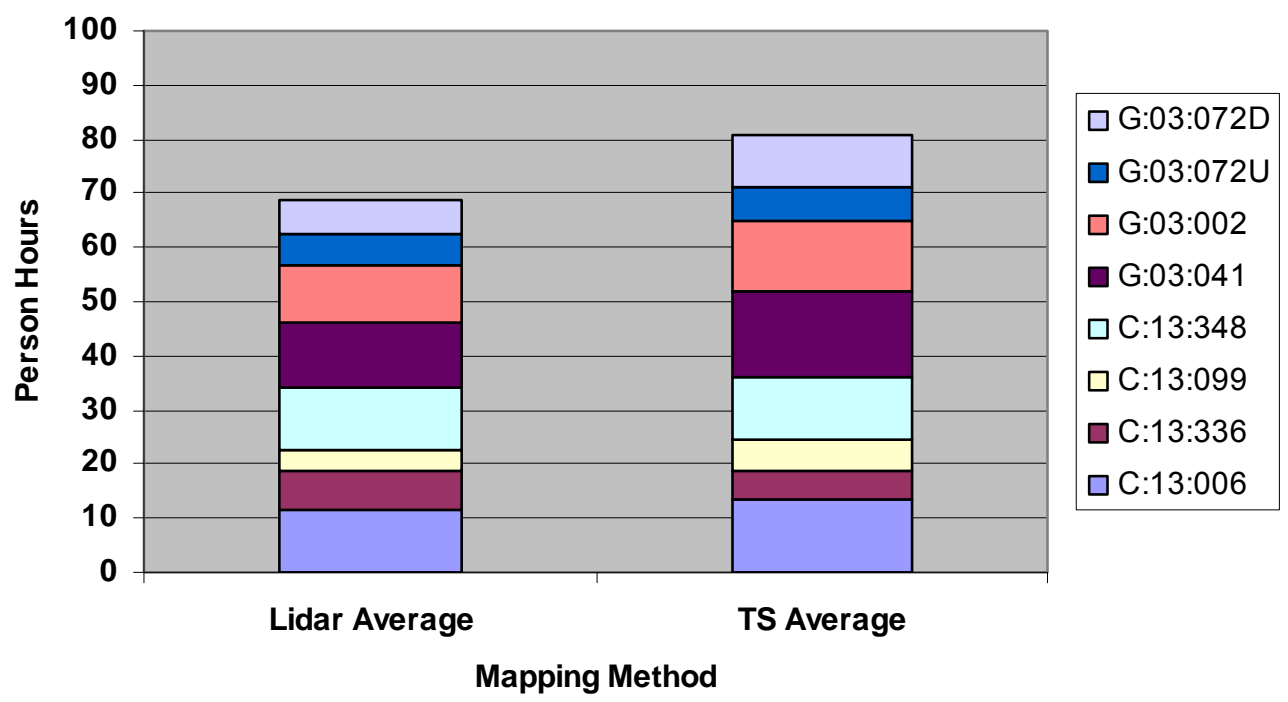

Figure 29. Comparison of cumulative total survey time for terrestrial light detection and ranging (LIDAR) and total station (TS) methods plotted for each site and for each data collection effort (upper graph) and averaged for both surveys (2006 and 2007) (lower graph). Sites are ordered from top to bottom as indicated in the legend. 
Figures 27 and 28 show notable variation between mapping methods (LIDAR versus total station) as well as variation within each type of mapping method from 2006 to 2007. The magnitude of the time and footstep values between sites also varies; this variation is a result of the number and complexity of the gully systems that were mapped. In general, total field survey time was higher by approximately 15 percent for total station surveys (fig. 29, lower), while time in sensitive area and footstep counts were similar ( \pm 8 percent) for both methods. Because this cursory explanation of the results masks several attributes not immediately visible in the graphs, the A and B variation parameters set forth in equations 1 and 2 are used for additional analysis of the data. Results from these calculations are presented in appendix $\mathrm{C} 1$ for the variation within each mapping method (A-parameters) and in appendix C2 for variation between mapping methods (B-parameters). Range and overall averages for both sets of parameters are summarized in table 5 and discussed separately in the following sections.

\section{Variations within Survey Methods (Consistency Check—Parameters A1, A2, A3)}

In general, total survey time for both methods was consistent between survey efforts. Although the difference in the total survey time for LIDAR and total station data collection (parameter A1, table 5 ) at each site varied by $8.7 \mathrm{~h}$ and $11 \mathrm{~h}$, respectively, the average difference in data collection times per site from 2006 to 2007 were near zero ( $-0.5 \mathrm{~h}$ for LIDAR and $2.9 \mathrm{~h}$ for total station). The decrease in survey time for total station cannot be attributed to any one factor, but increased familiarity with the sites probably accounts for at least some of this difference.

The difference in the time in the sensitive area from 2006 to 2007 at each site (parameter A2, table 5) varied by $6.3 \mathrm{~h}$ for LIDAR data collection and by $9 \mathrm{~h}$ for total station surveying. The average difference for time in the sensitive area for both mapping methods shows a decrease in hours spent in the sensitive area in 2007 and likely reflects increased familiarity with each study site.

The difference in footstep impact from 2006 to 2007 (parameter A3, table 5) varied by about 4,500 footsteps for LIDAR data collection and by about 6,300 footsteps for total station surveying. The average difference in footstep impact shows that LIDAR surveying has more consistent footstep impact values and that the efficiency of total station surveying increased in 2007. Results indicate consistency within each survey method with slight increases in efficiency between survey efforts. 
Table 5. Summary of variation of impact evaluation results between terrestrial light detection and ranging (LIDAR) and total station surveying.

\begin{tabular}{|c|c|c|c|c|c|}
\hline \multicolumn{6}{|c|}{ Total survey time within each mapping method } \\
\hline Parameter & Method & Minimum & Maximum & Average & $\begin{array}{c}\text { Range } \\
\text { Difference }\end{array}$ \\
\hline A1 & LIDAR & -4.7 & 4 & -0.5 & 8.7 \\
\hline A1 & Total station & -1.5 & 9.5 & 2.9 & 11.0 \\
\hline \multicolumn{6}{|c|}{ Total survey time between LIDAR and total station for each date } \\
\hline Parameter & Date & Minimum & Maximum & \multicolumn{2}{|c|}{ Average } \\
\hline B1 & 2006 & -3.5 & 8 & \multicolumn{2}{|c|}{3.0} \\
\hline B1 & 2007 & -2.5 & 2 & \multicolumn{2}{|c|}{-0.4} \\
\hline \multicolumn{6}{|c|}{ Time in sensitive area within each mapping method } \\
\hline \multirow[t]{2}{*}{ Parameter } & Method & Minimum & Maximum & Average & $\begin{array}{c}\text { Range } \\
\text { Difference }\end{array}$ \\
\hline & Method & Min & Max & Ave & $\begin{array}{l}\text { Range } \\
\text { Diff. }\end{array}$ \\
\hline A2 & LIDAR & -0.5 & 5.8 & 1.4 & 6.3 \\
\hline $\mathrm{A} 2$ & Total station & -1 & 8 & 2.3 & 9.0 \\
\hline \multicolumn{6}{|c|}{ Time in sensitive area between LIDAR and total station for each date } \\
\hline Parameter & Date & Minimum & Maximum & \multicolumn{2}{|c|}{ Average } \\
\hline B2 & 2006 & -6.5 & 3.8 & \multicolumn{2}{|c|}{0.4} \\
\hline B2 & 2007 & -4 & 5 & \multicolumn{2}{|c|}{-1.0} \\
\hline \multicolumn{6}{|c|}{ Footstep count within each mapping method } \\
\hline \multirow[t]{2}{*}{ Parameter } & Method & Minimum & Maximum & Average & $\begin{array}{c}\text { Range } \\
\text { Difference }\end{array}$ \\
\hline & Method & Min & Max & Ave & $\begin{array}{l}\text { Range } \\
\text { Diff. }\end{array}$ \\
\hline $\mathrm{A} 3$ & LIDAR & $-2,469$ & 2,071 & -25.3 & 4,540 \\
\hline $\mathrm{A} 3$ & Total station & $-2,015$ & 4,279 & 800 & 6,294 \\
\hline \multicolumn{6}{|c|}{ Footstep count between LIDAR and total station for each date } \\
\hline Parameter & Date & Minimum & Maximum & \multicolumn{2}{|c|}{ Average } \\
\hline B3 & 2006 & $-1,886$ & 5,153 & \multicolumn{2}{|c|}{654.4} \\
\hline B3 & 2007 & $-1,595$ & 2,083 & \multicolumn{2}{|c|}{-218.4} \\
\hline
\end{tabular}

\section{Variations between Survey Methods (Impact Difference Check—Parameters B1, B2, B3)}

The difference in person-hours between LIDAR and total station for total survey time (parameter B1, table 5) shows that the positive numbers are higher in relative magnitude and of higher frequency for all sites considered, showing LIDAR to be more efficient than total station surveying in 2006 
(appendix C2, top). In 2007, the difference in total survey time is more balanced between the two survey methods, as expressed by the difference average near zero.

Both survey methods show a comparable time in the sensitive area of each site (parameter B2, table 5), expressed in the average difference near zero in 2006, with LIDAR surveying being slightly higher in 2007. Although the overall average values (table 5) are very similar, the data must be studied carefully to extract meaningful conclusions. For example, a positive value for parameter B2 occurs only once in 2007 (appendix C2), indicating total station surveying as being more efficient that year; however, the overall average for the dataset was near zero (table 5), indicating that there was no appreciable difference when the project was considered as a whole.

For footstep count, the data (appendix C2) indicates a nearly equivalent number of occurrences for which each method scored more efficient values. The average values (table 5, parameter B3) support this conclusion, with each method scoring as more efficient depending on the year. The data also show that the footstep impact is consistent both years for each method at five of the seven sites surveyed. In summary, in terms of statistics, the two methods are not significantly different.

\section{Postprocessing Time Comparison}

The person-hours required to postprocess the LIDAR data and total station data to State Plane coordinates for the three topographic data comparison sites are detailed in table 6. As expected, the data show that the postprocessing person-hours for LIDAR data are an order of magnitude higher than for total station data, since the total station data are essentially collected in a near-processed format, whereas the LIDAR data must be postprocessed according to the series of steps highlighted in the methods section of this report. Although the goal of this study was to compare the time required to obtain georeferenced coordinates of the gully thalweg, it should be noted for future consideration that the LIDAR postprocessing produced georeferenced models of the entire site topography, as well.

Table 6. Processing time for terrestrial light detection and ranging (LIDAR)-derived and total station surveying-derived topographic data (May 2006 sites).

\begin{tabular}{llc}
\hline Site name & Survey method & $\begin{array}{c}\text { Total } \\
\text { postprocessing } \\
\text { time }(\mathrm{h})\end{array}$ \\
\hline C:13:006 & LIDAR & 11.5 \\
& Total station & 1.5 \\
G:03:041 & LIDAR & 16 \\
& Total station & 1.5 \\
G:03:072 DS & LIDAR & 11 \\
& Total station & 0.75 \\
\hline
\end{tabular}

\section{Discussion}

This section explores in more detail issues related to the results that highlight the strengths, limitations, and variability of the two survey methods. The discussion is focused primarily on interpretation of the impact and gully thalweg comparisons of LIDAR to total station survey methods; however, the following discussion also focuses on additional issues particular to terrestrial LIDAR surveying. 


\section{Topographic Data Evaluation}

\section{Thalweg Extraction Comparison}

The primary technical comparison of the data was performed by assessing the ability of the LIDAR technique to extract gully thalweg topography that is at least as accurate as that obtained by the total station method. The results showed that although most of the data were within the error limits of the selected methodologies, errors outside these limits were common within the thalweg datasets. These errors highlight a limitation of the LIDAR method: LIDAR's limited ability to track key field-visible features such as the gully thalweg. Whereas LIDAR was able to accurately model the topography of each site, it was not capable of identifying exactly the entire length of the selected geomorphic feature chosen for evaluation in this study (that is, the thalweg) within that same topography. One explanation for this conclusion is simply that digital, automated methods are not able to resolve such subtle features. Another explanation is that the subtle nature of some thalwegs result in a miscalculation of the exact position of the thalweg by the total station rodman (In some cases, there may be in fact more than one thalweg and determining which thalweg assumes the majority of overland flow may be hard to detect visually.) However, an additional explanation exists and concerns the methodology with which the LIDAR data were processed. As outlined previously, the goal of this study was to develop topographic models of the gully topography and extract key geomorphic features. In the construction of the topographic model, filtering of the full-density point cloud was necessary for processing efficiency, which removed many points from the dataset used for thalweg extraction. It is therefore possible that the measured errors could be reduced by using a higher resolution point cloud $(<5 \mathrm{~cm}$ TIN edge length), but this would have prevented the efficient construction of the whole site topographic model. Generally speaking, it appears that the human eye may be a better judge of the exact thalweg location than the position calculated by automated methods. In fact, one of the reasons that thalwegs are surveyed with total station methods is because these features are often most readily identified in the field by the eyes of trained observers.

An additional limitation concerns the use of automated thalweg extractor algorithms in areas of subtle topography. In this study, this algorithm generally broke down because of point cloud noise and the subtle features littering the ground surface (small rocks, etc.). In these cases, the thalweg was either not extracted, formed a closed loop, or took a longer path within a flat section of the gully, and, as a result, the thalweg became less steep. This outcome is clearly shown in the data for Site C:13:006 (fig. 16), which show flatter long profiles along the entire gully lengths and results in underestimation of the thalweg elevation beginning in the upper reaches, causing overestimation in the lower reaches.

The manually linked contour methodology provided a reasonable solution to this problem, but this method also had limitations. When linked $1-\mathrm{cm}$ contours are used to define the thalweg, the total plan view thalweg length is likely to be greater than that obtained by the total station method. At site G:03:072 - Gully 1 (fig. 24), the total plan view thalweg length using the LIDAR data was $41.4 \mathrm{~m}$, obtained by connecting 1,374 individual contour lines. Using the total station data for identical start and end elevation points as the LIDAR data, a total plan view thalweg length of $37.7 \mathrm{~m}$ was obtained from 130 connected points. Likewise, this computation shows that the linked contour interval method from the LIDAR data will also result in a longer, more sinuous, and subdued long-profile section compared to the total station survey data. Thus, whether the automated or manual algorithm was used, the results show that plan view and long profiles generated from the LIDAR data are subject to explainable but inherent systematic limitations for fine-scale thalweg mapping. That said, it could be argued, at least as 
an academic exercise, that digitally extracting a higher resolution, more sinuous thalweg could be more accurate in terms of modeling the exact pathway of low-flow water in a channel. Either way, this points out the importance of consistency in gully thalweg extraction analysis. However, for the purposes of the present study, this point is not investigated any further.

\section{Feature Identification}

As discussed, one of the most important differences between the LIDAR and total station methods is each method's ability to identify particular features from the data. In total station surveying, the prism rod is placed on the feature of interest and identified by a point identification label (for example, ckdm for check dam, $\mathrm{k}$ for knickpoint, etc.). In postprocessing, these features can then be readily identified for analysis and change detection. Thus, it is known for certain that the surveyed point actually represents the feature of interest. With LIDAR surveying, individual points are not identified in this way, although some features can be recognized based on their shape and color. In general, features with sharp edges and obvious shapes are easiest to identify (tripods, prisms, people, etc.), whereas natural features are harder to distinguish.

The LIDAR gully datasets were examined carefully to identify such items as knickpoints and check dams constructed of both rocks and woody debris. With the exception of large knickpoints, identifying the exact locations of specific features was not possible. Large-size knickpoint (tens of centimeters) locations from the LIDAR data could be successfully extracted based directly on the processed topography but with less confidence than by field identification. Knickpoints of subtle topography (for example, fig. 30) could not always be identified in the LIDAR data. At this location, only the lower two knickpoints are obvious in the LIDAR long profile; the upper knickpoint is not readily identifiable. Check dam locations could only be identified through the use of either accompanying photographs of the site or through comparison with the total station dataset collected in tandem. Part of this problem is related to the LIDAR data processing methods, which emphasized creating continuous topographic models of each gully. It is not, therefore, the accuracy of the LIDAR data or processing methodology that is called into question but rather the resolution of the data to pick out exact features. Additional detail of the gully thalweg could be extracted, if the entire point cloud dataset were to be used for the gully bottom (with typical point spacing on the order of only 2 to $3 \mathrm{~cm}$ ). Even then, however, it must be acknowledged that the exact location of a feature can only be identified as an approximation with the LIDAR method (that is, a knickpoint could still be located between two LIDAR data points and not be perfectly identified).

This limitation of the presented LIDAR data collection and processing methods could be rectified in the future by scanning with increased density or by inclusion of site-specific reflectors (control points) located on the features of interest. Here, site-specific "tags" consisting of small but highly reflective targets could be placed on the feature locations. The tags would then be more easily identified in the point cloud data. Both of these solutions has a cost—processing time increases with increased point density in the former case, and field layout time and site impact increases in the latter case. The cost-benefit ratio of tracking these types of features, therefore, needs to be weighed on a caseby-case basis. A third alternative to overcoming the feature recognition limitation of LIDAR is to use a laser scanning system that incorporates photo-draping capabilities; this option is discussed in more detail in a following section of this report dealing with future directions. 


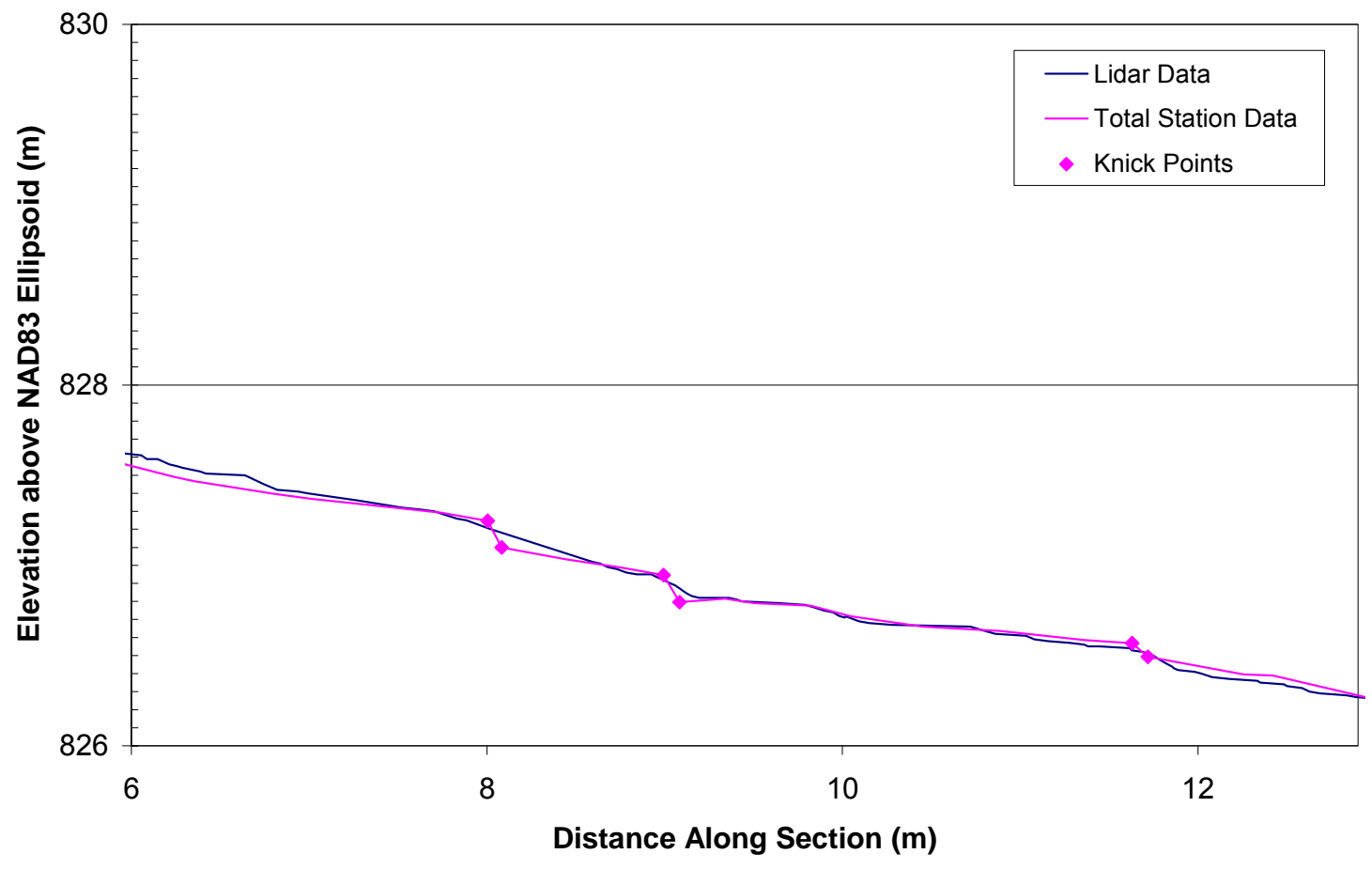

Figure 30. Section of long-profile comparison of terrestrial light detection and ranging (LIDAR) and total station data showing knickpoint locations determined by total station surveying (site C:12:006 - Gully 2).

\section{Surface Modeling and Whole-Site Monitoring}

In contrast to the limitations presented concerning feature identification, the ability to efficiently collect the entire site topography is an obvious advantage of the terrestrial LIDAR data. A brief description of how these data can be used for whole-site monitoring is provided here to highlight this advantage. Table 3 shows that the LIDAR method collects roughly 1,000 times the density of point data than does the total station method. This finding was previously highlighted for a small section of one of the gullies (fig. 13). Reaching a LIDAR-equivalent density of data using the total station method to survey an archeological site would be time and cost prohibitive and result in extremely high footstep impacts.

Figure 31 provides an overview of the types of features that can be accurately identified. Here, vegetation, boulders, and the entire site topography are visible in the point data. Thus, surface models created from temporally different datasets can be compared to one another. Should vegetation features change or massive erosion events such as debris flows affect a site, the point data collected before the change can provide an accurate baseline for change-detection measurements. But as outlined previously, if the resolution of the point cloud data is not sufficiently high or the feature not particularly well defined in the topography, change detection of smaller, visibly distinguished features is not always possible. 

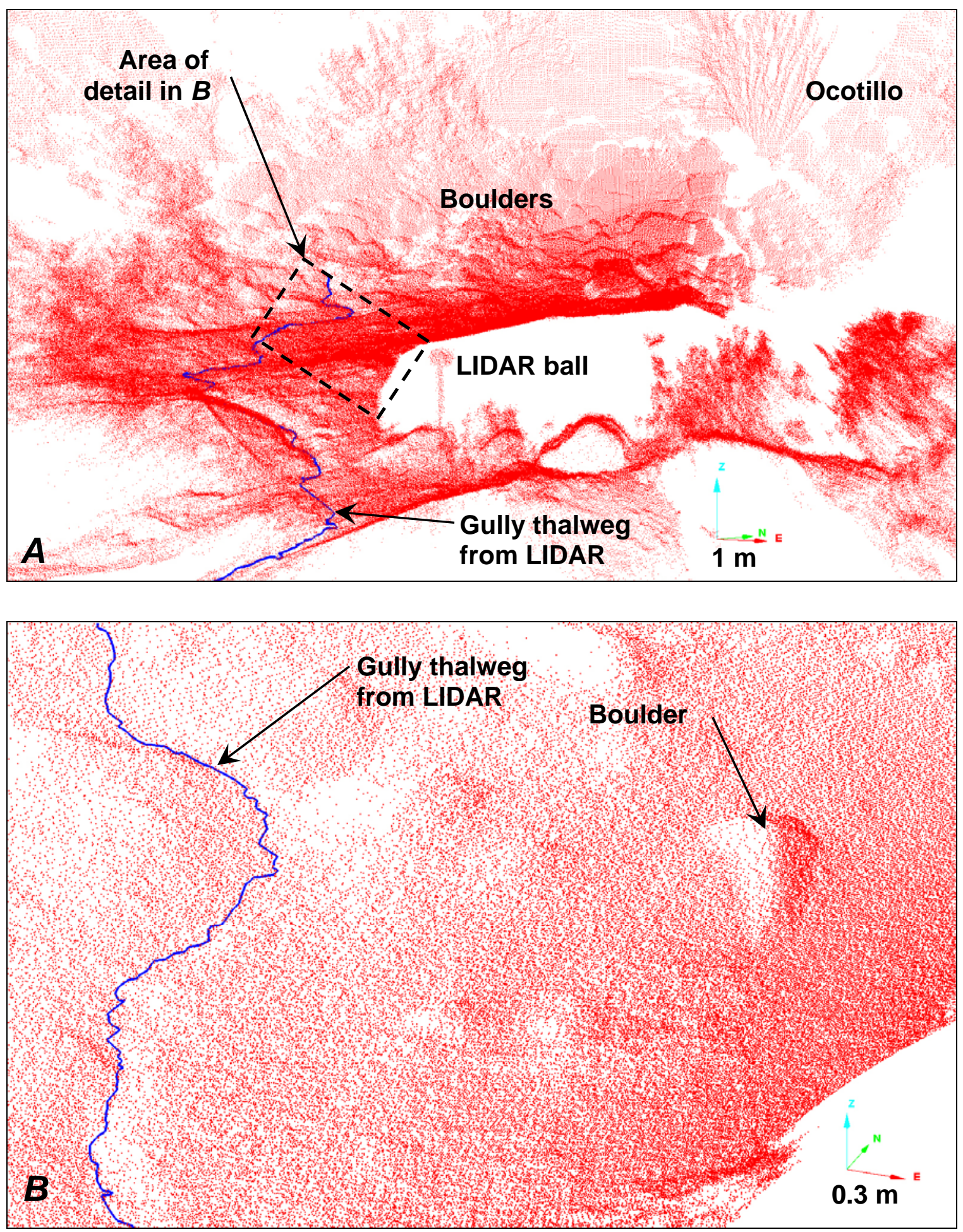

Figure 31. Detail of terrestrial light detection and ranging (LIDAR) point data from a single scan showing key features (site G:03:072 — Gully 1). Distance between points in $A$ varies greatly depending on distance from scanner origin. Typical distance between adjacent points in $B$ is $5 \mathrm{~cm}$. 


\section{Vegetation}

The presence of vegetation in gullies creates inaccuracies in the resulting topographic data using both survey methods. In total station surveying, vegetation can prevent the survey rodman from locating the precise gully bottom. In LIDAR surveying, vegetation can block the transmission of laser pulses, and the gully itself may not be visible. This is one of the reasons why multiple scan setup locations are often used, although sufficiently dense vegetation may not be penetrable from any vantage point.

The problems of dealing with vegetation (and likewise, the magnitudes of error from vegetation in each method) are treated in different ways according to each survey method. In total station surveying, several centimeters of error can be expected from an improperly placed survey rod. Likewise, several centimeters of error can also be expected if the survey rod must be extended above the vegetation by two rod lengths or higher because of the side-to-side flexibility of the survey rod and potential shifting from wind, if present. Total station surveyors are able to minimize this error by waiting for the prism to "center out" in the course of any side-to-side movement; overall, a few centimeters of additional error, however, may be expected when working in these areas.

In LIDAR surveying, errors may be generated by either poor surface registration of vegetation points collected from two different angles or through misinterpretation of the vegetation as bare ground in the final surface model. Both of these error sources can be minimized through use of postprocessing filters that remove most aboveground points. However, if filters are not used correctly, useful data can be lost by the improper removal of points, and points remaining in error can lead to a final surface that does not accurately model the bare-earth ground surface. In the worst case, dense vegetation may prevent data collection from the ground surface entirely (that is, Gully 2 at site G:03:041; see figs. 19, 20 , and 22). Sites should be carefully examined with this issue in mind before surveying.

\section{Impact Evaluation Comparison}

\section{Factors Affecting the Direct Impact Evaluation—Footstep Count}

The footstep count is directly related to the number of people supporting each surveying technique in the sensitive area. Since LIDAR surveying essentially requires two people to carry the equipment from one setup location to another, and total station surveying requires one person only to move around the site, the footstep count from the LIDAR team could be expected to be larger. However, before undertaking this study, it appeared that the LIDAR survey crew might be able to eliminate entry into the sensitive area altogether by using a survey device capable of remote sensing. The results show that this was not possible at many of the sites because of the sinuous nature of the gully systems, which often required multiple, and closely spaced, scan setups to capture the required data.

The weight of the LIDAR equipment also plays a role in site impacts, which was not quantified for this study. Personnel carrying heavier equipment can produce deeper footprints than a single person carrying a total station prism pole. However, the impacts resulting from the additional weight of LIDAR equipment may be a limited factor here because the LIDAR survey locations were typically never in the geomorphic feature being surveyed, as opposed to total station survey, which may have required less heavy equipment but had to be located directly in the feature being measured (the gully). Both survey methods may lead to the introduction of new trail systems to the archeological sites. There is possibly more potential for new trails from the LIDAR survey method because the required setup locations are 
generally in new, undisturbed areas of the site, while the total station survey locations are already within gullies. The footstep impact of total station surveying is concentrated in the critical gully area, where standing or placing the survey rod on the top edge of the gully or on top of a knickpoint may cause collapse of the steep face, exacerbating erosion. The physical impact from total station surveying includes both footprints and the outline of the 3-inch-diameter prism pole, although a conscientious, light-footed rodman should be able to cause minimal overall impact. Whether additional erosion of an existing gully feature is less desirable than the possibility of introducing new erosion in other areas of a site is a difficult tradeoff to quantify, but it is highlighted here as a factor for consideration for future surveys.

\section{Factors Affecting the Indirect Impact Evaluation—Time in Sensitive Area}

The time in sensitive area element of the study - based on the assumption that the more time spent within the sensitive area, the more time for additional impacts to occur-provided an alternative estimate for assessing the impact associated with each survey technique. Impacts were also assumed to be exacerbated with the increased number of support personnel working within the sensitive area. While both survey techniques were accomplished at times with only one person in the sensitive area, the effect of single versus multiple personnel was not examined in this study.

An additional factor affecting the time element for both the total time of survey and time in the sensitive area impact parameters is the experience level, or quality factor, of the personnel collecting the data. Quality factors include familiarity with the project objectives and the study sites, as well as familiarity with the equipment, software or mechanical problems, and troubleshooting hardware. The quality of personnel during this assessment was similar for both survey techniques. The lead surveyor for both techniques was present for both impact data collection events, while the support personnel for both techniques varied. For LIDAR, the support technician was in training for the sites beginning with $\mathrm{C}$ in 2006 and was considered experienced in 2007. (No support personnel were used at the sites beginning with $\mathrm{G}$ in 2006.) The support personnel for total station surveying were knowledgeable for the beginning of 2006 (sites beginning with C) and the end of 2007 (sites beginning with G), but in training for the end of 2006 and beginning of 2007 (sites beginning with G). An increase in personnel experience was reflected in the footstep count and the person-hour data: with a few exceptions caused by equipment problems, both methods posted decreases in total survey time, time in sensitive area, and footstep count (figs. 27, 28) when experienced personnel accompanied the lead surveyor. An evaluation of this comparison is not possible for the LIDAR survey between the end of 2006 and end of 2007 because of the use of different numbers of personnel during these times.

\section{Other Factors_-Postprocessing Methods}

The main parameters for assessing the overall efficiency of a mapping technique are the total survey time and the postprocessing time. The postprocessing time for LIDAR data obviously reduces the overall efficiency, but the field time necessary to acquire the LIDAR data was also slightly (15 percent) lower. A factor not accounted for in these results is the use of total station survey equipment and personnel to measure georeferenced coordinate values for the LIDAR survey team in the field. This is reflected in the 2006 cumulative mapping time (fig. 29) for total station surveying, which exceeded the LIDAR survey by more than $20 \mathrm{~h}$ in 2006 (although the exact contribution to that time of additional surveying for the LIDAR team cannot be quantified). When the LIDAR survey used an independent real-time kinematic global positioning system (RTK GPS) for georeferencing laser and LIDAR ball control in 2007, the total station and LIDAR surveys were comparable in cumulative time (fig. 29), 
although this also indicates that the LIDAR survey was much more efficient in 2007, since collection of both LIDAR and GPS data was performed by the LIDAR survey team.

The additional postprocessing time required by LIDAR data is a direct result of two factors: (1) the data collection and processing methodology and (2) the data selected for comparison. The LIDAR data in this study were collected as a series of independent point clouds georeferenced to the scan origin and aligned to other scans through a best fit of overlapping point data. This procedure is time consuming because of the number of degrees of freedom that exist in registering overlapping point clouds - each cloud may rotate about three axes. Thus, a large number of possible combinations exist, with only one exact solution. Finding this solution is often time consuming and computationally demanding. Processing methodologies are constantly evolving, and newer methods rely on the presence of overlapping control points in adjacent scans to find this best fit solution. This makes for a computationally simpler postprocessing methodology but requires additional field time necessary for setup, surveying, and take down of the control points. Additional studies using these newer methods are ongoing with respect to evaluating the pros and cons of field versus postprocessing time.

In this study, the long profile of the gully thalweg was selected for use in topographic comparisons. Whereas this is essentially directly surveyed by total station methods, it is a metric that must be extracted from postprocessed LIDAR data. Development of a surface model followed by subsequent hydrologic analysis must therefore be performed. Investigations of small-scale gully thalweg metrics will likely always be more time consuming using LIDAR methods. Other possible metrics, such as the total amount of surface change between temporally different datasets, are more easily realized from LIDAR data but were not directly compared (or collected) in the total station surveys because of the marked differences in data density collected by the two methods.

\section{Future Directions}

Two new technologies, RTK GPS surveying and dual-mode terrestrial LIDAR image draping may provide solutions to the survey and impact limitations highlighted in this report. They are presented here as background for future studies.

High-accuracy GPS surveying at the river level in Grand Canyon may be possible because of the increased number of available satellites for data collection; satellite capacity has increased, in part, as the result of the increased availability of signals from the Russian-based GLONASS satellites. To date, GPS reception has been spotty and inconsistent because of the height and steepness of the canyon walls and the lack of the needed line of sight to a sufficient number of satellites. After base-station set up is complete, GPS surveying has the advantage that only one person is required for data collection. In addition, the survey rod is kept low and is not impacted by windy conditions. Finally, multiple GPS rover units can be used simultaneously to further reduce survey time for sites with neighboring gullies. Although total survey time may decrease with GPS surveying, site impact can still be expected because of the need to occupy the gullies directly to make the required measurements. RTK GPS was used successfully in this study for georeferencing the LIDAR instrument and in collecting baseline datasets of five gully thalwegs in 2007. Whereas medium-range ( 2 to 5 minute) occupations were successful in generating accurate points for the LIDAR instrument locations, assessment of the accuracy of the gully data using short (1 to 10 seconds) occupation is currently in progress.

Dual-mode terrestrial LIDAR image draping combines the high accuracy and point density of terrestrial LIDAR with the feature-recognition capabilities of digital photo analysis. Here, highresolution digital photos are orthometrically rectified to the LIDAR data, providing a method in which features can be simultaneously identified in the photo and measured in the LIDAR data. This may 
provide a solution to the key limitations identified in this study concerning the ability to map the location of fine-scale geomorphic features such as gully thalwegs and knickpoints. The workflow in the field using this methodology is generally more time consuming, requiring the use of a network of reflector control points and the collection of both the LIDAR data and the photos. However, if wholesite topographic monitoring is not desired, the survey could focus completely on the gully system using potentially fewer locations. The postprocessing workflow time commitment is likely to be less than that required by this study. Using field-placed reflectors, registration time will decrease and the thalweg extraction will be more conclusive, thereby also reducing the postprocessing effort. The most promising improvement with this type of system may be with regard to data accuracy - the final measurements are likely to be an order of magnitude less than those presented in this evaluation because of the higher accuracy of these newer laser systems, the higher accuracy achieved by the reflector-dependent registration process, and the positive identification of the geomorphic feature in the photos.

\section{Conclusions}

This investigation evaluated the use of terrestrial LIDAR surveying to collect topographic data and map key geomorphic features while also minimizing site impacts at archeological sites in Grand Canyon National Park. The results of the topographic data evaluation show that although terrestrial LIDAR is capable of determining overall site topography and accurately mapping the general location of gully thalwegs in comparison to that provided by total station data, terrestrial LIDAR in its presented application did not map the entire plan and longitudinal profiles of the gullies to the required accuracy of this investigation. Further, it was not possible to identify fine-scale features such as knickpoints and check dams from the point cloud data. Although terrestrial LIDAR provides a higher point density, it is limited in its ability to identify the precise locations of subtle features because of the inherent differences between in-field feature identification by a trained eye and postprocessing feature extraction by computerized methods. It is noted for future reference that recent advances in technology may change these results.

The results of the impact evaluation indicate that LIDAR and total station surveying are similar in their site impacts, as measured by the time spent in the sensitive area (defined at each survey site) and the number of footsteps taken within the sensitive area. The total survey time taken by LIDAR was approximately 15 percent less than total station surveying, but the postprocessing time was an order of magnitude greater. Several factors must be considered when making decisions based on these results, including the number, location, and training of personnel. With LIDAR, the number of personnel working inside the sensitive area may be higher; in total station surveying, the location of the personnel is more likely to directly affect the area of interest; and in both methods, highly trained personnel are required to maximize efficiency.

Whether the goal of a project is to track key geomorphic features, as was evaluated in this study, or it is to track overall topographic change, as is being evaluated in a complementary study anticipated in early 2009, there will be key tradeoffs depending on the type of survey method selected. Making a choice must therefore be determined by selecting the method that is most suitable for the data to be collected. For geomorphic surveys of archeological sites, LIDAR is more time consuming given the postprocessing effort required but provides increased data density and considerably more spatial coverage for slightly less field effort. However, as discussed, the older generation of LIDAR technology applied in this study was not capable of fine-scale feature recognition-a significant limitation, considering that until now geomorphic feature mapping of gully thalwegs has been the most commonly used method for tracking archeological site erosion. Compared to total station surveying, RTK GPS 
may provide an amenable solution to shortening site occupation time and increasing data accuracy for measuring these features. Similarly, different LIDAR postprocessing methodologies or newer LIDAR data collection techniques may also increase data accuracy and possibly lessen site impacts. However, these methods remain untested at such fine scale in Grand Canyon.

Given the aims and goals of a particular project, the benefits and limitations of each survey methodology should be weighed accordingly. The following summary of the findings of this evaluation between terrestrial LIDAR surveying and total station surveying has been compiled to assist researchers and land managers involved in geomorphologic monitoring at archeological sites in Grand Canyon National Park.

Clear benefits of terrestrial LIDAR surveying include

- the ability to collect data remotely and, in some cases, outside of the erosion features;

- the ability to collect the entire site topography for whole-site monitoring and for historical archiving purposes; and

- the potential for increased accuracy with next-generation LIDAR systems.

Issues posed by LIDAR surveying and potential solutions are listed below:

- LIDAR surveying is unable to identify the precise location of fine-scale geomorphic features. The newest generation of lasers that combine digital photo draping on the collected topography may provide an amenable solution to this problem; this solution has not been tested.

- Laser penetration through dense vegetation is limited. No specific solution is available, except extremely close-range scanning to penetrate the vegetative canopy.

- Additional postprocessing time is required. The quantity of data obtained is the tradeoff for this limitation.

Clear benefits of total station surveying include

- the ability to collect data of the specific features of interest (that is, "feature coding"), including in-field recognition and identification of geomorphic features;

- the ability to obtain results with minimal postprocessing, which allows for nearer realtime change detection; and

- the ability to work in densely vegetated areas;

Issues related to the use of total station surveying and possible solutions are listed below:

- Wind affects the quality and accuracy of total station surveying results. A potential solution to this issue may be to use RTK GPS systems, which do not require survey rods to be extended.

- Total station surveying concentrates site impacts on the features being monitored. This problem is inherent in the method and can be minimized by using trained personnel but cannot be eliminated.

- It is not possible to map an entire site efficiently or with the level of detail necessary for tracking topographic change on a landscape scale using total station surveying. For this application, LIDAR surveying is preferable. 


\section{Acknowledgments}

Funding for this research was provided by a cooperative work agreement between the USGS Grand Canyon Monitoring and Research Center and the USGS Western Coastal Marine Geology Team. The authors would like to thank the following individuals for their assistance with the data collection effort: Robert Kayen and Diane Minasian, USGS; Jennifer Dierker and Lisa Leap, NPS; and Joel Pederson, Gary O’Brien, Ben Dejong, Mike Keller, Chris Tressler, and Tim Andrews, Utah State University. Thanks also to Carol Fritzinger, USGS GCMRC logistics coordinator, and the boatmen and women from Humphrey Summit Support Services who provided logistical support for this project.

\section{References}

Collins, B.D., and Kayen, R., 2006, Applicability of terrestrial LIDAR scanning for scientific studies in Grand Canyon National Park, Arizona: U.S. Geological Survey, Open-File Report 2006-1198, http://pubs.usgs.gov/of/2006/1198/, accessed March 17, 2008, 27 p.

Collins, B.D. and Sitar, N., 2004, Application of high resolution 3D laser scanning to slope stability studies, in Symposium on Engineering Geology and Geotechnical Engineering, 39 ${ }^{\text {th }}$, Butte, Mont., May 18-21, 2004 [Proceedings], p. 79-92.

Collins, B.D., and Sitar, N., 2008, Processes of coastal bluff erosion in weakly lithified sands, Pacifica, California, USA: Geomorphology, v. 97, p. 483-501.

Davis, P.A., 2004, Review of results and recommendations from the GCMRC 2000-2003 remotesensing initiative for monitoring environmental resources within the Colorado River ecosystem: U.S. Geological Survey Open-File Report 2004-1206.

Doneus, M., and Neubauer, W., 2005, Laser scanners for 3D Documentation of stratigraphic excavations, in Baltsavias and others, eds., Recording, modeling and visualization of cultural heritage: Taylor and Francis, p. 193-203.

Draut, A.E., and Rubin, D.M., 2008, The role of eolian sediment in the preservation of archeologic sites along the Colorado River corridor in Grand Canyon National Park, Arizona: U.S. Geological Survey Professional Paper 1756, 71 p.

Fairley, H.C., 2005, Cultural resources in the Colorado River corridor, in Gloss, S.P., Lovich, J.E., Melis, T., eds., The state of the Colorado River ecosystem in Grand Canyon, U.S. Geological Survey Circular 1282, p. 177-192.

Fairley, H.C., Bungart, P.W., Coder, C.M., Huffman, J., Samples, T.L., and Balsom, J.R., 1994, The Grand Canyon river corridor survey project: Archaeological survey along the Colorado River between Glen Canyon Dam and Separation Canyon: Cooperative Agreement No. 9AA-40-07920, Grand Canyon National Park. Prepared in cooperation with the Bureau of Reclamation, Glen Canyon Environmental Studies, Flagstaff, Ariz.

Fairley, H.C., Collins, B.D., Draut A., Leap, L., and O'Brien, G., 2007, FY07-FY11 Archaeological site monitoring and research development project, research proposal dated July 30, 2007, submitted to Grand Canyon National Park and National Park Service Research Permit Application System, March 5, 2007. Copy on file at the U.S. Geological Survey, Grand Canyon Monitoring and Research Center, Flagstaff, Ariz., 149 p. 
Hereford, R., 1993, Description of map units and discussion to accompany map showing surficial geology and geomorphology of the Palisades Creek archaeologic area, Grand Canyon National Park, Arizona: U.S. Geological Survey Open-File Report 93-553.

Hereford, R., Burke, K.J., and Thompson, K.S., 1996, Description of map units and discussion to accompany map showing quaternary geology and geomorphology of the Nankoweap Rapids area, Marble Canyon, Arizona: U.S. Geological Survey Open-File Report 96-502.

Hereford R., Fairley, H.C., Thompson, K.S., Balsom, J.R., 1991, The effect of regulated flows on erosion of archaeologic sites at four areas in eastern Grand Canyon National Park, Arizona-A preliminary analysis: Flagstaff, Ariz., Bureau of Reclamation, Glen Canyon Environmental Studies.

Hereford, R., Fairley, H.C., Thompson, K.S., and Balsom, J.R., 1993, Surficial geology, geomorphology and erosion of archaeologic sites along the Colorado River, Eastern Grand Canyon, Grand Canyon National Park, Arizona: U.S. Geological Survey Open-File Report 93-517.

Hough, I., and Brennan, E., 2008, Architectural documentation and preservation of Havasupai and Navajo wooden pole structures in Grand Canyon National Park, in Berger, T.R., ed., Reflections of Grand Canyon historians-Ideas, arguments and first-person accounts: Grand Canyon Association, $\mathrm{p}$. 81-88.

I-SiTE Inc., 2008, 3D Laser Scanning Software, http://www.isite3d.com, accessed February 1, 2008.

Kayen, R., and Collins, B.D., 2005, Terrestrial LIDAR imagery and analysis of Hurricane Katrina levee failures in the city of New Orleans: Eos, Transactions, American Geophysical Union, v. 86, no. 52, Fall Meeting, Suppl., Abstract H42C-07.

Leap, L.M., Andrews, N.B., and Kunde, J.L., 1996, 1996 summary report-monitoring of archaeological sites along the Colorado River corridor in Grand Canyon National Park. River Corridor Monitoring Project Report No. 37: Grand Canyon, Ariz., Grand Canyon National Park.

Leap, L.M., and Kunde, J.L., 2000, Summary report—archaeological site monitoring and management along the Colorado River corridor in Grand Canyon National Park. River Corridor Management Plan Report No. 68: Submitted to Bureau of Reclamation, Upper Colorado Region, salt Lake City, Utah, http://www.nps.gov/grca/historyculture/upload/FY2000.pdf.

Leap, L.M., Kunde, J.L., Hubbard, D.C., Andrews, N.B., Downum, C.E., Miller, A.R., and Balsom, J.R., 2000, Grand Canyon monitoring project 1992-1999—synthesis and annual report for FY99. River Corridor Monitoring Project Report No. 66: Submitted to Bureau of Reclamation (Acquisition No. 99-AA-40-23400, Upper Colorado Region, Salt Lake City, Utah. (Executive summary, http://www.nps.gov/grca/historyculture/upload/FY1999.pdf, accessed August 1, 2008)

Nagihara, S., Mulligan, K. R., and Xiong, W., 2004, Use of a three dimensional laser scanner to digitally capture the topography of sand dunes in high spatial resolution: Earth Surface Processes and Landforms, v. 29, p. 391-398.

Pederson, J.L., Petersen, P.A., MacFarlane, W.W., Gonzales, M.F., and Kohl, K., 2003, Mitigation, monitoring, and geomorphology related to gully erosion of cultural sites in Grand Canyon: Cooperative Agreement No. 01 WRAG0074 between Utah State University and U.S. Geological Survey, Grand Canyon. Grand Canyon Monitoring and Research Center, Flagstaff, Ariz., 250 p., http://www.gcmrc.gov/library/reports/cultural/Archaeology/Pederson2003.pdf.

Riegl, 2008, Terrestrial scanning laser systems, http://www.rieglusa.com, accessed February 1, 2008. 
U.S. Geological Survey, 2008, Survey control operations for the Colorado River Ecosystem, http://www.gcmrc.gov/about/programs/isp/dasa/survey/operations.aspx, accessed August 11, 2008. 


\section{Appendix A. Evaluation Metrics}

\begin{tabular}{|c|c|c|c|}
\hline $\begin{array}{c}\text { Evaluation } \\
\text { characteristic }\end{array}$ & $\begin{array}{c}\text { Evaluation } \\
\text { measurement }\end{array}$ & Equipment needed & Protocol \\
\hline $\begin{array}{l}\text { Equipment and } \\
\text { manpower cost }\end{array}$ & U.S. dollars & $\begin{array}{l}\text { Equipment purchase } \\
\text { quote or receipt and } \\
\text { equipment manual }\end{array}$ & $\begin{array}{l}\text { Tally all dollar expenses associated with } \\
\text { purchasing or leasing equipment, or } \\
\text { contracting data collections services. } \\
\text { Assess personnel requirements, that is, the } \\
\text { minimum number of people required to use } \\
\text { the equipment vs. the most efficient } \\
\text { number of people. }\end{array}$ \\
\hline Time of survey effort & Time & Wrist watch & $\begin{array}{l}\text { Measure time spent in field, including } \\
\text { mobilization, survey time, and } \\
\text { demobilization. Measured on a per-person } \\
\text { basis, including fixed survey personnel. }\end{array}$ \\
\hline $\begin{array}{l}\text { Time of postprocessing } \\
\text { effort }\end{array}$ & Time & Clock/stop watch & $\begin{array}{l}\text { Measure time spent postprocessing each } \\
\text { dataset once raw data is collected (scans } \\
\text { and point measurements). This effort } \\
\text { includes time spent postprocessing the data } \\
\text { either in the field or office. }\end{array}$ \\
\hline $\begin{array}{l}\text { Wear and tear on } \\
\text { equipment }\end{array}$ & U.S. dollars & Expense report & $\begin{array}{l}\text { Tally all dollar expenses associated with } \\
\text { repairing or replacing equipment damaged } \\
\text { in the field and with purchasing specialized } \\
\text { equipment needed for Grand Canyon } \\
\text { survey work. }\end{array}$ \\
\hline \multirow[t]{2}{*}{ Impact on Land } & Distance & Pedometer & $\begin{array}{l}\text { Measure total distance traveled upon } \\
\text { entering the archeological study area via } \\
\text { pedometer installed on each member of the } \\
\text { survey team. Measured on a per-person } \\
\text { basis. Does not include fixed survey } \\
\text { personnel if base station is not located } \\
\text { within the study area. }\end{array}$ \\
\hline & Photograph & Camera & $\begin{array}{l}\text { Photo document and tally significant } \\
\text { impacts to a site (for example, stepping on } \\
\text { cryptogrammic soil, etc). Significant } \\
\text { impacts to be established by principal } \\
\text { investigator (Helen Fairley). }\end{array}$ \\
\hline Quantity of data & $\begin{array}{l}\text { Number of } \\
\text { points }\end{array}$ & $\begin{array}{l}\text { Laser/survey } \\
\text { software }\end{array}$ & $\begin{array}{l}\text { Calculate the total number of points utilized } \\
\text { in creating topographic surfaces of the } \\
\text { study area. Does not include points filtered } \\
\text { from the data (that is, scanned vegetation, } \\
\text { cliffs, etc.). }\end{array}$ \\
\hline
\end{tabular}




\begin{tabular}{|c|c|c|c|}
\hline $\begin{array}{l}\text { Evaluation } \\
\text { Characteristic }\end{array}$ & $\begin{array}{c}\text { Evaluation } \\
\text { measurement }\end{array}$ & Equipment needed & Protocol \\
\hline Area of survey & $\begin{array}{l}\text { Plan area of } \\
\text { collected data }\end{array}$ & $\begin{array}{l}\text { Laser/survey/GIS } \\
\text { software }\end{array}$ & $\begin{array}{l}\text { Calculate the total 2-D plan area of data } \\
\text { collection within the study area. }\end{array}$ \\
\hline Accuracy of point data & $\begin{array}{l}\text { Absolute error of } \\
\text { equipment }\end{array}$ & $\begin{array}{l}\text { Laser/total station } \\
\text { specifications }\end{array}$ & $\begin{array}{l}\text { Absolute equipment error is defined by the } \\
\text { survey equipment manufacturer along with } \\
\text { periodic calibration tests. Measurements } \\
\text { within a single data scan are subject to this } \\
\text { error. }\end{array}$ \\
\hline $\begin{array}{l}\text { Accuracy of } \\
\text { topographic model }\end{array}$ & $\begin{array}{l}\text { RMS error of } \\
\text { final registration } \\
\text { of individual } \\
\text { scans (for } \\
\text { LIDAR survey) }\end{array}$ & Laser/GIS software & $\begin{array}{l}\text { The RMS error of the registration } \\
\text { procedure defines the overall fit of the scan } \\
\text { data within a particular model. } \\
\text { Measurements within and between } \\
\text { topographic surfaces are subject to this } \\
\text { error. }\end{array}$ \\
\hline \multicolumn{4}{|c|}{ Product } \\
\hline $\begin{array}{l}\text { Reporting and } \\
\text { compiling of results }\end{array}$ & $\begin{array}{l}\text { Publication or } \\
\text { Open-File } \\
\text { Report }\end{array}$ & N/A & $\begin{array}{l}\text { Compile information collected for each } \\
\text { evaluation characteristic from scanned } \\
\text { topography and surveyed topography. } \\
\text { Written report comparing the two } \\
\text { techniques using graphs, tables, maps, and } \\
\text { illustrations as needed. }\end{array}$ \\
\hline
\end{tabular}




\section{Appendix B. Impact Evaluation Results}

\begin{tabular}{|c|c|c|c|c|}
\hline Site name & Survey method & $\begin{array}{l}\text { Total time of } \\
\text { survey effort } \\
\text { (person-hours) }\end{array}$ & $\begin{array}{c}\text { Total time in } \\
\text { sensitive area- } \\
\text { indirect impact } \\
\text { (person-hours) }\end{array}$ & $\begin{array}{c}\text { Footstep impact- } \\
\text { direct impact } \\
\text { (number of } \\
\text { footsteps) }\end{array}$ \\
\hline \multirow{4}{*}{ C:13:006 } & LIDAR May 2006 & 12 & 3.2 & 1,316 \\
\hline & LIDAR May 2007 & 11.5 & 3 & 1,113 \\
\hline & Total station May 2006 & 13 & 7 & 2,269 \\
\hline & Total station May 2007 & 13.5 & 8 & 3,196 \\
\hline \multirow{4}{*}{ C:13:336 } & LIDAR May 2006 & 9 & 9 & 2,840 \\
\hline & LIDAR May 2007 & 5 & 3.2 & 2,329 \\
\hline & Total station May 2006 & 5.5 & 2.5 & 954 \\
\hline & Total station May 2007 & 5.5 & 3 & 797 \\
\hline \multirow{4}{*}{ C:13:099 } & LIDAR May 2006 & 5 & 5 & 2,071 \\
\hline & LIDAR May 2007 & 3 & 2 & $\mathrm{n} / \mathrm{a}^{1}$ \\
\hline & Total station May 2006 & 6 & 4 & 962 \\
\hline & Total station May 2007 & $\mathrm{n} / \mathrm{a}^{1}$ & $\mathrm{n} / \mathrm{a}^{1}$ & $\mathrm{n} / \mathrm{a}^{1}$ \\
\hline \multirow{4}{*}{ C:13:348 } & LIDAR May 2006 & 9 & 9 & 3,815 \\
\hline & LIDAR May 2007 & 13.7 & 9.5 & 4,298 \\
\hline & Total station May 2006 & 10.5 & 7.5 & 4,133 \\
\hline & Total station May 2007 & 12 & 5.5 & 6,148 \\
\hline \multirow{4}{*}{ G:03:041 } & LIDAR May 2006 & 12.5 & 8.5 & 2,231 \\
\hline & LIDAR May 2007 & 12 & 7 & 4,700 \\
\hline & Total station May 2006 & 19 & 11.5 & 7,384 \\
\hline & Total station May 2007 & 12.5 & 7 & 3,105 \\
\hline \multirow{4}{*}{ G:03:002 } & LIDAR May 2006 & 10 & 8.25 & 4,239 \\
\hline & LIDAR May 2007 & 11 & 7.5 & 3,650 \\
\hline & Total station May 2006 & 18 & 12 & 3,868 \\
\hline & Total station May 2007 & 8.5 & 4 & 2,770 \\
\hline \multirow{4}{*}{$\begin{array}{l}\text { G:03:072 } \\
\text { Downstream }\end{array}$} & LIDAR May 2006 & 5.25 & 4 & 947 \\
\hline & LIDAR May 2007 & 6.5 & 3 & 1,299 \\
\hline & Total station May 2006 & 8 & 4 & 2,910 \\
\hline & Total station May 2007 & 4 & 2 & 1,374 \\
\hline \multirow{4}{*}{$\begin{array}{l}\text { G:03:072 } \\
\text { Upstream }\end{array}$} & LIDAR May 2006 & 4.25 & 4.25 & 2,768 \\
\hline & LIDAR May 2007 & 8.25 & 4.5 & 3,040 \\
\hline & Total station May 2006 & 11 & 5.5 & 2,982 \\
\hline & Total station May 2007 & 9 & 4.5 & 1,510 \\
\hline
\end{tabular}

${ }^{1}$ Site C:13:099 was not surveyed by total station in 2007, and the LIDAR footstep count was not measured. 
This page intentionally left blank 
Appendix C1. Variation Within Each Mapping Method for Total Time of Survey, Time in Sensitive Area, and Footstep Impact
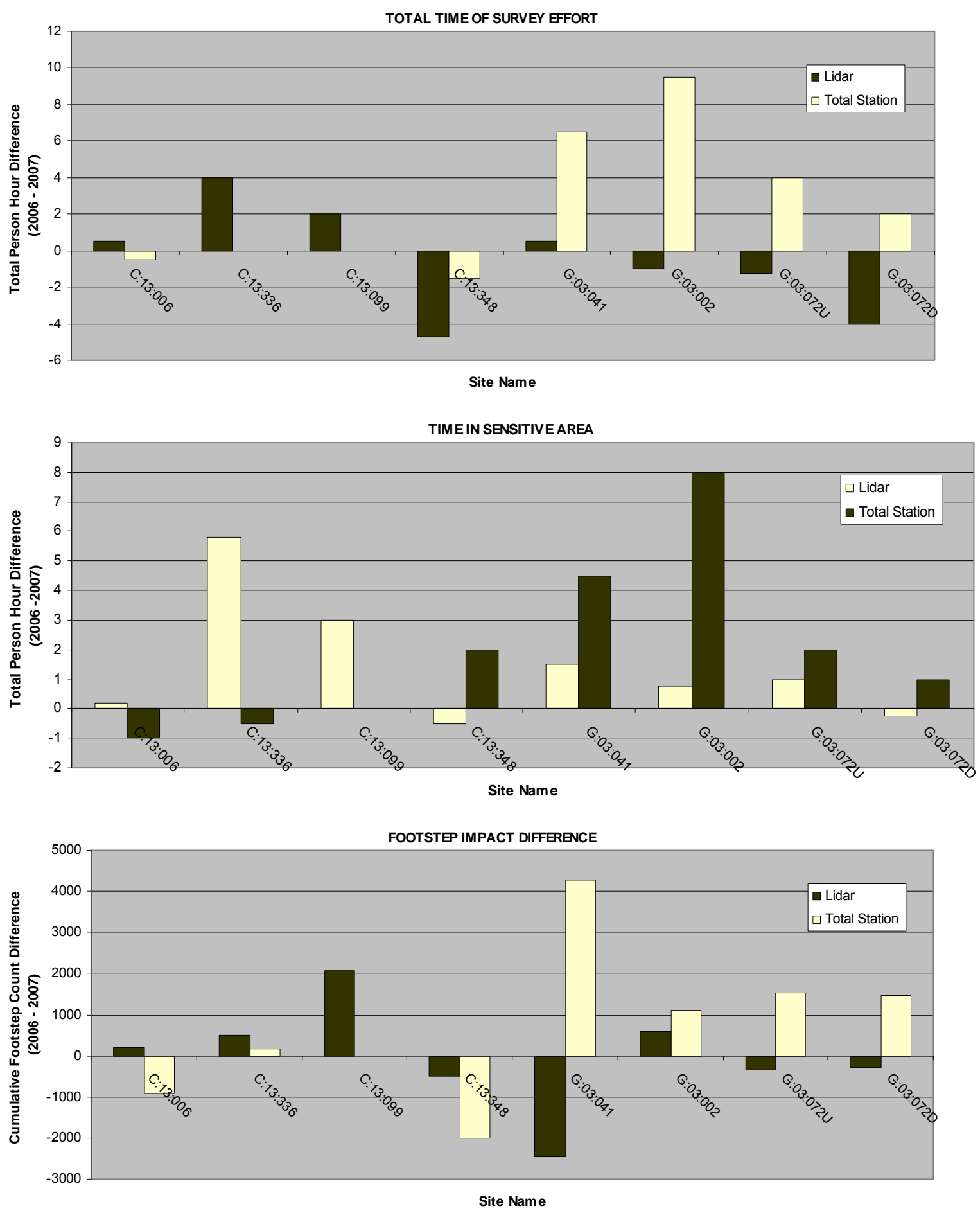


\section{Appendix C2. Variation Between Total Station and LIDAR Methods for Total Time of Survey, Time in Sensitive Area, and Footstep Impact}
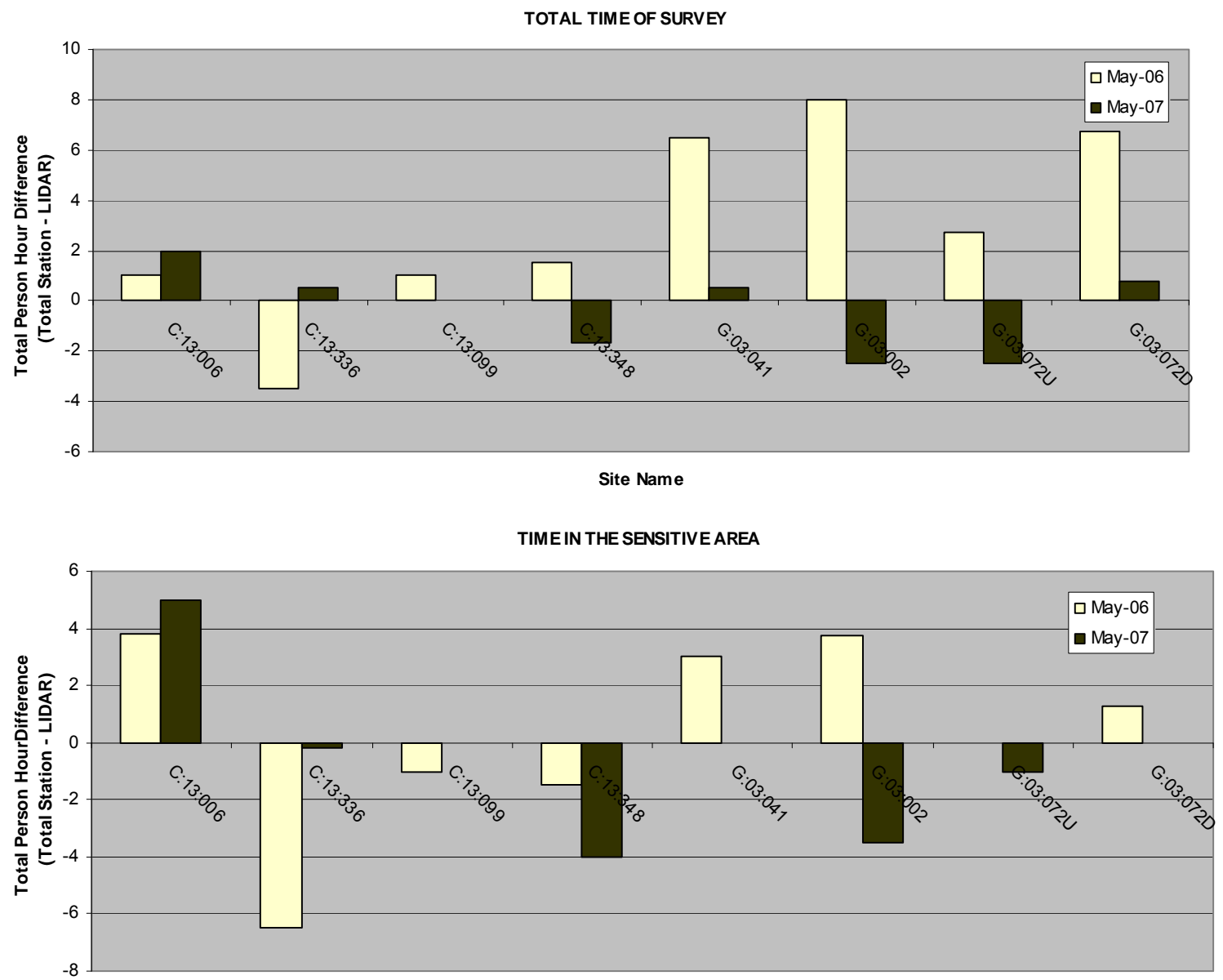

Site Name

FOOTSTEP IMPACT

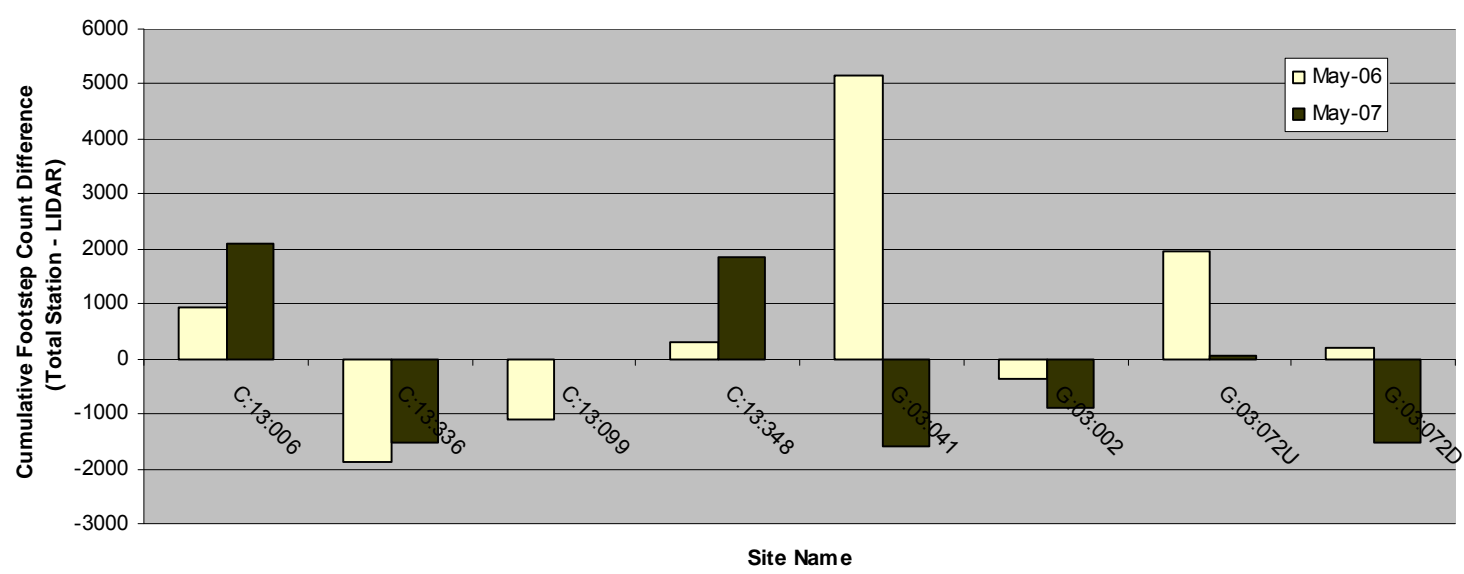


This page intentionally left blank 


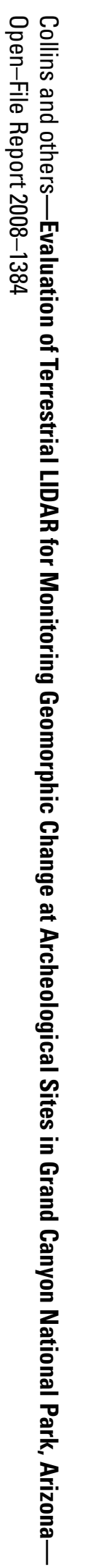

